\title{
Compositional variation in Apollo 16 impact-melt breccias and inferences for the geology and bombardment history of the Central Highlands of the Moon
}

\author{
RANDY L. KOROTEV \\ Department of Earth and Planetary Sciences and McDonnell Center for the Space Sciences, \\ Washington University, St. Louis, MO 63130. USA
}

(Recerved Noncmber 9, 1992: acceped in revised form Harch 26, 1994)

\begin{abstract}
High-precision data for the concentrations of a number of lithophile and siderophile elements were obtained on multiple subsamples from 109 impact-melt rocks and breccias (mostly crystalline) from the Apollo 16 site. Compositions of nearly all Apollo 16 melt rocks fall on one of two trends of increasing $\mathrm{Sm}$ concentration with increasing Sc concentration. The Eastern trend (lower $\mathrm{Sm} / \mathrm{Sc}, \mathrm{Mg}$ / $\mathrm{Fe}$, and $\mathrm{Sm} / \mathrm{Yb}$ ratios) consists of compositional groups 3 and 4 of previous classification schemes. These melt rocks are feldspathic, poor in incompatible and siderophile elements, and appear to have provenance in the Descartes formation to the east of the site. The Western trend (higher $\mathrm{Sm} / \mathrm{Sc}, \mathrm{Mg} / \mathrm{Fe}$, and $\mathrm{Sm} /$ $\mathrm{Yb}$ ratios) consists of compositional groups 1 and 2 . These relatively mafic, KREEP-bearing breccias are a major component $(\sim 35 \%)$ of the Cayley plains west of the site and are unusual, compared to otherwise similar melt breccias from other sites, in having high concentrations of Fe-Ni metal ( $1-2 \%)$. The metal is the carrier of the low-Ir/Au $(\sim 0.3 \times$ chondritic $)$ siderophile-element signature that is characteristic of the Apollo 16 site.

Four compositionally distinct groups ( $1 \mathrm{M}, 1 \mathrm{~F}, 2 \mathrm{DB}$, and 2NR) of Western-trend melt breccias occur that are each represented by at least six samples. Compositional group 1 of previous classification schemes (the "poikilitic" or "LKFM" melt breccias) can be subdivided into two groups. Group IM (represented by six samples, including 60315 ) is characterized by lower $\mathrm{Al}_{2} \mathrm{O}_{3}$ concentrations, higher $\mathrm{MgO}$ and alkali concentrations, and higher $\mathrm{Mg} / \mathrm{Fe}$ and $\mathrm{Cr} / \mathrm{Sc}$ ratios than group $1 \mathrm{~F}$ (represented by fifteen samples, including 65015 ). Group $1 \mathrm{M}$ also has siderophile-element concentrations averaging about twice those of group IF and Ir/Au and Ir/ Ni ratios that are even lower than those of other Western-trend melt rocks ( $\mathrm{Ir} / \mathrm{Au}=0.24 \pm 0.03$, CI-normalized). At the mafic extreme of group 2 ("VHA" melt breccias), the melt lithology occurring as clasts in feldspathic fragmental breccias from North Ray crater (group 2NR) is compositionally distinct from the melt lithology of dimict breccias from the Cayley plains (group 2DB) in having higher concentrations of $\mathrm{Sc}, \mathrm{Cr}$, and heavy rare earth elements and lower concentrations of siderophile elements. The distinct siderophile-element signature (high absolute abundances, low Ir/Au ratio) suggest that the four groups of mafic melt breccia are all somehow related. Ratios of some lithophile elements also suggest that they are more closely related to each other than they are to melt breccias from other Apollo sites. However, none of the breccia compositions can be related to any of the others by any simple process of igneous fractionation or mixing involving common lunar materials. Thus, the origin of the four groups of mafic melt breccia is enigmatic. If they were produced in only one or two impacts. then a mechanism exists for generating regimes of impact-melt breccia in a single impact that are substantially different from each other in composition. For various reasons, including the problem of delivering large volumes of four different types of melt to the Apollo 16 site, it is unlikely that any of these breccias were produced in basin-forming impacts. If they were produced in as many as four crater-forming impacts, then the unusual siderophile-element signature is difficult to explain. Possible explanations are (1) the four groups of melt breccia all contain metal from a single, earlier impact, (2) they were each formed by related metal-rich meteoroids, or (3) some common postimpact process has resulted in metal of similar composition in each of four melt pools.

Within a compositional group, most intrasample and intersample variation in lithophile element concentrations is caused by differences among samples in the proportion of a component of normative anorthosite or noritic anorthosite. In most cases, this compositional variation probably reflects variation in clast abundance. For group 2DB (and probably $2 \mathrm{NR}$ ), differences in abundance of a component of ferroan anorthosite (estimated $\mathrm{Al}_{2} \mathrm{O}_{3} \approx 32 \%$ ) accounts for the compositional variation. For groups $1 \mathrm{M}$ and $I F$, the anorthositic component is more mafic (estimated $\mathrm{Al}_{2} \mathrm{O}_{3} \approx 26 \%$ ). Some group-2 samples may be related by a troctolitic component of varying abundance.
\end{abstract}

\section{INTRODUCTION}

IMPACT-MEIT BRFCCIAS and rocks are the most common lithologies occurring at the Apollo 16 site in the lunar Central Highlands. Of the 543 samples described in the Catalog of Apollo 16 Rocks (RYDER and NORMAN, 1980), which includes all "rocks" greater than $1 \mathrm{~g}$ in mass, $30 \%$ are described as some type of crystalline melt breccia or clast-poor melt rock. Another $17 \%$ are glassy breccias, glass bombs, or glassy fragments, all of which are a type of impact product. About $3 \%$ are dimict (dilithologic) breccias in which one of the two predominant lithologies is crystalline impact melt and the other is anorthosite (STOFFLER el al., 1980; JAMES, 1981). Together, these melt lithologies account for $50 \%$ of the re- 
turned rocks. Most of the rest are polymict breccias (e.g., fragmental breccias, regolith breccias) that contain lithified impact melt as clasts. The high abundance of impact-melt breccias among returned rocks is not simply the result of sampling bias (e.g., SPUDIS, 1984). In order to account for the high concentrations of ITEs (incompatible trace elements) in mature Apollo 16 regolith $(<1 \mathrm{~mm}$ fines $)$, mass balance models require an average of $35 \%$ components of crystalline melt breccia rich in ITEs (KEMPA et al., 1980; MORRIS et al., 1986), and the soils undoubtedly also contain ITE-poor melt breccias.

Although impact-melt lithologies from Apollo 16 are compositionally diverse, some compositions are more prevalent than others. This has led to speculation that different compositional "groups" each represent different impact events and that some melt compositions can be attributed to specific craters or basins (FIORAN et al., 1976; HERTOGEN et al., 1977; JAMES et al., 1984; LINDSTROM, 1984; MCKINLEY et al.. 1984: SPUDIS, 1984; REIMOLD and NEIBER-REIMOLD, 1984). Previous studies have not achieved consensus on the number of compositional groups represented by the Apollo 16 melt rocks or the number of impacts required to produce the observed compositional diversity. At one extreme, the melt rocks are considered to be dominated by a few basinforming events (HERTOGEN et al., 1977; SPUDIS, 1984), while at the other, numerous smaller impacts are favored (RYDER, 1981: REIMOLD and NiEBER-REIMOLD, 1984). It is not the purpose of this paper to determine the specific number of impact events required to account for the Apollo 16 impactmelt rocks, however. Any significant advancement in this area will required an extensive, self-consistent set of geochronological data, which does not presently exist. Instead, the main purpose is to present and review the constraints imposed by sample compositions on models for the impact history of the Central Highlands. Data obtained here show that the samples impose a more rigid set of constraints than previously realized. The paper will focus on the most enigmatic samples, the mafic (noritic) melt breccias with high concentrations of incompatible and siderophile elements (the "LKFM" and "VHA basalts"). A secondary goal is to explore causes of compositional variation among melt-breccia samples that were likely produced in a single impact.

There have been several previous studies of compositional groupings within the suite of Apollo 16 melt rocks (FLORAN et al. 1976; RYDER and SEYMOUR, 1982; MCKINLEY et al., 1984; SPUDIS, 1984; REIMOLD and NIEBER-REIMOLD, 1984). However, all have been impeded by the small number of analyzed samples, the consequent necessity to compare results obtained by a variety of different analytical techniques from a number of different laboratories, and the almost total lack of information on intrasample compositional variation. Thus, I have analyzed multiple subsamples of a large number of rocks by a common technique. Because glassy impact melts have been well studied in previous works, samples studied here are mainly crystalline melt rocks, which are believed to be produced in larger impacts than those yielding glassy melt rocks (MORRIS et al., 1986; BORCHARDT et al., 1986). However, I discuss possible relationships between the crystalline and glassy melts.

Compositional data reported in this work were obtained by INAA (instrumental neutron activation analysis) using isotopes with half-lives $>12$ hours. This provides data of high precision ( $<3 \%$ relative standard deviations) for some elements (e.g., Na, Sc, Cr, Fe, Co, La, Sm, and Eu), data of intermediate precision (typically $5-15 \%$ ) for other elements (e.g., $\mathrm{Ca}, \mathrm{Ni}, \mathrm{Sr}, \mathrm{Cs}, \mathrm{Au}, \mathrm{Ir}, \mathrm{Th}$, and U), but no data for certain elements that have been favored in other studies, namely $\mathrm{Mg}, \mathrm{Al}, \mathrm{K}$, and Ti ( HUBBARD et al., 1973b; FLORAN et al., 1976; NANEY et al., 1977; RYDER, 1981; RYDER and SEYMOUR, 1982; LINDSTROM, 1984; MCKINLEY et al., 1984; SPUDIS, 1984; REIMOLD and NiEbER-REIMOLD, 1984; STOFFLER et al., 1985). This is not a serious shortcoming. Factors that cause variation in abundances of these four major and minor elements are adequately reflected by variation in concentrations of trace elements determined well by INAA. Because of their relatively simple mineralogy (primarily plagioclase, pyroxenes, and olivine), major-element concentrations vary predictably in Apollo 16 melt rocks (and polymict samples from the lunar highlands, in general). The first-order effect is that concentrations of elements such as $\mathrm{Fe}, \mathrm{Mg}, \mathrm{Mn}$, $\mathrm{Sc}$, and $\mathrm{Cr}$ that are associated with mafic minerals vary inversely with the concentrations of $\mathrm{Al}$ and, to a lesser extent, $\mathrm{Ca}$ as the ratio of plagioclase to mafic minerals varies (Fig. 1). Second-order effects, such as variation in $\mathrm{Fe} / \mathrm{Mg}$ ratio of mafic minerals or the relative abundances of olivine, ilmenite, and spinel have a stronger relative influence on the concentrations of elements such as $\mathrm{Sc}$ and $\mathrm{Cr}$ than on $\mathrm{Mg}$ and $\mathrm{Al}$. As a result, differences among samples or groups of related samples are more evident on plots involving $\mathrm{Sc}$ and $\mathrm{Cr}$ than on plots using $\mathrm{Mg}$ and $\mathrm{Al}$. Thus, presentation of lithophileelement data in this paper relies largely on plots of $\mathrm{Sc}, \mathrm{Cr}$, and $\mathrm{Sm}$ concentrations. Samarium is used to represent the ITEs; plots involving other precisely determined ITEs yield similar conclusions because concentrations of all ITEs are highly correlated in the samples.

\section{SOME CONVENTIONS}

Throughout the paper, the term "sample" refers to a specific rock with a five-digit NASA identification number (e.g., rock sample 65015 ) whereas "subsample" refers to that portion of a rock sample actually analyzed in these experiments. The term "split" refers to the subsample allocated for study by NASA (e.g. NASA split number 65105.60 ) and "subsplit" refers to subsamples of a split made in this laboratory.

Each of the Apollo 16 samples studied here is coded by a single unique 'keyboard" character in the figures. The key to this scheme is described in the "Sampling and Analysis" section and presented in Table 1. For convenience, discussion of a specific sample often includes the plot symbol in square brackets following the five-digit NASA sample number (e.g., 65015[\#]). Italicized alphanumeric plot symbols are used exclusively for samples from station 13 .

Most of the rocks studied here are breccias in that they contain mineral and lithic clasts. In the classification of STOFFLER et al. (1985), the designation "impact-melt rock" is reserved specifically for clast-free melt rocks. Because no petrographic information is available for some of the samples studied here, l sometimes refer to samples (or groups of samples) as melt "rocks" for convenience, with no implication about clast content (e.g., IRVING, 1975).

\section{SAMPIJING AND ANALYSIS}

\section{Sampling}

Selection of samples was based on descriptions in RYDER and NORMAN (1980) and STOFFLER et al. ( 1985 ) and was biased in favor of crystalline rocks: most are described as "basaltic" or "poikilitic impact melt" (RYDFR and NORMAN, 1980). The sample request to 


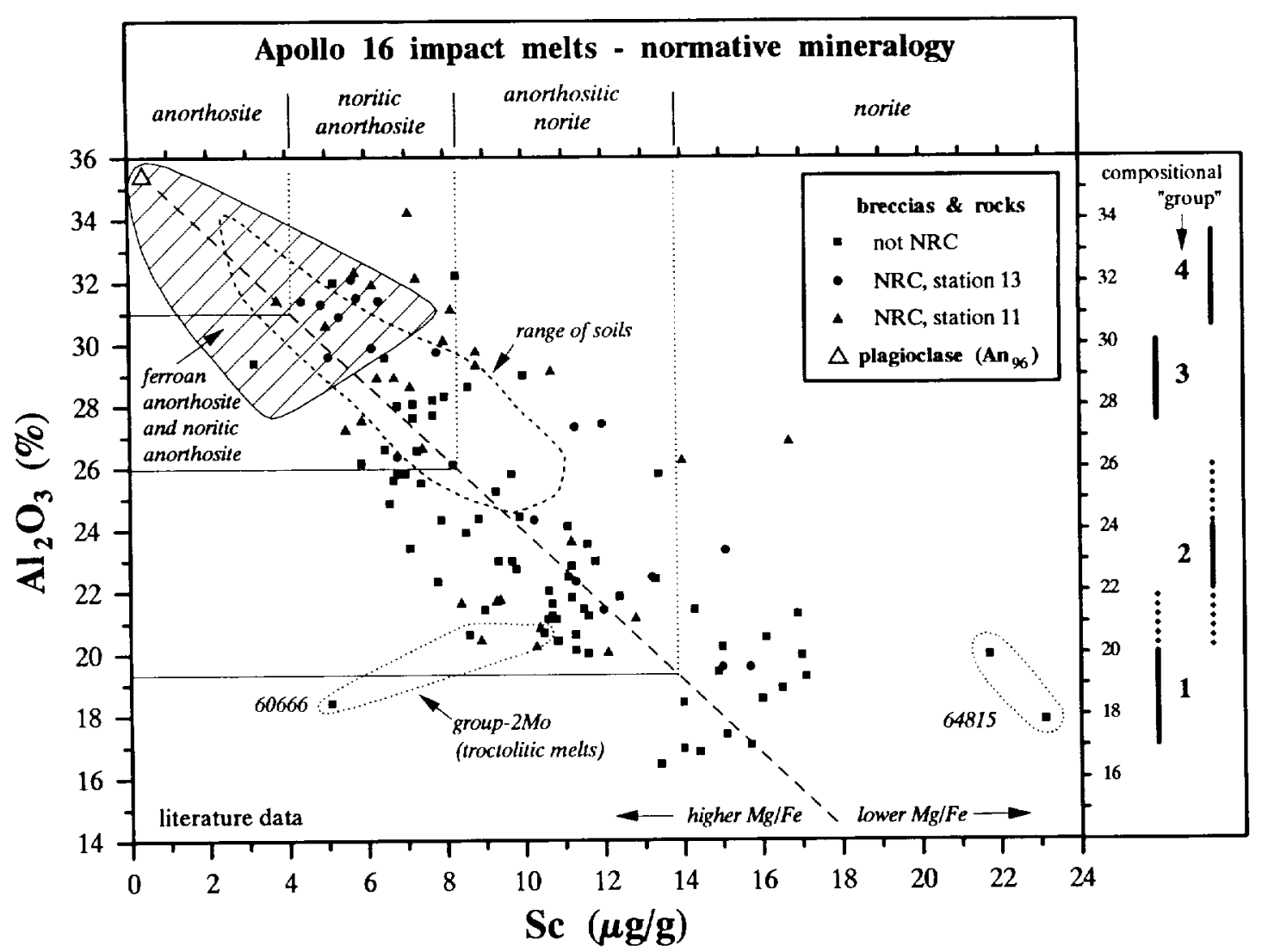

FIG 1 . Anticorrelation of $\mathrm{Al}_{2} \mathrm{O}_{3}$ and Sc concentrations in Apollo 16 impact-melt rocks. Although the dashed diagonal line is 'eveballed' and has no special significance, it serves as a rough calibration between the concentrations of $\mathrm{Sc}$. an element determined in this work, and $\mathrm{Al}_{2} \mathrm{O}_{3}$, which was not. If normative mineral proportions are calculated for the rocks and the mass fractions of minerals converted to volume percent. the compositions can be classified by the scheme at the top of the figure (based on STOFFL.FR et al., 1980). The most mafic melt rocks are noritic, although some contain enough olivine to be considered troctolitic (group 2Mo; see text). The ranges in $\mathrm{Al}_{2} \mathrm{O}_{3}$ concentration generally associated with the compositional groups, as defined in previous studies, are shown on the right (based largely on FLORAN et al., 1976, and MCKIviEY et al., 1984, but also other references in Table 2): this scheme is modified somewhat in this work. For a given $\mathrm{Al}_{2} \mathrm{O}_{3}$ concentration, samples with high $\mathrm{Mg} / \mathrm{Fe}$ ratios tend to have lower $\mathrm{Sc}$ concentrations than those with low $\mathrm{Mg} / \mathrm{Fe}$ ratios. For example. the five points with group- 1 composition that plot on the low-Sc side of the line are for samples 60315 and 60526 , which have high $\mathrm{Mg} / \mathrm{Fe}$ ratios (group $1 \mathrm{M}$ ), whereas all group- 1 samples plotting on the high-Se side of the line are for low-Mg/Fe samples (group IF: sce Table 4). Sample 60666 has an extremely high $\mathrm{Mg} / \mathrm{Fe}$ ratio. For comparison. the field for ferroan anorthosites and noritic anorthosites (i.e., samples with $>77.5 \%$ modal plagioclase) is also shown, as is a point for pure plagioclase such as is found in most Apollo 16 anorthosites (HASkIN et al., 1981). NRC = samples from North Ray crater. Sources of melt rock data: BoYNTON et al. (1975, 1976): BrUNFELT et al. (1973): FloRAN et al. (1976); FrIICHTFR et al. (1974); HASKIN et al. (1973): JAMES et al. (1984): LAU1. et al. (1974), LAUI and SCHMITT (1973); LINDSTROM and SAIPAS(1981, 1983): MARVIN and LINDSTROM (1983): MARVIN et al. (1987); MCKINLFy et al. (1984); MORRISON et al. (1973); Mural.l et al. (1977); PALME et al. (1978): RYDER and SFYMOUR (1982), STOFFIFR et al. (1985, combined with Se data obtained here); WANKE et al. (1973, 1974, 1976); WARREN and WASSON (1978): and WASSON et al. (1977). Soil data from KOROTEV $(1981,1991)$.

NASA for those splits that were requested specifically for this study (all but a few) included instructions that they be as free as possible of glass coatings and large clasts.

Most of the samples were analyzed as part of one of three experiments. In the "big rock" experiment, two or three splits from different locations on thirty-four large samples $(5 \mathrm{~g}-11.7 \mathrm{~kg})$ were studied Most of the samples have been well characterized previously, both compositionally and petrographically. Each of the eighty-one splits derives from a different NASA "parent" split number. In each case. the analyzed subsample is the entire quantity of the allocated splits. which ranged in mass from 100 to $170 \mathrm{mg}$. In the figures, samples from the big-rock experiment are coded by unitalicized upper case letters, including $\Sigma, \Theta, \Phi, \Gamma, \tilde{N}, \Omega, \beta$, and the symbol \& (Table 1$)$. For the "little-rock experiment," thirty-six small rake samples were selected $(1.3-12 \mathrm{~g})$. Most of these have not been previously studied and compositional data and petrographic descriptions are unavailable.
Samples were received as one split of $\sim 100 \mathrm{mg}$ and each was subdivided into three subsplits of approximately equal mass for analysis. In the figures, samples studied as part of the little-rock experiment are coded by unitalicized numerals (except for $63558[0]$ ) and lowercase letters (Table 1). In the "station-13 experiment." thirty melt rocks from station 13 on the ejecta blanket of North Ray crater (Fig. 2) were studied (sample numbers $63 \times x \times$ ). Except for one sample (63558[0]), none of the melt rocks included in the other two experiments are from North Ray stations 11 or 13. Two or three subsplits each of one or two splits were studied, i.e.. for each of the thirty rocks. 2-6 subsamples ranging in mass from 40 to $80 \mathrm{mg}$ were analyzed. In the figures, samples of the station- 13 experiment are coded hy italicized symbols. In total, I analyzed a total of 315 subsamples of 109 rocks (Table 1 ).

Data were also obtained for multiple subsamples of melt rocks that do not fit into any of the three main experiments, including 
Table 1. List of samples studied, with plot symbols (S), total mass analyzed $(\mathrm{mg})$, number of subsplits $(\mathrm{N})$ and number of splits $(M)$ analyzed, experiment designation ( $E: L=$ little-rock experiment, $B=$ big-rock experiment, 3 = station-13 experiment, and $X=$ miscellaneous sample not part of any particular experiment), and compositional group (G: $U$ = ungrouped; for others, see text).

\begin{tabular}{|c|c|c|c|c|c|c|c|c|c|c|c|c|c|c|c|c|c|c|c|c|}
\hline$S$ & sample & $\mathrm{mg}$ & $\mathrm{N}$ & $M$ & $E$ & G & $\mathrm{S}$ & sample & $\mathrm{mg} \mathrm{N}$ & $\mathrm{NN}$ & $\mathbf{M}$ & E & $G$ & $\mathrm{~S}$ & sample & $\mathrm{mg} \mathrm{l}$ & $\mathrm{NI}$ & $\mathbf{M}$ & $E$ & \\
\hline \multicolumn{7}{|c|}{ Apollo 14} & 5 & 63526 & 1352 & 2 & 1 & 3 & 4 & $\mathrm{i}$ & 64817 & 103 & 3 & 1 & & $\mathrm{U}$ \\
\hline & 14078 & 170 & & l & $\mathrm{x}$ & & $E$ & 63527 & 253 & & 2 & 31 & $1 \mathrm{M}$ & $\#$ & 65015 & 323 & 2 & 1 & & IF \\
\hline & 14310 & 476 & 4 & $i$ & $x$ & & 6 & 63528 & 1392 & 21 & 1 & 3 & 4 & $\#$ & 65015 & 74 & 3 & 1 & $\mathrm{~L}$ & IF \\
\hline & & & & & & & 7 & 63529 & 222 & & 2 & 34 & 4 & $£$ & 65055 & 173 & 2 & 1 & & \\
\hline & ollo 16 & & & & & & $Q$ & 63535 & 258 & & 2 & 32 & 2NR? & $\mathrm{n}$ & 65349 & 97 & 3 & 1 & $\mathrm{~L}$ & $2 \mathrm{M}$ \\
\hline$\%$ & 60018 & 876 & 8 & 4 & $\mathrm{x}$ & $2 \mathrm{M} / \mathrm{F}$ & $\vec{C}$ & 63536 & 1262 & & 1 & 32 & $2 \mathrm{M}$ ? & $\Omega$ & 65357 & 240 & 2 & 2 & B & IF \\
\hline$\&$ & 60315 & 451 & 3 & 3 & $\mathrm{~B}$ & IM & $\bar{Y}$ & 63537 & 1392 & 2 & 1 & 33 & 3 & 6 & 65358 & 89 & 3 & $\vec{l}$ & $\mathrm{~L}$ & $1 \mathrm{~F}$ \\
\hline$¥$ & 60335 & 165 & 2 & i & $\mathrm{X}$ & $2 \mathrm{M}$ & $i$ & 63545 & 2525 & 5 & 2 & 32 & $2 \mathrm{M}$ ? & 0 & 65365 & 102 & 3 & $i$ & $\mathrm{~L}$ & $2 \mathrm{DB}$ \\
\hline$T$ & 60525 & 231 & 2 & 2 & B & lF & $A$ & 63546 & 1202 & 2 & 1 & 3 & 4 & $z$ & 65757 & 218 & 2 & 2 & B & $2 \mathrm{DB} / \mathrm{M}$ \\
\hline C & 60526 & 233 & 2 & 2 & B & $\mathrm{IM}$ & $L$ & 63547 & 1563 & 3 & $i$ & 3 & 2NR & $\bar{p}$ & 65758 & 103 & 3 & 1 & $\mathrm{~L}$ & $\mathrm{U}$ \\
\hline B & 60615 & 242 & 2 & 2 & B & $2 \mathrm{M}$ & $\bar{S}$ & 63548 & 1512 & 2 & $i$ & 3 & 4 & $\Sigma$ & 65777 & 222 & 2 & 2 & B & IF \\
\hline 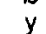 & 60616 & 107 & 3 & 1 & $\mathrm{~L}$ & $2 \mathrm{M}$ & $\mathrm{J}$ & 63549 & 2465 & 5 & 2 & 3 & 3 & 7 & 65778 & 92 & 3 & 1 & $\mathrm{~L}$ & if \\
\hline D & 60625 & 467 & 3 & 3 & B & $2 \mathrm{DB}$ & 8 & 63555 & 231 & 4 & 2 & 3 & 4 & $\Theta$ & 65779 & 269 & 2 & 2 & B & $2 \mathrm{DB}$ \\
\hline $\mathrm{E}$ & 60627 & 238 & 2 & 2 & B & $2 \mathrm{Mo}$ & $D$ & 63556 & 235 & 4 & 2 & 3 & IF & $\mathrm{K}$ & 65785 & 260 & 2 & 2 & B & $2 \mathrm{NR}$ \\
\hline 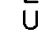 & 60635 & 245 & 2 & 2 & B & 3 & $K$ & 63557 & 1012 & 2 & 1 & 3 & 4 & 8 & 65905 & 93 & 3 & 1 & $\mathrm{~L}$ & IF \\
\hline $\mathrm{Q}$ & 60636 & 346 & 3 & 3 & B & lF & 0 & 63558 & 1013 & 3 & 1 & $\mathrm{~L}$ & IM & $\grave{j}$ & 65906 & 100 & 3 & 1 & $\mathrm{~L}$ & $2 \mathrm{DB}$ \\
\hline$F$ & 60645 & 228 & 2 & 2 & B & $2 F$ & 9 & 63579 & 221 & 4 & 2 & 3 & 4 & $r$ & 65915 & 97 & 3 & 1 & $\mathrm{~L}$ & $2 \mathrm{M}$ \\
\hline L & 60666 & 238 & 2 & 2 & B & $2 \mathrm{Mo}$ & $G$ & 63585 & 3556 & 6 & 2 & 3 & $2 \mathrm{NR}$ & $w$ & 66095 & 444 & 3 & 3 & B & $2 \mathrm{DB}$ \\
\hline$@$ & 61016 & 269 & 2 & 2 & B & $2 F$ & $R$ & 63586 & 1012 & 2 & 1 & 3 & 4 & 0 & 68415 & 441 & 3 & 3 & B & 3 \\
\hline$\breve{H}$ & 61156 & 455 & 3 & 3 & B & $2 \mathrm{~F}$ & $M$ & 63587 & 208 & 4 & 2 & 3 & $2 \mathrm{M}$ & $x$ & 68416 & 408 & 3 & 3 & B & 3 \\
\hline$v$ & 61225 & 108 & 3 & 1 & $\mathrm{~L}$ & $2 \mathrm{M}$ & $x$ & 63596 & 93 & 2 & 1 & 3 & IF & s & 68505 & 102 & 3 & 1 & $\mathrm{~L}$ & $2 \mathrm{DB}$ \\
\hline 9 & 61247 & 97 & 3 & 1 & $\mathrm{~L}$ & IF & $F$ & 63597 & 1122 & 2 & $i$ & 3 & U & $t$ & 68 & 99 & 4 & $i$ & $\mathrm{~L}$ & $2 \mathrm{~F}$ \\
\hline$\Phi$ & 61547 & 236 & 2 & 2 & B & $2 \mathrm{M}$ & $H$ & 63598 & 238 & 4 & 2 & 3 & IF & $\overline{\mathrm{N}}$ & 68525 & 242 & 2 & 2 & B & $1 \mathrm{~F}$ \\
\hline J & 61548 & 239 & 2 & 2 & B & $2 F$ & $Y$ & 64476 & 4403 & 3 & 31 & B & 2DB & $w$ & 68526 & 99 & 3 & 1 & $\mathrm{~L}$ & 4 \\
\hline a & 61549 & 108 & 3 & 1 & $\mathrm{~L}$ & $2 \mathrm{Mo}$ & d & 64 & 88 & 3 & 11 & $\mathrm{~L}$ & $2 F$ & i & 68 & 101 & 3 & 1 & $\mathrm{~L}$ & $2 \mathrm{~F}$ \\
\hline$\Gamma$ & 61568 & 225 & 2 & 2 & B & $2 \mathrm{M}$ & $\mathrm{e}$ & 64506 & 983 & 3 & 1 & L ? & $2 \mathrm{M}$ & $x$ & 68845 & 97 & 3 & I & $\mathrm{L}$ & 4 \\
\hline$v$ & 61569 & 309 & 2 & 2 & B & $\mathrm{U}$ & $\mathrm{q}$ & 64 & 953 & 3 & 1 & $\mathrm{~L}$ & $2 \mathrm{NR}$ & z & & 93 & 3 & i & $\mathrm{L}$ & 4 \\
\hline$G$ & 62235 & 465 & 3 & 3 & B & lF & $\vec{P}$ & 64 & 4083 & 3 & 3 & $\mathrm{~B}$ & $2 \mathrm{~F} / \mathrm{M}$ & 2 & 69945 & $99 ?$ & 3 & l & $\mathrm{L}$ & $1 \mathrm{M}$ \\
\hline b & 62245 & 99 & 3 & 1 & $\mathrm{~L}$ & $2 \mathrm{NR}$ & A & 64536 & 403 & 3 & $3 i$ & B & $2 \mathrm{DB}$ & & & & & & & \\
\hline$M$ & 62255 & 430 & 3 & 3 & $\mathrm{~B}$ & $2 \mathrm{DB}$ & $R$ & 64 & 2412 & & 3 & B & $2 \mathrm{D}$ & po & ollo & & & & & \\
\hline c & 62287 & 96 & 3 & 1 & $\bar{L}$ & $2 \mathrm{~F}$ & $\mathrm{~s}$ & 64567 & 2132 & 2 & 21 & B & $2 \mathrm{Mo}$ & & 76135 & 304 & 4 & 2 & $\mathrm{x}$ & \\
\hline$N$ & 62295 & 484 & 3 & 3 & B & $2 \mathrm{M}$ & 9 & 64568 & 913 & 3 & 31 & L & $2 \mathrm{DB}$ & & 77035 & 388 & 3 & 1 & $\mathrm{X}$ & \\
\hline 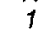 & 63335 & 218 & 4 & 2 & 3 & 4 & 4 & 64575 & 953 & 3 & 11 & $\mathrm{~L}$ & IF & & & & & & & \\
\hline$\dot{U}$ & 63355 & 207 & 4 & 2 & 3 & $2 \mathrm{NR}$ & $\mathrm{h}$ & 64576 & 103 & 3 & 11 & $\mathrm{~L}$ & $2 \mathrm{Mo}$ & Lite & rature & & & & & \\
\hline$W$ & 63505 & 143 & 2 & I & 3 & 4 & $\mathrm{~m}$ & 64578 & 1013 & & 1 & L & $2 \mathrm{DB}$ & $\$$ & 61015 & 652 & & 1 & $\mathrm{X}$ & $2 \mathrm{DB}$ \\
\hline$T$ & 63506 & 121 & 2 & i & 3 & 4 & $i$ & 64579 & 1033 & 3 & i & $\overrightarrow{\mathrm{L}}$ & $2 F$ & 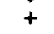 & $60002 c$ & & 8 & i & $\mathrm{x}$ & \\
\hline$N$ & 63508 & 125 & 2 & i & 3 & 4 & $k$ & 64585 & 1023 & 3 & 1 & & 2DB & V & 61569 & $?$ & 1 & I & B & U \\
\hline 2 & 63509 & 101 & 2 & 1 & 3 & 4 & $\tilde{u}$ & 64586 & 893 & $J$ & 1 & L & $2 \mathrm{DB}$ & B & 64815 & & 2 & 2 & B & $\mathbf{U}$ \\
\hline 3 & 63515 & 112 & 2 & 1 & 3 & 4 & $B$ & 64815 & 2372 & & 2 & $\mathrm{~B}$ & $\mathrm{U}$ & $\Delta$ & $67513 c$ & 2521 & & I & $\bar{X}$ & $2 \mathrm{NR}$ \\
\hline 4 & 63525 & 101 & 2 & l & 3 & 4 & 5 & 64816 & 1073 & 3 & 11 & $\bar{L}$ & IM & & & & & & & \\
\hline
\end{tabular}

literature data: JAMEs et al (1984) for 61015 (mcan of 6); KOROTEV (1991) for particle 2.19 from 60002,139: WAsson et al. (1977) for 61569 and 64815; WäNkE et al (1976) for 64815; JolLIFF $(1991,1992)$ for particles from 67513.

samples from Apollos 14 (14310 and 14078) and 17 (76135 and 77035 ). Also reported are analytical results for a single, large ( 400 $700 \mathrm{mg}$ ) subsplit each of $61015[B], 61016[@]$, and $65015[\#]$. These results represent mass-weighted mean concentrations of magnetic and nonmagnetic fractions from an experiment described by KOROTEV (1990), where results from siderophile elements only were reported. In the figures, the miscellaneous samples are coded with various nonalphanumeric symbols (Table 1).

New INAA data obtained as part of other studies of this laboratory are also reported here. These include data for clasts extracted from six regolith breccias, and particles from the $2-4-\mathrm{mm}$ grain-size fractions of soil 67513 (JOLLIFF, 1991, 1992). These experiments will be described in more detail elsewhere, but the data provide useful comparison to data obtained in this study.

\section{Analysis}

Subsamples werc analyzed by INAA using procedures similar to those described in KOROTEV (1991), except that (1) subsamples in the little-rock experiment were irradiated for $48 \mathrm{~h}$, those in the station13 experiment were irradiated for $36 \mathrm{~h}$, and all others were irradiated for $24 \mathrm{~h}$, and (2) all samples received an additional radioassay during the time period 5-6 days following neutron irradiation for a total of three radioassays.

\section{LITHOPHILE ELEMENTS AND COMPOSITIONAL GROUPINGS}

Discussion of compositional grouping within the suite of Apollo 16 melt rocks is hampered by the wide variety of names that have been used to refer to rocks of a particular composition or petrographic character, some of which are misleading if taken literally (e.g., "very high alumina [ VHA] basalts": Table 2). For convenience of discussion, I refer to a particular composition or group of rocks with similar composition as a "compositional group" (Fig. 3). As a working model, but with some modifications, I adopt the four compositional groups of MCKINLEY et al. (1984), which are based on three groups of FLORAN et al. (1976). These four groups have numeric designations that, although not as colorfully descriptive as some of the wordier names (Table 2), avoid textural connotations in what is essentially a compositional classification system. In the schemes of FLORAN et al. (1976) and MCKINLEY et al. (1984), group numbers correlate with alumina concentration (Fig. 1); thus, the most mafic (noritic) samples are included in group 1 and the most feldspathic samples are in group 4 . In this section, I argue that there are compositionally distinct subgroups of some of the four previously recognized groups and that not all samples fall into one of the four groups. Note that the lumping of different samples into a particular group or subgroup based on composition is not intended to imply that the samples are all products of a single impact or that one group or subgroup is genetically distinct from another; it is merely a convenience 


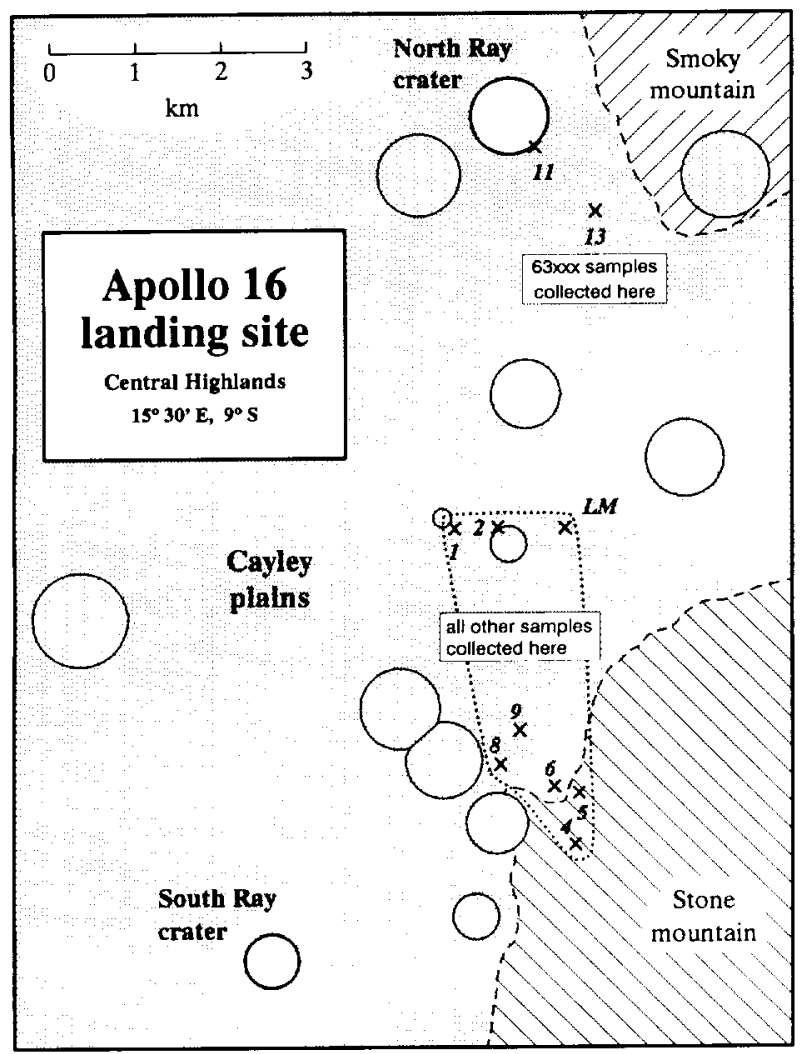

FIG. 2. Schematic map of the Apollo 16 landing site. Numbered sample collection stations are marked by an X. Station 13 is within the continuous ejecta blanket of North Ray crater. a relatively recent crater $(\sim 50 \mathrm{Ga})$; South Ray crater is even younger $(\sim 2 \mathrm{Ga})$ (ARVIDSON et al.. 1975). Nearly all melt rocks ( $>1$ g) collected at station 13 were analyzed in this study. All other samples analyzed in this work were collected from the central and southern stations, although literature data for some samples from station $11(67 \times x \times)$ are presented.

for discussion of samples of similar composition that may or may not be genetically related. Thus, I make no statistical justifications for the groupings. However, below I discuss compositional features (e.g., element ratios) that distinguish samples of one group or subgroup from another.

To simplify presentation of data in some figures, I have computed sample mean compositions based on the mutliple subsamples (Fig. 4). Simple means of the sample means are presented in Table 3 for samples belonging to the same compositional group, along with intragroup RSDs (relative standard deviations). I have also computed intrasample RSDs by group; these data are not presented, but some conclusions based on the results are discussed below.

\section{Systematic Compositional Variation-Anorthosite Mixing}

A theme that will be developed numerous times throughout this section is that much of the compositional variation in Apollo 16 melt rocks, both intrasample and intragroup, derives from variation in the proportions of two components. an anorthosite component poor in most lithophile elements and a melt component that is more mafic and richer in ITEs.
The anorthosite-melt mixing effect is a common cause of intrasample compositional variation. Typically, on two-element variation diagrams involving lithophile elements, replicate subsamples of a given rock define or suggest linear trends. These trends usually lead to positive correlations between $\mathrm{Sc}$ and $\mathrm{Sm}$ concentrations (Fig. 5a,b); if Sc concentrations are highly variable, negative correlations between $\mathrm{Sc}$ and $\mathrm{CaO}$ concentrations are also observed (Fig. $5 \mathrm{c}$ ). Some samples where the anorthosite-mixing effect is most apparent are 60018 [\%], 60015 [ $\beta$ ], 60625[D].61016[@],63335[1], 63529 [7], and $64578[\mathrm{~m}]$. The effect is particularly common in group 2, occurs in groups 3 and 4, but is not seen in group 1. For many samples, the compositional variation most likely results from variability in abundance of anorthosite clasts. either discrete clasts or clasts dissolved in the melt. For others, (e.g., 64535[P]), the most feldspathic subsamples are, or contain a component of, glass. Such glass occurs as coatings on and veins in dimict breccias and is compositionally more feldspathic than the crystalline melt (JAMES et al., 1984). Extreme cases of the anorthosite-mixing effect are seen among subsamples of $60018[\%]$ and $61016[@]$. which are shocked rocks containing group- 2 melt rock, anorthosite, and glass lithologies. For such rocks it is nearly impossible to obtain uncontaminated subsamples of the melt rock. On twoelement variation diagrams, subsamples from these two rocks plot along mixing lines between anorthosite and mafic melt rock similar to that in the dimict breccias (Fig. 5b,c).

\section{Group 1: ITE-Rich, Poikilitic Melt Breccias}

Group 1 is restricted here to samples with average concentrations of $\mathrm{Sm}$ exceeding $15 \mu \mathrm{g} / \mathrm{g}$, consistent with the usage of FLORAN et al. ( 1976) and MCKINLEY et al. (1984). Including the three type specimens $(60315,62235$, and 65015 ; FLORAN et al., 1976), twenty-one of the samples studied here are group-1 melt rocks. All of the samples for which petrographic data are available are described as poikilitic ( RYDER and NORMAN, 1980), although some are texturally heterogeneous $(63527[E])$. Group-1 samples are characterized by having low concentrations of $\mathrm{CaO}$ and $\mathrm{Al}_{2} \mathrm{O}_{3}$ and the highest concentrations of ITEs and elements associated with mafic phases among common Apollo 16 lithologies. Usually, ITE concentrations alone are sufficient to separate samples of group 1 from those of group 2 (Fig. 4). Only two samples analyzed here, $63596[X]$ and $68525[\tilde{\mathrm{N}}]$, are at all ambiguous in having lower ITE concentrations than the others and also being more feldspathic (higher $\mathrm{CaO}$, lower $\mathrm{Sc}$ and $\mathrm{Cr}$; Fig. 6). However, based on their $\mathrm{Cr} / \mathrm{Sc}$ ratios, the samples are clearly related to group 1 (group 1 F; Fig. 7a), not group 2; texturally, they are poikilitic melt rocks of group 1 with unusually high clast contents, not anomalous group-2 samples ("Correlation of clast content ..." section).

\section{Subdivision of group I}

On plots involving $\mathrm{Cr}$, six of the samples $(1 \mathrm{M})$ are separated from the other fifteen ( $1 \mathrm{~F}$ ) by a gap (Fig. $6 \mathrm{a}$ ). The most Cr-rich samples are poorest in Ca (Fig. 6b). I designate these two subgroups "group IM" (mafic) and "group 1F" ( feldspathic) and advocate that these two sets of samples represent different populations of melt rock. 


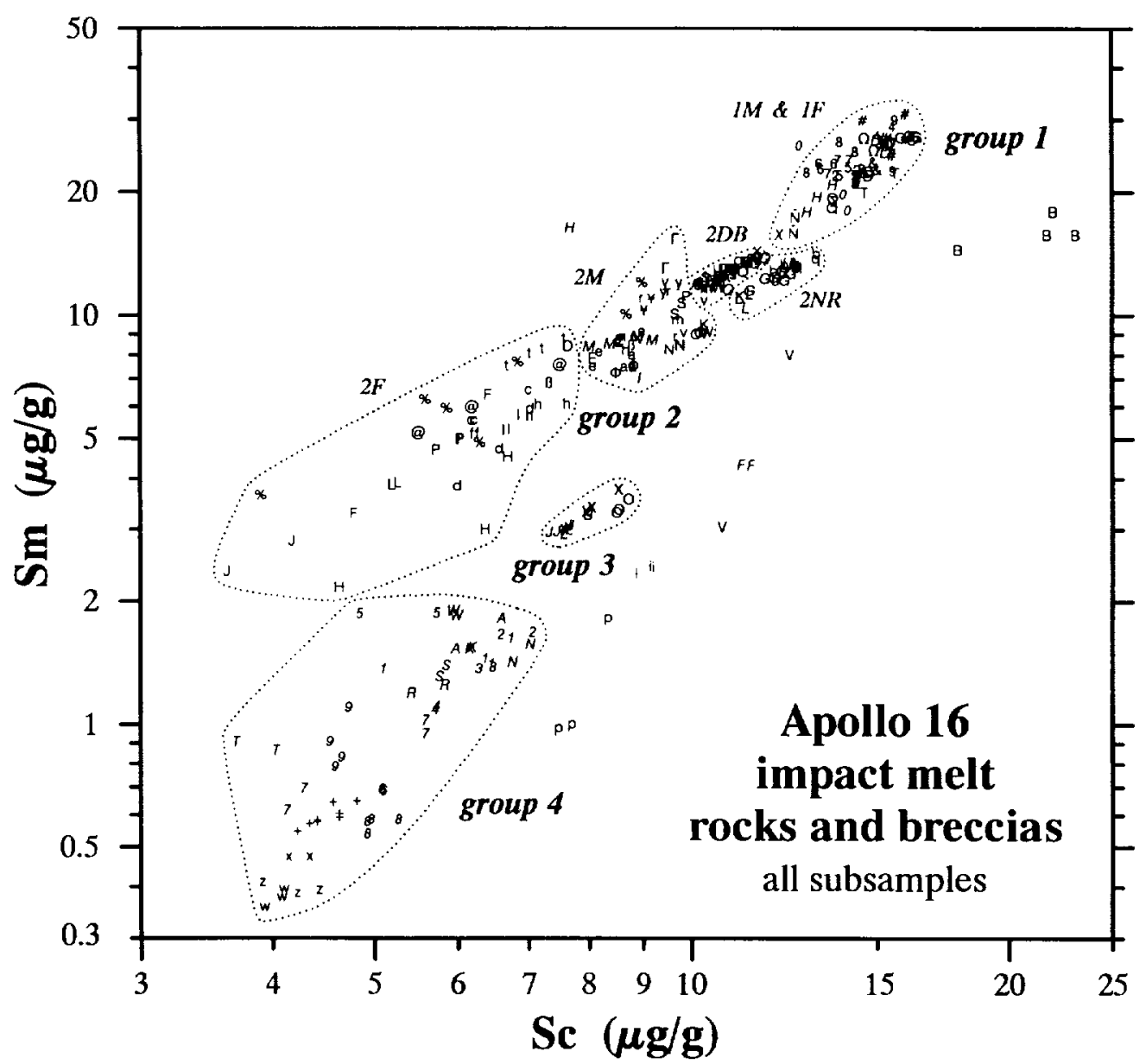

FIKi. 3. Sm and Sc concentrations in all subsamples of Apollo 16 melt rocks and breccias studied here, plotted on logarithmic scales to show relative differences. The four numbered compositional groups of MC KINL.FY et al. (1984) (based on FlORAN et al.. 1976) are indicated, along with major subdivisions of group 2 as defined in this work (for clarity, subgroup group $2 \mathrm{Mo}$ is not distinguished, but see Figs. 18a and 24). In this and subsequent figures, each of the different 'keyboard' characters represents a different sample; two to eight subsamples are plotted for each sample ( see Table I for symbol key). All italicized characters represent samples from station 13 near North Ray crater. Among the group- 4 samples, numeric characters represent samples that are microporphyritic in texture and upper-case alphabetic characters represent intergranular samples, except that 63505 [ $W$ ] is micropoikilitic and $63506[T]$ is subophitic-intersertal (STOFFler et al., 1985). All group-4 sample are from station 13, except that 68526 [w] 68845[ $\mathrm{x}$ ]. and 68846 [z] are from station 8 and $60002 \mathrm{c}[+]$ is from the bottom of the deep drill core at the LM station (KOROTEv, 1991).

Although the gap in $\mathrm{Cr}$ concentrations is small and it is possible that data for additional samples would fill the gaps, other data suggest that two populations occur. The strongest compositional argument is that on a plot of Sc and $\mathrm{Cr}$ concentrations (Figs. 6b, 7a), samples of group IF define a trend consistent with anorthosite mixing and the samples of group $\mathrm{IM}$ do not plot on this trend, i.e., two separate batches of mafic melt appear to be involved. Curiously, on the Sc-Sm plot (Fig. 8), which is usually one of the most useful in separating different compositional groups, samples of groups IM and $\mathrm{IF}$ overlap and are indistinguishable from the each other. However, if the dichotomy in the group-1 samples is accepted, then other compositional differences between the two subgroups are evident in averages (although there is considerable overlap among individual splits). Group IM has concentration of $\mathrm{Na}, \mathrm{K}, \mathrm{Rb}$, and $\mathrm{Cs}$ that average $15-20 \%$ greater than those of group IF, even though concentrations of tri- valent REEs, $\mathrm{Hf}, \mathrm{Ta}, \mathrm{Th}$, and $\mathrm{Ba}$ are nearly identical for the two groups (Tables 4,5 ). Also, concentrations of $\mathrm{Sr}$ and $\mathrm{Eu}$ average $4 \%$ greater in group $1 \mathrm{M}$, despite that $\mathrm{CaO}$ concentrations are $10-15 \%$ lower (Fig. $7 \mathrm{~b}$ ), leading to a slightly shallower Eu anomaly in group $1 \mathrm{M}$ than group IF (Fig. 9). These observations are all consistent with a greater abundance of alkali feldspar in group $1 \mathrm{M}$.

Literature data for other major elements are consistent with the differences observed in the INAA data, but are not sufficient to prove the dichotomy because so few analyses are available. Precise major-element data are available for only one group-IM sample, 60315 [\&], and less precise analyses are available for 60526 [C] (Table 4). Both analyses confirm that these two rocks are unusual compared to typical groupIF melt breccias (e.g., 65015 [\#]) in being poorer in $\mathrm{Al}_{2} \mathrm{O}_{3}$ and considerably richer in $\mathrm{MgO}$ ( $\mathrm{MgO}: 13.4 \%$ for group $1 \mathrm{M}$ and $\sim 10 \%$ for group $1 F$ ). (Note in Table 4 and Fig. 6 that 
Table 2. Designations used here for compositional groups of Apollo 16 impact-melt breccias and rocks, with alternate designations and type specimens.

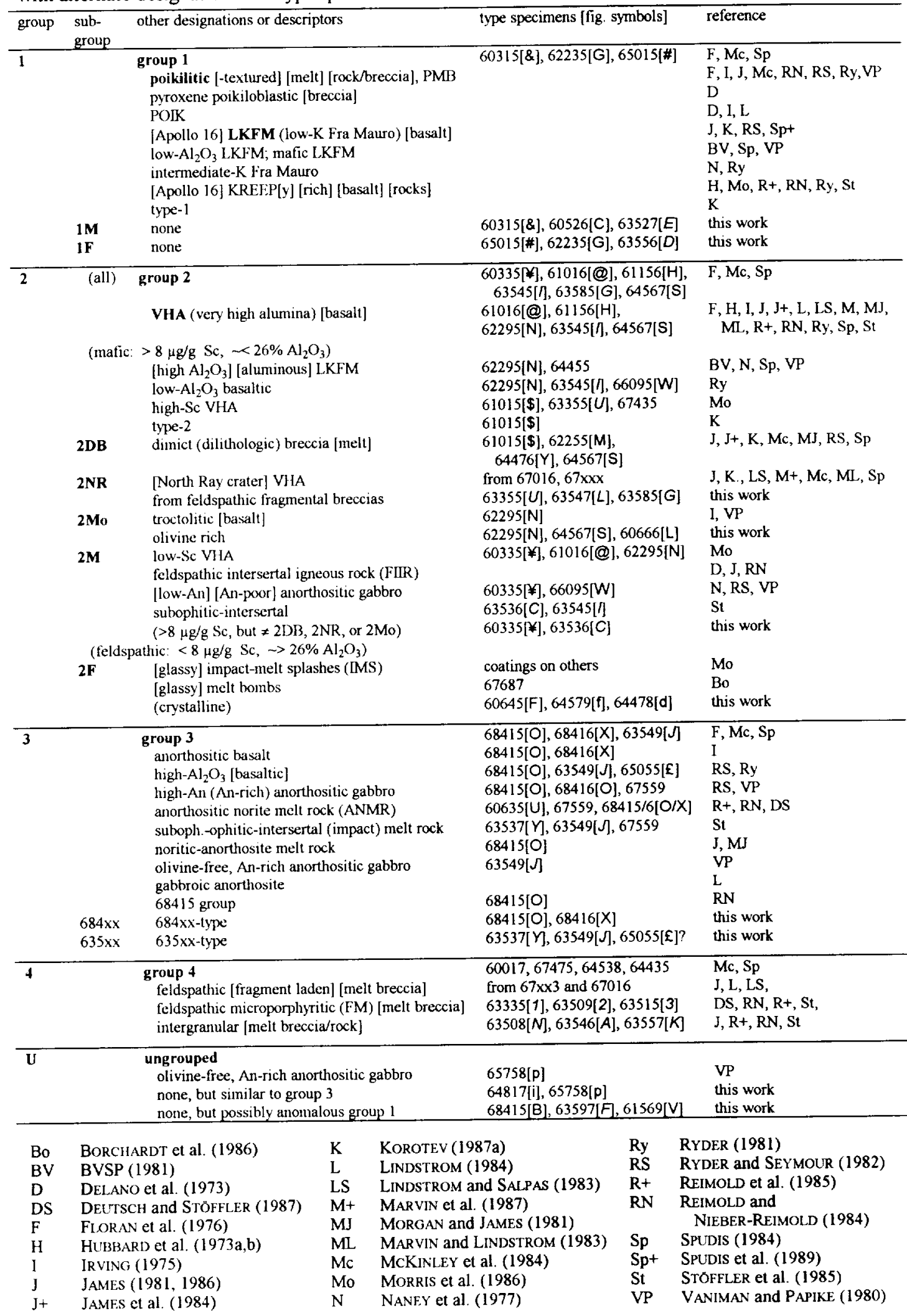




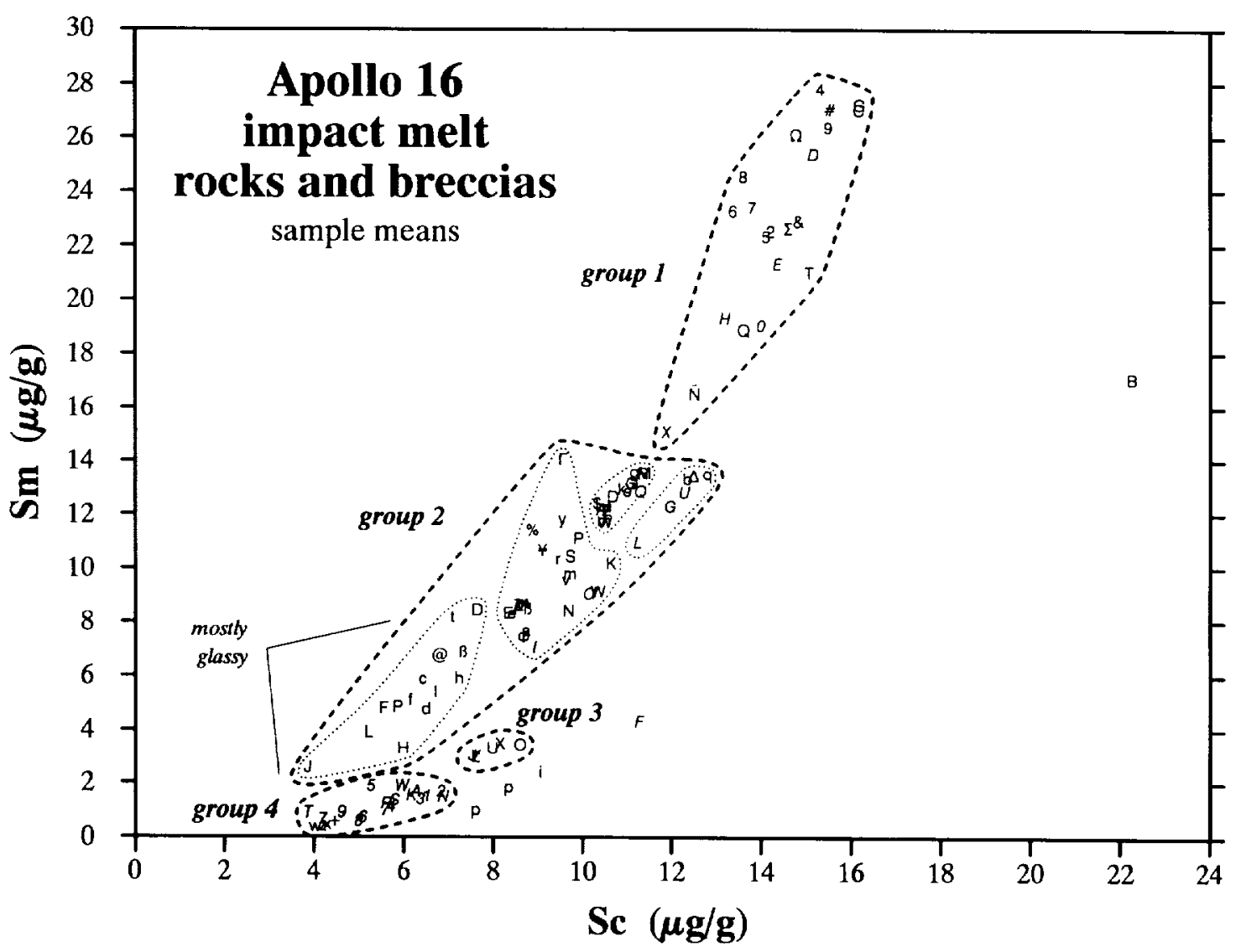

FIG. 4. Comparison of Sc and Sm concentrations in all Apollo 16 melt groups using sample mean compositions plotted on linear scales (compare with Fig. 3). For most samples, sample means were calculated as mass-weighted means of element concentrations in all subsamples. For five samples, one each highly anomalous subsample has been ignored $(60636[Q], 63335[l], 63558[O], 63598[H]$, and $64815[B]$. For a few samples, two mean compositions are calculated and plotted if one or more subsamples differ considerably in composition from the others but none are unusual with respect to other samples (e.g., 64535[P]). Compositionally nonuniform samples and samples with compositionally anomalous subsamples are noted in Table Al. Highly heterogencous sample 61569[V] is excluded (Fig. 3).

sample $62235[\mathrm{G}]$ is one of the most mafic of the group-1F samples, yet there is still a significant difference in $\mathrm{MgO}$ and $\mathrm{Al}_{2} \mathrm{O}_{3}$ concentrations between 62235 and the two groups- $1 \mathrm{M}$ samples.) To a first approximation, addition of olivine to the composition of group $1 \mathrm{~F}$ accounts for the composition of group $1 \mathrm{M}$. In detail, however, the mass balance requires an unlikely assemblage: group $1 \mathrm{M}$ corresponds normatively to a mixture of $88.4 \%$ group IF, $9.0 \%$ olivine $\left(\mathrm{Fo}_{88}\right), 1.9 \%$ alkali feldspar $\left(\mathrm{Ab}_{65} \mathrm{Or}_{35}\right), 0.1 \%$ chromite, and $0.6 \%$ ilmenite. This constraint provides a hurdle to models attempting to relate the two compositions ("Siderophile Elements" section).

Some of the compositional differences between groups IM and $1 \mathrm{~F}$ are reflected in petrographic differences reported among poikilitic rocks. Of the poikilitic melt rocks studied by SIMONDS et al. (1973), three are assigned here to group $1 \mathrm{M}(60315,63558$, and 64816$)$ and three to group $1 \mathrm{~F}(63556$, 64575 , and 65015). Average compositions of the orthopyroxene oikocrysts are in the range $E_{n_{65-73}}$ for group $1 F$ and $\mathrm{En}_{79-82}$ for group $1 \mathrm{M}$. Olivine is about twice as abundant in group $1 \mathrm{M}(2-6 \%)$ as in group $1 \mathrm{~F}(1-3 \%)$. The differences in mineral compositions and $\mathrm{MgO}$ concentration led to a significantly different bulk $M g^{\prime}\left(M g^{\prime}=\right.$ mole percent $\mathrm{Mg}$ /
$[\mathrm{Mg}+\mathrm{Fe}])$ for the two groups, although bulk $M g^{\prime}$ is not straightforward to evaluate because of the large and varied concentrations of Fe-Ni metal in the samples ("Siderophile Elements" section ). $M g^{\prime}$ based on total Fe is $71 \pm 1$ for group $1 \mathrm{M}$ and $67 \pm 1$ for group $1 \mathrm{~F}$, but these are increased to $\sim 76$ and 70 , respectively, in the nonmetal portion of the samples (Table 4).

That the group-1 might be divisible was previously suggested by REIMOLD and NIEBER-REIMOLD ( 1984), who noted that $65015[\#]$ and $63556[D]$ contained less normative olivine than 60315 [\&] and 64815 [B]. In subsequent discussion, I assume that groups $I F$ and $1 \mathrm{M}$ represent two discrete batches of melt (possibly from the same impact). However, even if they represent a poorly sampled continuum within a single batch of melt, the observations summarized here provide information on processes that cause melt heterogeneity and most of the conclusions reached below remain valid.

\section{Anorthosite mixing in group I}

At the scale of sample masses used in these experiments, both intrasample and intragroup compositional variation is 
Table 3. Average concentrations in Apollo 16 melt-rock groups for elements determined by INAA, and intragroup relative standard deviations (RSDs).

\begin{tabular}{|c|c|c|c|c|c|c|c|c|c|c|c|c|c|c|}
\hline $\begin{array}{l}\text { Concen- } \\
\text { trations }\end{array}$ & $\bar{N}$ & $\bar{M}$ & $\begin{array}{r}\mathrm{Na}_{2} \mathrm{O} \\
\%\end{array}$ & $\begin{array}{r}\mathrm{CaO} \\
\% \\
\end{array}$ & $\begin{array}{r}\mathrm{Sc} \\
\mu \mathrm{g} / \mathrm{g}\end{array}$ & $\begin{array}{r}\mathrm{Cr} \\
\mu \mathrm{g} / \mathrm{g} \\
\end{array}$ & $\begin{array}{l}\mathrm{Fe} \\
\% \\
\end{array}$ & $\begin{array}{r}\mathrm{Co} \\
\mu \mathrm{g} / \mathrm{g} \\
\end{array}$ & $\begin{array}{r}\mathrm{Ni} \\
\mu \mathrm{g} / \mathrm{g}\end{array}$ & $\begin{array}{r}\mathrm{Rb} \\
\mu \mathrm{g} / \mathrm{g}\end{array}$ & $\begin{array}{r}\mathrm{Sr} \\
\mu \mathrm{g} / \mathrm{g}\end{array}$ & $\begin{array}{r}\mathrm{Zr} \\
\mu \mathrm{g} / \mathrm{g}\end{array}$ & $\begin{array}{r}\mathrm{Cs} \\
\mu \mathrm{g} / \mathrm{g}\end{array}$ & $\begin{array}{r}\mathbf{B a} \\
\mu \mathrm{g} / \mathrm{g} \\
\end{array}$ \\
\hline $\begin{array}{l}\text { IM } \\
\text { IF most* } \\
\text { IF all } \\
64815\end{array}$ & $\begin{array}{r}6 \\
11 \\
15 \\
1\end{array}$ & $\begin{array}{r}17 \\
33 \\
42 \\
4\end{array}$ & $\begin{array}{l}0.622 \\
0.536 \\
0.530 \\
0.525\end{array}$ & $\begin{array}{l}10.8 \\
12.3 \\
12.7 \\
11.9\end{array}$ & $\begin{array}{l}14.6 \\
14.8 \\
14.3 \\
22.3\end{array}$ & $\begin{array}{l}1520 \\
1220 \\
1160 \\
1690\end{array}$ & $\begin{array}{l}7.53 \\
6.49 \\
6.24 \\
7.35\end{array}$ & $\begin{array}{l}63.9 \\
40.8 \\
40.1 \\
45.9\end{array}$ & $\begin{array}{r}1090 \\
590 \\
570 \\
610\end{array}$ & $\begin{array}{r}11.4 \\
9.8 \\
9.7 \\
6.4\end{array}$ & $\begin{array}{l}187 \\
178 \\
179 \\
146\end{array}$ & $\begin{array}{l}740 \\
790 \\
730 \\
500\end{array}$ & $\begin{array}{l}0.52 \\
0.42 \\
0.43 \\
0.33\end{array}$ & $\begin{array}{l}489 \\
514 \\
474 \\
367\end{array}$ \\
\hline $\begin{array}{l}2 \mathrm{DB} \\
2 \mathrm{NR}\end{array}$ & $\begin{array}{r}16 \\
6\end{array}$ & $\begin{array}{l}39 \\
24\end{array}$ & $\begin{array}{l}0.494 \\
0.486\end{array}$ & $\begin{array}{l}13.0 \\
12.4\end{array}$ & $\begin{array}{l}10.8 \\
12.2\end{array}$ & $\begin{array}{l}1110 \\
1190\end{array}$ & $\begin{array}{l}6.22 \\
5.98\end{array}$ & $\begin{array}{l}65.8 \\
44.1\end{array}$ & $\begin{array}{r}1070 \\
650\end{array}$ & $\begin{array}{l}5.6 \\
6.0\end{array}$ & $\begin{array}{l}185 \\
166\end{array}$ & $\begin{array}{l}380 \\
400\end{array}$ & $\begin{array}{l}0.22 \\
0.22\end{array}$ & $\begin{array}{l}265 \\
277\end{array}$ \\
\hline $\begin{array}{l}3, \text { all } \\
3,6841 \times \\
3,635 \times x\end{array}$ & $\begin{array}{l}6 \\
2 \\
2\end{array}$ & $\begin{array}{r}17 \\
6 \\
6\end{array}$ & $\begin{array}{l}0.488 \\
0.489 \\
0.488\end{array}$ & $\begin{array}{l}16.1 \\
16.2 \\
16.1\end{array}$ & $\begin{array}{r}7.9 \\
8.38 \\
7.57\end{array}$ & $\begin{array}{l}650 \\
659 \\
648\end{array}$ & $\begin{array}{l}3.33 \\
4.32 \\
4.25\end{array}$ & $\begin{array}{l}16.9 \\
13.5 \\
17.4\end{array}$ & $\begin{array}{l}190 \\
137 \\
195\end{array}$ & $\begin{array}{l}2.2 \\
2.1 \\
2.6\end{array}$ & $\begin{array}{l}178 \\
184 \\
175\end{array}$ & $\begin{array}{l}100 \\
113 \\
100\end{array}$ & $\begin{array}{l}0.09 \\
0.09 \\
0.08\end{array}$ & $\begin{array}{l}79 \\
86 \\
75\end{array}$ \\
\hline \multirow[t]{2}{*}{ 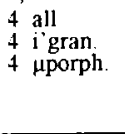 } & $\begin{array}{r}20 \\
5 \\
9\end{array}$ & $\begin{array}{l}56 \\
10 \\
25\end{array}$ & $\begin{array}{l}0.533 \\
0.581 \\
0.537\end{array}$ & $\begin{array}{l}17.2 \\
17.1 \\
17.0\end{array}$ & $\begin{array}{l}5.4 \\
6.2 \\
5.6\end{array}$ & $\begin{array}{l}360 \\
345 \\
385\end{array}$ & $\begin{array}{l}2.26 \\
2.48 \\
2.30\end{array}$ & $\begin{array}{l}6.9 \\
6.2 \\
8.1\end{array}$ & $\begin{array}{l}43 \\
32 \\
60\end{array}$ & $\begin{array}{l}0.9 \\
1.0 \\
1.0\end{array}$ & $\begin{array}{l}192 \\
201 \\
189\end{array}$ & $\begin{array}{l}35 \\
46 \\
36\end{array}$ & $\begin{array}{l}0.04 \\
0.02 \\
0.05\end{array}$ & $\begin{array}{l}42 \\
51 \\
42\end{array}$ \\
\hline & $\begin{array}{r}\mathrm{La} \\
\mu \mathrm{g} / \mathrm{g}\end{array}$ & $\begin{array}{r}\mathrm{Ce} \\
\mu \mathrm{g} / \mathrm{g}\end{array}$ & $\begin{array}{r}N d \\
\mu \mathrm{g} / \mathrm{g}\end{array}$ & $\begin{array}{r}\mathrm{Sm} \\
\mu \mathrm{g} / \mathrm{g}\end{array}$ & $\begin{array}{r}\mathrm{Eu} \\
\mu \mathrm{g} / \mathrm{g}\end{array}$ & $\begin{array}{r}\mathrm{Tb} \\
\mu \mathrm{g} / \mathrm{g} \\
\end{array}$ & $\begin{array}{r}\mathrm{Yb} \\
\mu \mathrm{g} / \mathrm{g}\end{array}$ & $\begin{array}{r}\mathrm{Lu} \\
\mu \mathrm{g} / \mathrm{g}\end{array}$ & $\begin{array}{r}\mathrm{Hf} \\
\mu \mathrm{g} / \mathrm{g}\end{array}$ & $\begin{array}{r}\mathrm{Ta} \\
\mu \mathrm{g} / \mathrm{g}\end{array}$ & $\begin{array}{r}\text { Ir } \\
\mathrm{ng} / \mathrm{g}\end{array}$ & $\begin{array}{r}\mathrm{Au} \\
\mathrm{ng} / \mathrm{g}\end{array}$ & $\begin{array}{r}\text { Th } \\
\mu \mathrm{g} / \mathrm{g}\end{array}$ & $\begin{array}{r}\mathrm{U} \\
\mu \mathrm{g}\end{array}$ \\
\hline $\begin{array}{l}1 \mathrm{M} \\
\mathrm{lF} \text { most* } \\
\mathrm{lF} \text { all } \\
64815\end{array}$ & $\begin{array}{l}49.6 \\
54.6 \\
50.3 \\
35.6\end{array}$ & $\begin{array}{r}129 \\
142 \\
131 \\
92.5\end{array}$ & $\begin{array}{l}78 \\
84 \\
78 \\
58\end{array}$ & $\begin{array}{l}22.5 \\
24.8 \\
22.9 \\
17.1\end{array}$ & $\begin{array}{l}1.97 \\
1.94 \\
1.86 \\
1.69\end{array}$ & $\begin{array}{l}4.51 \\
4.99 \\
4.59 \\
3.53\end{array}$ & $\begin{array}{l}15.4 \\
16.8 \\
15.5 \\
12.1\end{array}$ & $\begin{array}{l}2.07 \\
2.26 \\
2.09 \\
1.64\end{array}$ & $\begin{array}{l}17.3 \\
18.8 \\
17.3 \\
12.0\end{array}$ & $\begin{array}{l}1.93 \\
2.00 \\
1.86 \\
1.32\end{array}$ & $\begin{array}{l}21.0 \\
12.8 \\
12.7 \\
12.3\end{array}$ & $\begin{array}{l}24.7 \\
12.0 \\
11.5 \\
10.8\end{array}$ & $\begin{array}{l}8.1 \\
8.8 \\
8.2 \\
5.5\end{array}$ & $\begin{array}{l}2.13 \\
2.24 \\
2.09 \\
1.42\end{array}$ \\
\hline $\begin{array}{l}\text { 2DB } \\
2 \mathrm{NR}\end{array}$ & $\begin{array}{l}27.5 \\
27.6\end{array}$ & $\begin{array}{l}72 \\
72\end{array}$ & $\begin{array}{l}43 \\
43\end{array}$ & $\begin{array}{l}12.7 \\
12.7\end{array}$ & $\begin{array}{l}1.49 \\
1.51\end{array}$ & $\begin{array}{l}2.54 \\
2.52\end{array}$ & $\begin{array}{l}8.56 \\
8.86\end{array}$ & $\begin{array}{l}1.16 \\
1.20\end{array}$ & $\begin{array}{l}9.3 \\
9.6\end{array}$ & $\begin{array}{l}1.02 \\
1.11\end{array}$ & $\begin{array}{l}26.3 \\
15.9\end{array}$ & $\begin{array}{l}22.9 \\
13.4\end{array}$ & $\begin{array}{l}4.3 \\
4.4\end{array}$ & $\begin{array}{l}1.14 \\
1.26\end{array}$ \\
\hline $\begin{array}{l}3, \text { all } \\
3,6841 x \\
3,635 \times x\end{array}$ & $\begin{array}{l}6.99 \\
7.54 \\
6.60\end{array}$ & $\begin{array}{l}18.2 \\
19.6 \\
17.1\end{array}$ & $\begin{array}{l}11 \\
12 \\
10\end{array}$ & $\begin{array}{l}3.19 \\
3.45 \\
3.06\end{array}$ & $\begin{array}{l}1.06 \\
1.13 \\
1.03\end{array}$ & $\begin{array}{l}0.65 \\
0.70 \\
0.61\end{array}$ & $\begin{array}{l}2.35 \\
2.50 \\
2.26\end{array}$ & $\begin{array}{l}0.325 \\
0.343 \\
0.311\end{array}$ & $\begin{array}{l}2.42 \\
2.61 \\
2.31\end{array}$ & $\begin{array}{l}0.28 \\
0.30 \\
0.28\end{array}$ & $\begin{array}{l}8.7 \\
5.4 \\
9.1\end{array}$ & $\begin{array}{l}3.1 \\
3.6 \\
2.4\end{array}$ & $\begin{array}{l}1.16 \\
1.23 \\
1.12\end{array}$ & $\begin{array}{l}0.31 \\
0.34 \\
0.31\end{array}$ \\
\hline $\begin{array}{l}4 \text { all } \\
4 \text { i'gran. } \\
4 \text { нporph. }\end{array}$ & $\begin{array}{l}2.37 \\
3.07 \\
2.47\end{array}$ & $\begin{array}{l}6.1 \\
7.9 \\
6.4\end{array}$ & $\begin{array}{l}3.9 \\
5.0 \\
3.9\end{array}$ & 1.12 & $\begin{array}{l}1.14 \\
1.24 \\
1.12\end{array}$ & $\begin{array}{l}0.23 \\
0.30 \\
0.24\end{array}$ & $\begin{array}{l}0.91 \\
1.16 \\
0.95\end{array}$ & $\begin{array}{l}0.127 \\
0.162 \\
0.133\end{array}$ & $\begin{array}{l}0.85 \\
1.11 \\
0.89\end{array}$ & $\begin{array}{l}0.12 \\
0.15 \\
0.13\end{array}$ & $\begin{array}{l}\sim 2 \\
\sim 2 \\
\sim 2\end{array}$ & $\begin{array}{l}<1 \\
<1 \\
<1\end{array}$ & $\begin{array}{l}0.37 \\
0.47 \\
0.40\end{array}$ & $\begin{array}{l}0.11 \\
0.14 \\
0.11\end{array}$ \\
\hline RSDs (\%) & $\mathrm{N}$ & $\mathrm{M}$ & $\mathrm{Na}_{2} \mathrm{O}$ & $\mathrm{CaO}$ & $\mathrm{Sc}$ & $\mathrm{Cr}$ & $\mathrm{Fe}$ & $\mathrm{Co}$ & $\mathrm{Ni}$ & $\mathrm{Rt}$ & $\mathrm{Sr}$ & $\mathrm{ZI}$ & Cs & $B$ \\
\hline $\begin{array}{l}1 \mathrm{M} \\
\mathrm{lF} \text { most* } \\
\mathrm{lF} \text { all }\end{array}$ & $\begin{array}{l}6 \\
11 \\
15\end{array}$ & $\begin{array}{l}17 \\
33 \\
42\end{array}$ & $\begin{array}{l}6.0 \\
8.9 \\
8.2\end{array}$ & $\begin{array}{l}2.8 \\
4.6 \\
6.4\end{array}$ & $\begin{array}{l}5.5 \\
6.0 \\
8.7\end{array}$ & $\begin{array}{r}4.6 \\
6.1 \\
10.5\end{array}$ & $\begin{array}{l}7.1 \\
7.6 \\
9.7\end{array}$ & $\begin{array}{l}22 \\
38 \\
33\end{array}$ & $\begin{array}{l}22 \\
43 \\
38\end{array}$ & $\begin{array}{l}9 \\
17 \\
18\end{array}$ & $\begin{array}{l}4.6 \\
8.6 \\
7.3\end{array}$ & $\begin{array}{r}12 \\
8 \\
18\end{array}$ & $\begin{array}{l}11 \\
15 \\
15\end{array}$ & $\begin{array}{r}92 \\
10.5 \\
17\end{array}$ \\
\hline 2DB & $\begin{array}{c}16 \\
6\end{array}$ & $\begin{array}{l}39 \\
24\end{array}$ & $\begin{array}{l}4.1 \\
2.5\end{array}$ & $\begin{array}{l}1.9 \\
1.8\end{array}$ & $\begin{array}{l}3.2 \\
4.4\end{array}$ & $\begin{array}{l}3.5 \\
3.7\end{array}$ & $\begin{array}{l}7.3 \\
7.7\end{array}$ & $\begin{array}{l}25 \\
46\end{array}$ & $\begin{array}{l}26 \\
50\end{array}$ & $\begin{array}{l}22 \\
10\end{array}$ & $\begin{array}{l}4.7 \\
2.9\end{array}$ & $\begin{array}{r}12 \\
6\end{array}$ & $\begin{array}{l}17 \\
20\end{array}$ & 4 \\
\hline \multirow[t]{2}{*}{3} & $\begin{array}{c}6 \\
20\end{array}$ & $\begin{array}{l}17 \\
56\end{array}$ & $\begin{array}{r}1.6 \\
15.3\end{array}$ & $\begin{array}{l}0.3 \\
2.9\end{array}$ & $\begin{array}{r}5.2 \\
17.7\end{array}$ & $\begin{array}{r}4.2 \\
21.3\end{array}$ & $\begin{array}{r}3.7 \\
15.1\end{array}$ & $\begin{array}{l}38 \\
48\end{array}$ & $\begin{array}{l}59 \\
96\end{array}$ & $\begin{array}{l}27 \\
55\end{array}$ & $\begin{array}{l}4.0 \\
8.4\end{array}$ & $\begin{array}{r}9 \\
47\end{array}$ & $\begin{array}{r}11 \\
105\end{array}$ & 6. \\
\hline & $\mathbf{L}$ & $\mathrm{Ce}$ & $\mathrm{Nd}$ & Sm & Eu & $\mathrm{Tb}$ & $\mathrm{Yb}$ & Lu & $\mathrm{Hf}$ & $\mathrm{Ta}$ & Ir & Au & Th & \\
\hline $\begin{array}{l}\text { IM } \\
\text { IF most* } \\
\text { IF all }\end{array}$ & $\begin{array}{r}12.0 \\
9.2 \\
17.4\end{array}$ & $\begin{array}{r}11.6 \\
8.9 \\
17.3\end{array}$ & $\begin{array}{r}12.6 \\
7.9 \\
16.6\end{array}$ & $\begin{array}{r}11.6 \\
8.8 \\
17.2\end{array}$ & $\begin{array}{l}4.2 \\
4.8 \\
9.3\end{array}$ & $\begin{array}{r}11.8 \\
8.2 \\
17.2\end{array}$ & $\begin{array}{r}10.8 \\
8.6 \\
16.4\end{array}$ & $\begin{array}{r}11.0 \\
8.1 \\
16.1\end{array}$ & $\begin{array}{r}11.0 \\
9.3 \\
17.5\end{array}$ & $\begin{array}{r}11.4 \\
9.8 \\
16.1\end{array}$ & $\begin{array}{l}29 \\
42 \\
36\end{array}$ & $\begin{array}{l}23 \\
55 \\
49\end{array}$ & $\begin{array}{l}11.6 \\
10.0 \\
16.6\end{array}$ & $\begin{array}{r}12 . \\
7 . \\
14.8\end{array}$ \\
\hline $2 \mathrm{DB}$ & $\begin{array}{l}4.7 \\
7.3\end{array}$ & $\begin{array}{l}4.6 \\
8.0\end{array}$ & $\begin{array}{l}6.3 \\
7.6\end{array}$ & $\begin{array}{l}4.7 \\
7.8\end{array}$ & $\begin{array}{l}1.7 \\
2.5\end{array}$ & $\begin{array}{l}5.2 \\
7.9\end{array}$ & $\begin{array}{l}4.8 \\
7.1\end{array}$ & $\begin{array}{l}4.6 \\
7.6\end{array}$ & $\begin{array}{l}4.8 \\
7.3\end{array}$ & $\begin{array}{l}5.3 \\
6.4\end{array}$ & $\begin{array}{l}26 \\
64\end{array}$ & $\begin{array}{l}26 \\
50\end{array}$ & $\begin{array}{l}5.5 \\
9.4\end{array}$ & 8. \\
\hline $\begin{array}{l}3 \\
4\end{array}$ & $\begin{array}{r}71 \\
47\end{array}$ & $\begin{array}{r}7.3 \\
47\end{array}$ & $\begin{array}{r}7.0 \\
43\end{array}$ & $\begin{array}{r}7.2 \\
45\end{array}$ & $\begin{array}{r}4.8 \\
14.4\end{array}$ & $\begin{array}{r}7.5 \\
43 \\
\end{array}$ & $\begin{array}{r}5.4 \\
43 \\
\end{array}$ & $\begin{array}{r}5.2 \\
42 \\
\end{array}$ & $\begin{array}{r}6.7 \\
47 \\
\end{array}$ & $\begin{array}{r}6.7 \\
52 \\
\end{array}$ & 61 & 57 & $\begin{array}{r}5.1 \\
63 \\
\end{array}$ & 8. \\
\hline
\end{tabular}

$\mathrm{N}=$ Number of samples averaged; $\mathrm{M}=$ Total number of subsamples. Mass-weighted mean concentrations were calculated first from all subsamples of each samplc (cxcluding a few highly anomalous subsamples), then simple averages $(\bar{x})$ and sample standard deviations $(s)$ of all samples in each group were calculated; $\mathrm{RSD}=100 s / \bar{x}$. * Excludes feldspathic, vesicular samples $60636[\mathrm{Q}], 63596[X], 63598[H]$, and $68525[\tilde{\mathrm{N}}]$.

greater in melt rocks of group 1 than in compositionally similar rocks of group 2 (e.g., group-2DB, below; Figs. 3,4). Most likely, these differences reflect differences in grain size and texture between the two types of melt. Although samples of group 2 are petrographically diverse, they are usually fine grained and seldom poikilitic. In contrast, oikocryst sizes in the group-1 samples ( up to $5 \mathrm{~mm}$; MCKINLEY et. al., 1984) approach the size of the analyzed subsamples. Nonuniform distribution of mesostasis phases (whitlockite and K-rich glass; e.g., SIMONDS et al., 1973) on the scale of the subsample size causes variation in REE and Ba concentrations (RSDs; Table 3 ). However, there is practically no difference in intrasample precision between samples of the big-rock and littlerock experiments for ITEs in group 1 despite the factor-offour difference in subsample mass.

Unlike for the other melt groups, intrasample compositional variation in group 1 is not obviously related to the anorthosite-mixing effect (e.g., 65015[\#]; Fig. 5a). However. intragroup variation exceeds intrasample variation, particularly in group- $1 \mathrm{~F}$, leading to linear trends on many twoelement variation diagrams (Figs. 6-8). Quantitative modal data are scarce, but samples reported as "clast laden" (60636[Q]) or having "numerous clasts most of which are plagioclase" (63596 $[X])$ are more typical among the Sc- and
Sm-poor samples (RYDER and NORMAN, 1980). Thus, the trends represent mixing between mafic, ITE-rich melt and more feldspathic, ITE-poor clasts.

Although plagioclase grains are one of the most common clasts types in these melt rocks, the mixing relationship implied by the linear trends of Figs. 7 and 8 require a feldspathic component considerably more mafic than pure plagioclase. On Fig. 8 the trends for both groups $1 \mathrm{M}$ and $1 \mathrm{~F}$ lead to $\mathrm{Sc}$ concentrations of about $7-8 \mu \mathrm{g} / \mathrm{g}$ when extrapolated to ITE concentrations typical of Apollo 16 anorthosites and noritic anorthosites ( e.g. $\leq 3 \mu \mathrm{g} / \mathrm{g} \mathrm{Sm}$ ). Similarly, among group- $1 \mathrm{~F}$ samples, $\mathrm{CaO}$ anticorrelates with $\mathrm{Sc}$ (Fig. 7), and extrapolation of the trend to $7-9 \mu \mathrm{g} / \mathrm{g}$ Sc leads to a component with $17 \pm 2 \% \mathrm{CaO}$. This composition corresponds to noritic anorthosite ( $\sim 85 \%$ plagioclase, by volume), similar in composition to some lunar meteroites (e.g., Fig. 6 of JolLIFF et al., 199 (b) and only slightly more feldspathic than estimates of the average or typical upper crust of the Moon (TAYLOR, 1975, 1982; KOROTEV et al., 1980). It also corresponds to the composition of the group-3 melt rocks (Tables 4,5 ). In fact, for all lithophile elements determined here, the compositions of the four most Sm-poor samples of group-1F can be modeled well as mixtures of noritic anorthosite, represented by the average composition of group- 3 melt, and nor- 

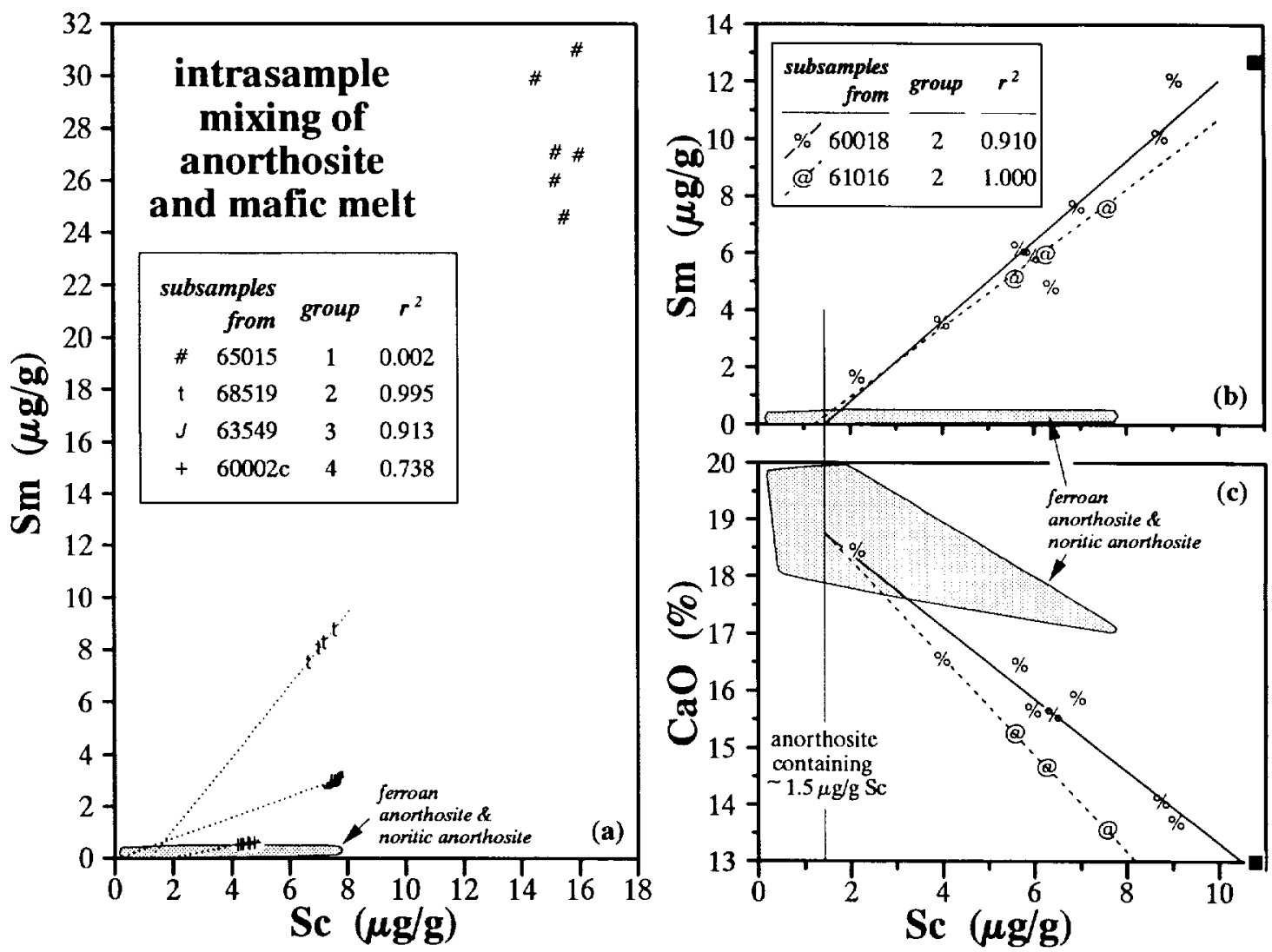

FIG. 5. The major cause of syrtematic intrasample compositional variation in many Apollo 16 melt rocks and breccias of groups 2, 3, and 4 is the mixing effect associated with varying abundance of anorthositic clasts in a melt matrix that is both more mafic (greater Sc) and richer in ITEs (Sm) than the anorthosite. (a) This effect leads to correlation of Sc and Sm concentrations among subsamples. The samples plotted here are not necessarily representative, but are some for which four or more subsamples were analyzed (one sample from each of the main compositional groups). For samples of groups 2,3 , and 4 , lines fit to the data usually extrapolate into the field for anorthosite $(<4$ $\mu \mathrm{g} / \mathrm{g} \mathrm{Sc}$, Fig. 1); the dotted lines represent simple linear regressions of Sc against Sm. In contrast. the coarse-grained. poikilitic texture of group- 1 rocks is the main cause of compositional variation among subsamples, not variation in clast abundance, so no correlation is observed (e.g., 65015 [\#]). (b) Subsamples of group-2 samples 60018 [\%] and $61016[@]$ are particularly variable in composition and plot along mixing lines between group-2 melt similar to that found in dimict breccias ( solid square) and anorthosite. Ferroan anorthosite has virtually no Sm, so extrapolation of the mixing lines to $\sim 0 \mu \mathrm{g} / \mathrm{g} \mathrm{Sm}$ yields the $\mathrm{Sc}$ concentration of the anorthosite. For both 60018 and 61016 , the anorthosite component has about $1.5 \mu \mathrm{g} / \mathrm{g} \mathrm{Sc}$, corresponding to about $34 \% \mathrm{Al}_{2} \mathrm{O}_{3}$ (Fig. 1). (c) Calcium is the only element determined here that anticorrelates with $\mathrm{Sc}$ as a result of the anorthosite mixing effect because $\mathrm{Ca}$ and $\mathrm{Al}$ (not determined) are the only elements that have greater concentrations in anorthosite than in the melt rocks. However, relative variation in $\mathrm{Ca}$ concentrations is not as great as those of $\mathrm{Sc}$ and $\mathrm{Sm}$, and $\mathrm{Ca}$ is not determined as precisely, thus the anticorrelation is not evident in most samples. This plot demonstrates that for 60018 and 61016 the correlations on the Sc-Sm plot (b) are not caused, for example. by olivine, which (like anorthosite) has low concentrations of Sc and Sm. For simplicity, in most subsequent plots only the two most Sc-rich of the 60018 subsamples are plotted because only these contain a high proportion of mafic melt.

itic melt having the average composition of the five most Smrich group-1F samples. In this model, the anorthositic norite component of the group-1 melt rocks ranges in abundance from $0 \%$ (by definition) up to $50 \%$ in the most feldspathic sample $(63596[X])$, suggesting a high clast content in some samples. If the clastic material observed petrographically in group-1 melt rocks is, in fact, predominantly plagioclase mineral grains and not lithic clasts of noritic anorthosite, then some of the mafic-mineral components of the original clasts have been preferentially assimilated by the melt ( $\mathrm{S}$ MONDS, 1975).
In addition to nonuniform distribution of clastic anorthosite and ITE-bearing phases, other phases cause compositional heterogeneity in group-1 melt rocks. Three subsamples are anomalous in containing high concentrations of $\mathrm{Sr}, \mathrm{Eu}$, and alkali elements (60636[Q], 63558[O], and $63598[H]$. The anomalous subsamples apparently contain an unrepresentatively high abundance of sodic plagioclase or alkali feldspar. For 60636 and 63558, the anomalous subsample also has the greatest concentrations of ITEs ( $\mathrm{Ba}, \mathrm{REEs}$, Th) among the subsamples, suggesting a physical association between the alkali-bearing phase (s) and ITE-rich phases. 

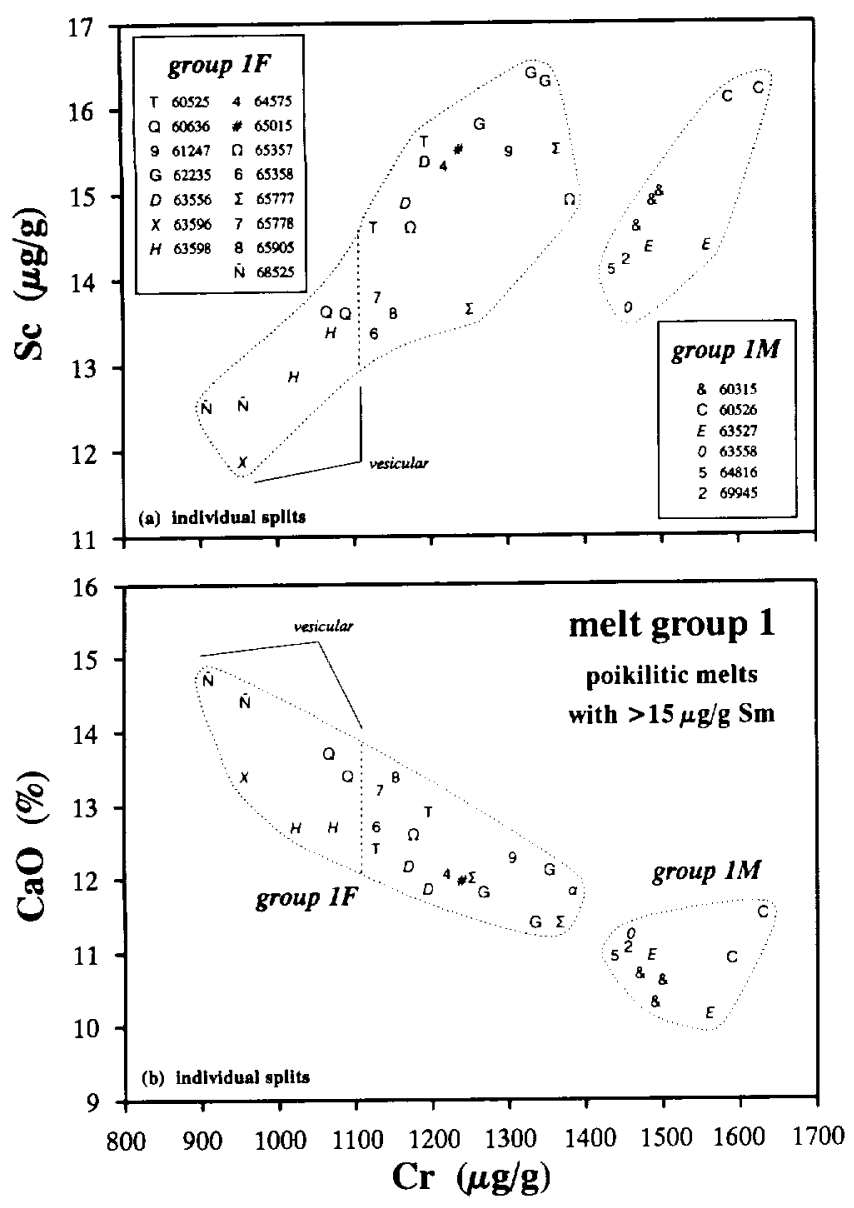

Fici 6. (a) The group-1 melt rocks can be divided into two subgroups. $1 \mathrm{M}$ and $\mathrm{IF}$, based mainly on $\mathrm{Cr}$ ( among elements analyzed here) and $\mathrm{Mg}$ concentrations. (b) Group- $\mathrm{M}$ also tends to be less feldspathic (lower $\mathrm{CaO}$ and $\mathrm{Al}_{2} \mathrm{O}_{3}$ ) than group- $I \mathrm{~F}$, but on average has higher concentrations of elements associated with alkali feldspars ( Na, K. Rb, Cs. Sr, and Eu: Tables 3 and 4). Samples that are highly vesicular or vuggy occur in group $I F$ and tend to be less mafic (higher $\mathrm{CaO}$, lower Sc and Cr: see also Fig. 8).

\section{Correlation of clast content with vesicularity in group-I} melt rocks

Of the twenty-one group-I samples studied here, the four most felspathic samples $(60636[\mathrm{Q}] .63596[X], 63598[H]$, and $68525[\mathrm{~N}]$; Fig. 6) are each described as being vesicular or, in the case of 60636 , having "many crystal-lined vugs:" the most feldspathic of these, $63596[X]$, is described as being "extremely vesicular" (RYDER and NORMAN, 1980). As inferred in the preceding section, these four samples are also those richest in clasts, suggesting a correlation between vesicularity and clast abundance. Clast-rich melt rocks are believed to cool more quickly during the first seconds of cooling (SIMONDS, 1975), which may lead to trapping of gas that might otherwise escape under conditions of slower cooling.

\section{Samples not included in group 1, but possibly related}

Some melt rocks are compositionally distinct from those designated here as group 1, but bear some similarities that suggest that may be related. These rocks are worthy of consideration because if the group- 1 rocks are products of a single impact, then compositionally anomalous samples of that melt may provide information about conditions of melt formation and cooling history.

Samples $61569[\mathrm{~V}]$ and $63597[F]$, although poikilitic and having Sc and $\mathrm{C} r$ concentrations at the low end of the range for group 1, are excluded here from group 1, primarily because of their low concentrations of ITEs (Fig. 8). Sample 63597 [ $F]$ is the most mafic of the low-ITE samples. Subsamples of 61569 [V] vary considerably in ITE and alkali concentrations (Fig. 8; Table A1) and represent an extreme case of non-

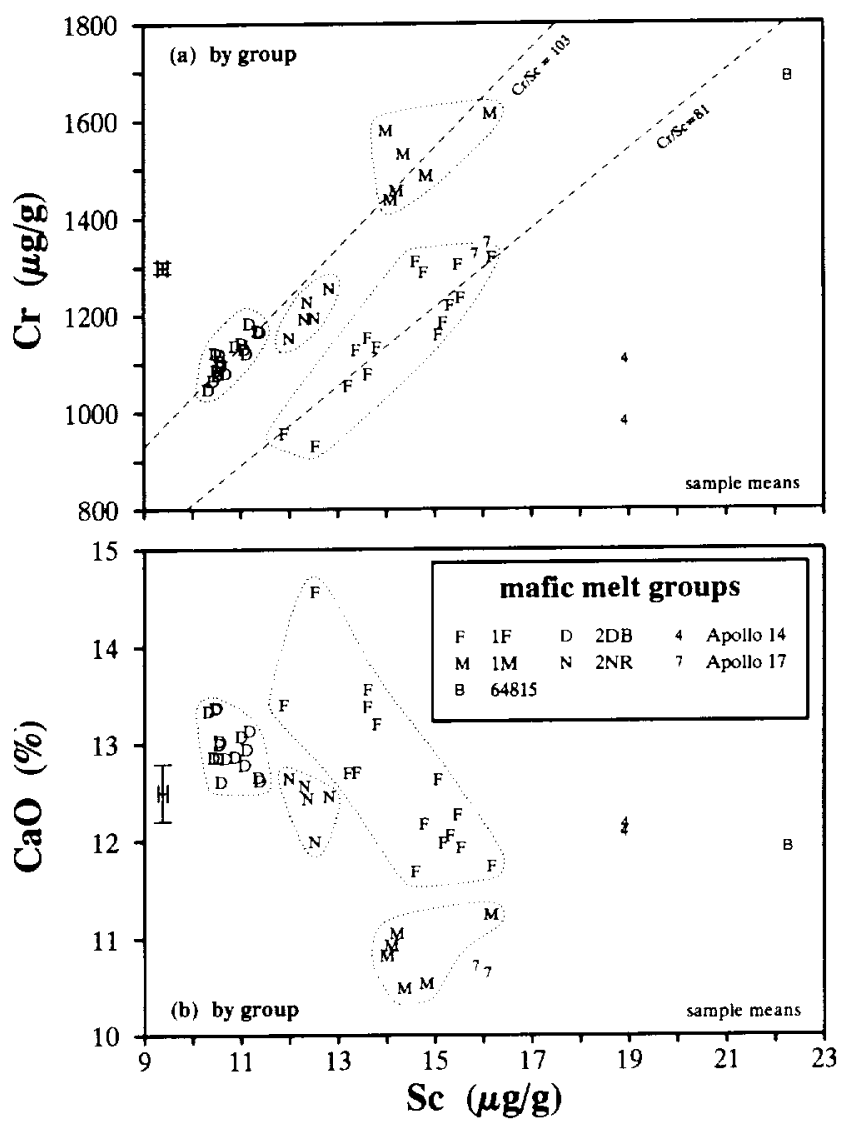

FIG. 7. Concentrations of elements associated with major mineral phases in mafic melt breccias. (a) For any given Apollo 16 mafic melt group ( IM. IF. 2DB. or 2NR), intragroup compositional variation is caused mainly by variation in the proportion of an anorthositic component, which causes correlated variation of $\mathrm{Cr}$ and $\mathrm{Sc}$ along trends (dashed lines) that pass through the origin. Melt groups IM and $2 \mathrm{DB}$ have similar $\mathrm{Cr} / \mathrm{Sc}$ ratios $(\sim 103)$. different from that of group $1 \mathrm{~F}(\sim 81)$. The $\mathrm{Cr} / \mathrm{Sc}$ ratios reflects mafic mineralogy and increase roughly with $\mathrm{Mg} / \mathrm{Fe}$ ratio (Fig. 11). The two group-IF points with the lowest Sc concentrations are samples $63596[X]$ and 68525 [ $\mathrm{N}$ ]: this figure supports the inclusion of these samples in group IF, not 2DB. as may he implied from Fig. 4. (b) Concentrations of $\mathrm{CaO}$ anticorrelate roughly with $\mathrm{Sc}$ in group $\mathrm{IF}$ hecause of variation in the anorthosite component. but this correlation is not apparent in the other groups because the relative variation for $\mathrm{CaO}$ is small and $\mathrm{CaO}$ is determined less precisely than $\mathrm{Sc}$ and $\mathrm{Cr}( \pm 1 \sigma$ uncertainty hars shown). For comparison. data for Apollo 14 melt rocks 14078 and 14310 and Apollo 17 mell breccias 76135 and 77035 are also shown. 


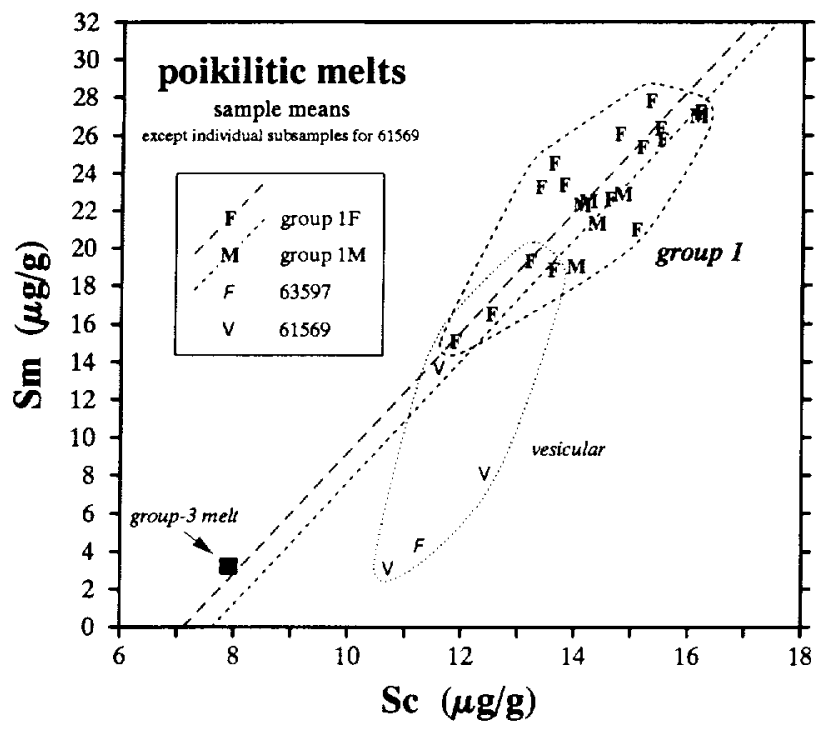

FIG. 8. Variation in Sc and Sm concentrations in samples of melt groups $I \mathrm{M}$ and $\mathrm{IF}$ and two "ungrouped" poikilitic melt breccias. Concentrations of the two elements correlate among samples of groups IF $\left(R^{2}=0.73, \mathrm{n}=15\right)$ and IM $\left(R^{2}=0.81, \mathrm{n}=6\right.$; however, $R^{2}$ $=0.35$ if sample $62235[\mathrm{G}]$ is excluded). If the trends represented in this figure and Figs. 6 and 7 represent binary mixing between two different compositions of mafic. ITE-rich melt and some anorthositic, ITE-poor component( $s$ ) (presumably clasts), then the anorthosite component, with $7-8 \mu \mathrm{g} / \mathrm{g} \mathrm{Sc}$, is similar in composition to melt group 3. i.e.. it is substantially more mafic than the implied clastic anorthositic component of group 2DB (Fig. 12). Compositions correlate with vesicularity; all of the most $\mathrm{Sc}$ - and $\mathrm{Sm}$-poor group-1 samples (all from group IF) are vesicular (Fig. 6). Although also mafic and poikilitic, samples $61569[\mathrm{~V}]$ and $63597[\mathrm{~F}]$ are not in cluded here in group 1 because both have low concentrations of ITEs. However, both are vesicular, suggesting that they may be related to the samples of group 1, but for some reason have low ITE concentrations. The scatter for the three subsamples of 61569 [V] suggests the low ITE-concentrations may simply be a sampling problem (one analysis from WASSON et al., 1977). The sample is unusual in that olivine is the oikocryst phase and the average oikocryst size is large (SIMONDS et al., 1973). Curiously, the subsample of 61569 with the lowest $\mathrm{Sm}$ concentration has the highest concentrations of $\mathrm{Rb}$ and Cs of any subsample analyzed here.

uniformity in distribution of ITE-rich and alkali-rich phases on the scale of the analyzed subsample size. If either of the two rocks was produced in the melting event(s) that produced the group-1 rocks, then some short-ranged effects(s) has acted to exclude intergranular phases rich in ITEs from $100-\mathrm{mg}$ volumes of poikilitic melt. In contrast, sample $61568[\Gamma]$, assigned here to group 2 because of its low $\mathrm{Sc}$ and $\mathrm{Cr}$ concentrations (Figs. 4, 10), has ITE concentrations nearly in the range of group 1 and a $\mathrm{Cr} / \mathrm{Sc}$ ratio similar to group $1 \mathrm{~F}$. Portions of the sample are poikilitic (RYDER and NORMAN, 1980 ) and it may be an anomalous group- 1 sample.

Sample 64815 [ B ] is unique among Apollo 16 melt rocks. This metamorphosed poikilitic rock was classified as a group1 melt by MCKINLEY et al. ( 1984 ) and REIMOLD and NIEBERREIMOLD (1984) but is excluded here from group 1 on the basis of its distinctly higher concentrations of $\mathrm{Sc}$ and $\mathrm{Cr}$ and relative enrichment in heavy REEs (Figs. 3, 7, 9). Although its $\mathrm{Al}_{2} \mathrm{O}_{3}$ concentration is typical of group- 1 melt rocks ( Fig. 1), 64815 has the greatest concentrations of Sc and $\mathrm{Cr}$ reported for an Apollo 16 melt rock (except for some highly ITE-rich melt clasts in 67975; LINDSTROM, 1984). There are no reported mineralogical features of 64815 that explain the high $\mathrm{Sc}$ and $\mathrm{Cr}$ concentrations, although the sample is somewhat unusual in having a higher concentration of $\mathrm{TiO}_{2}(1.6 \%)$ than group-1 melt rocks (1.2-1.4\%: Table 3). Despite the high $\mathrm{Cr}$ and $\mathrm{Sc}$ concentrations, the $\mathrm{Cr} / \mathrm{Sc}$ ratio is similar to that of the group-1F melt rocks, as are the $\mathrm{MgO} / \mathrm{FeO}$ (Figs. 7, 11) and Ir/Au ratios ("Siderophile Elements" section). This suggests that 64815 may be an anomalous sample of the melting event that yielded the group-1F samples. Because the two subsamples analyzed here differ somewhat from each other in concentrations of $\mathrm{Sc}, \mathrm{Cr}$, and $\mathrm{Fe}$, the database of this work has been supplemented with data for single subsamples of 64815 analyzed each by WÄNKE et al. ( 1976 ) and WASSON et al. (1977).

\section{Group 2: The Dimict Breccia and North Ray Crater "VHA Basalts"}

Group-2 melt breccias, which correspond to the "VHA basalts" of HUBBARD et al. (1973a,b) (Table 2), are more aluminous than group-1 melt breccias and have lower ITE concentrations, but similarly high $\mathrm{Sm} / \mathrm{Sc}$ ratios. On $\mathrm{Sc}-\mathrm{Sm}$ plots, samples regarded as group-2 melt breccias in previous classifications (i.e., those with $21-26 \% \mathrm{Al}_{2} \mathrm{O}_{3}$ or $8-13 \mu \mathrm{g} / \mathrm{g}$ Sc; Fig. 1 ) plot between group 1 and previously ungrouped samples (e.g., Fig. 6 of MC KINLEY et al., 1984) that are aluminous and poorer in ITEs $(2-8 \mu \mathrm{g} / \mathrm{g} \mathrm{Sm}$ : Figs. 3, 4). Because the "VHA basalts" and the previously ungrouped samples together define a trend with no clear 'break' and, as I argue below, some samples at the feldspathic end of the trend may be related to those at the mafic end, I regard all the samples of the trend as constituting group- 2 .

\section{Group 2DB: The dimict-breccia melt}

One of the most striking features of the $\mathrm{Sc}-\mathrm{Sm}$ plots is the tight cluster of points at the mafic (high-Sc) end of the group2 melt breccias (Fig. 3). In total, sixteen samples plot in this cluster (Fig. 12), although for some of the samples, individual splits or subsplits plot outside the range (Fig. 13a, Table A1). Four of the samples in this group (e.g., 61015[B] and 64476 [ $Y$ ]) are identified specifically as dimict breccias by RYDER and NORMAN (1980) and samples of other dimict breccias plot in this field (MCKINLEY et al., 1984; JAMES; JAMES and LINDSTROM, 1991a,b); thus, I designate this population "group 2DB" to indicate that it has the composition of the melt phase of the dimict breccias. Fragments of melt breccia with the group-2DB composition are common in regolith from the central and southern stations (Fig. 14), as well as in ancient regolith breccias (Fig. 15).

Petrographically, the samples of group 2DB are diverse (RYDER and NORMAN, 1980). Four have poikilitic textures (60625[D], $64568[\mathrm{~g}], 65365[\mathrm{o}], 68505[\mathrm{~s}])$ with $\sim 0.5 \mathrm{~mm}$ oikocrysts of low-Ca pyroxene. Most are described as finegrained, and some have varied textures ranging from subophitic to ophitic to glassy (JAMES et al., 1984). Most have 
Table 4. Average concentrations of major elements in Apollo 16 melt groups.

\begin{tabular}{|c|c|c|c|c|c|c|c|c|c|}
\hline group: & & & & & anom. & 2DB & 2NR & 3 & 4 \\
\hline$\%$ & 60315 & 60526 & 65015 & 62235 & $\overline{64815}$ & $\overline{\text { mean }}$ & $\overline{\text { mean }}$ & $\overline{\text { mean }}$ & $\overline{\text { mean }}$ \\
\hline $\mathrm{SiO}_{2}$ & 46.7 & 46.7 & 47.0 & 47.0 & 45.3 & 45.7 & 45.3 & 45.5 & 44.7 \\
\hline $\mathrm{TiO}_{2}$ & 1.34 & 1.4 & 1.18 & 1.21 & 1.60 & 0.93 & 1.0 & 0.34 & 0.36 \\
\hline $\mathrm{Al}_{2} \mathrm{O}_{3}$ & 17.3 & 16.9 & 19.8 & 18.7 & 19.0 & 22.0 & 21.2 & 28.7 & 31.1 \\
\hline $\mathrm{FeO}(\mathrm{t})$ & 8.81 & 10.62 & 8.16 & 9.24 & 9.49 & 8.06 & 7.7 & 4.24 & 3.05 \\
\hline $\mathrm{FeO}$ (nm) & 7.36 & 7.81 & 7.32 & 7.48 & 8.13 & 5.87 & 6.6 & - & - \\
\hline $\mathrm{Fe}^{0}$ & 1.13 & 2.18 & 0.65 & 1.37 & 1.06 & 1.70 & 0.88 & - & - \\
\hline $\mathrm{MnO}$ & 0.11 & 0.09 & 0.11 & 0.12 & 0.12 & 0.09 & 0.09 & 0.06 & 0.04 \\
\hline $\mathrm{MgO}$ & 13.5 & 13.2 & 9.7 & 10.1 & 12.0 & 10.9 & 11.1 & 4.46 & 2.80 \\
\hline $\mathrm{CaO}$ & 10.5 & 10.8 & 12.0 & 11.7 & 11. & 12.5 & 12.9 & 16.1 & 17.3 \\
\hline $\mathrm{Na}, \mathrm{O}$ & 065 & 0.64 & 056 & 053 & 0.53 & 0.49 & 0.5 & 0.49 & 0.53 \\
\hline $\mathrm{K}_{2} \mathrm{O}$ & 0.40 & 0.46 & 0.35 & 0.35 & 0.20 & 0.19 & 0.3 & 0.08 & 0.05 \\
\hline $\mathrm{P}_{2} \mathrm{O}_{5}$ & 0.46 & 0.43 & 0.40 & 0.40 & 0.31 & 0.24 & 0.19 & 0.09 & 0.04 \\
\hline $\mathrm{Cr}_{2} \mathrm{O}_{3}$ & 0.22 & 0.24 & 0.18 & 0.18 & 0.24 & 0.16 & 0.17 & 0.09 & 0.03 \\
\hline & 0.11 & & 0.12 & 0.10 & 0.11 & 0.10 & 0.11 & 0.04 & - \\
\hline sum* & 99.8 & 100.9 & 99.4 & 99.3 & 100.6 & 100.9 & 100.3 & 100.2 & 100.0 \\
\hline$M g^{\prime}(\mathrm{t})$ & 73.2 & 69. & 67.9 & 66.1 & 70.0 & 70.7 & 72. & 65.3 & 62.0 \\
\hline$M g^{\prime}(\mathrm{nm})$ & 76.6 & 75. & 70.3 & 70.6 & 72.5 & 76.8 & 75 . & - & - \\
\hline $\mathrm{Ni}(\mu \mathrm{g} / \mathrm{g})$ & 670 & 1250 & 390 & 760 & 600 & 1070 & 650 & 190 & 40 \\
\hline $\begin{array}{l}\mathrm{FeO}(\mathrm{t}) \\
\mathrm{FeO}(\mathrm{nm}) \\
\mathrm{Fe}^{0} \\
\mathrm{Mg}^{\circ}\end{array}$ & $\begin{array}{l}= \\
=\end{array}$ & & & & & & tratt & & tion \\
\hline
\end{tabular}

Data sources: This work and DUNCAN et al. (1973), HASKIN et al. (1973), HUBBBARD et al. (1973b, 1974), LSPET (1973); NAKAMURA et al. (1973), ROSE et al. (1973), TAYLOR et al. (1973), LAUl et al. (1974), NAVA (1974); BOYNTON et al. (1976); CHRSTLAN et al. (1976); WANKE et al. (1976), WASSON et al. (1977), PALME et al. (1978); LINDSTROM and SALPAS (1983); MARVDN and LINDSTROM (1983); JAMres et al. (1984). MCKINLEY et al. (1984); and STOFFLER et al. (1985); MARVTN et al. (1987). Data for 60526 are normalized values based on this work, the electron microprobe, defocused beam analygis of WARNER et al. (1976b) (quoted in RYDER and NORMAN, 1980), and the electron microprobe, fusod-bead analysis of RYDER \& SEYMOUR (1982).

glass coatings and glass veins. Clasts of anorthosite and grains of Fe-Ni metal are common. Some samples have rusty areas $(60625,68505)$, and sample $66095[\mathrm{~W}]$ is a well-studied, volatile-rich, rusty rock (TAYLOR et al., 1973; GARRISON and TAYLOR, 1980). Although only four of the samples of group 2DB are specifically identified as dimict breccias, the others are probably small fragments of the melt lithology found in dimict breccias. Most large samples of dimict breccia were found at station 4 , although some were also recovered from the central stations (LM, 1, and 2; Fig. 2) (RYDER, 1981). Seven of the sixteen samples classified here as group $2 \mathrm{DB}$ are from station 4 , and most of the rest are from other southern stations. It has been postulated that many of the dimict breccias collected at the site were excavated by the South Ray crater impact about $2 \mathrm{Ma}$ ago and that the glass coating on many of the breccias (Fig. 13a) is melt produced in that event (NORMAN and NAGLE, 1981; RYDER, 1981; JAMES, 1981; JAMES et al., 1984).

Dimict-breccia melt rock is notable for its compositional uniformity (RYDER and SEYMOUR, 1982; MC KINLEY et al., 1984; JAMES et al., 1984; JAMFS and LINDSTROM, 199 1a,b). For most precisely determined lithophile elements, intrasample RSDs are about $2 \%$ and intragroup RSDs are about 4-5\% ( section 4; Table 3). Relative concentrations of trivalent REEs are identical within analytical uncertainty for all samples (Fig. 16a). The $\mathrm{Cr} / \mathrm{Sc}$ ratio is exceedingly constant among the group-2DB samples (RSD: $1.5 \%$ ).

Although compositional variation among different samples of group 2DB is small, it is systematic and consistent with anorthosite mixing. On the Sc-Sm plot, the mixing trend ex- trapolates to $3-4 \mu \mathrm{g} / \mathrm{g} \mathrm{Sc}$ at low concentrations of Sm (Fig. 12 ), indicating that the average composition of the clastic anorthosite component is more feldspathic than the anorthosite component implied for the group-1 melt rocks (7-9 $\mu \mathrm{g} / \mathrm{g} \mathrm{Sc}$; Fig. 8). The most feldspathic samples of group 2DB $(64578[\mathrm{~m}]$ and $66095[\mathrm{~W}])$ correspond to a mixture of about $12 \%$ anorthosite and $88 \%$ melt having the composition of the most mafic samples ( 62255 [M], 64566 [R], 64568 [g]). A range of $12 \%$ clastic anorthosite component is small compared to the $50 \%$ range observed for group $1 \mathrm{~F}$ ("Anorthosite mixing . . ." section). However group 2DB, as defined here. excludes some feldspathic samples that are almost certainly dimict-breccia melt with a larger proportion of anorthosite component ("Feldspathic variants . . ." section).

\section{Group 2NR. from North Ray crater}

Samples of group-2 melt rock also occur at North Ray crater, but they are compositionally distinct from the group2 melt of dimict breccias from the southern part of the site (Fig. 17). I designate samples with this composition "group 2NR" to indicate that the composition is characteristic of group-2 melt from North Ray crater. The differences between groups $2 \mathrm{NR}$ and group 2DB have not been previously recognized because they are subtle and not evident in elements such as $\mathrm{Al}_{2} \mathrm{O}_{3}, \mathrm{TiO}_{2}, \mathrm{MgO}$, and ITEs that have been used to classify melt rocks in other studies. The main argument that group 2NR represents a different population of melt rock is that on the Sc-Sm plot ( Fig. 17), samples of group 2NR form a trend that is parallel to the trend of group 2DB. but offset 
Table 5a. Parameters for regression of concentrations of $\mathrm{Ni}$ against Ir and Au (all subsamples), with estimates of mean $\mathrm{Ni}$ concentration in nonmetal portion of melts based on Ni intercepts. Uncertainties $( \pm)$ are $95 \%$ confidence limits.

\begin{tabular}{|c|c|c|c|c|c|c|c|c|}
\hline \multirow[b]{2}{*}{ group } & \multicolumn{2}{|c|}{$\mathrm{R}^{2}$} & \multirow[t]{2}{*}{$\underline{\mathbf{N}}$} & \multicolumn{2}{|c|}{ "slope (g/mg) } & \multicolumn{3}{|c|}{${ }^{*} \mathrm{Ni}$ intercept $(\mu \mathrm{g} / \mathrm{g})$} \\
\hline & Ir & $\mathbf{A u}$ & & $\mathrm{Ni} / \mathrm{Ir}$ & $\mathrm{Ni} / \mathrm{Au}$ & Ir & $\mathrm{Au}$ & wt'd mean \\
\hline $\begin{array}{l}1 \mathrm{M} \\
1 \mathrm{~F} \\
2 \mathrm{DB} \\
2 \mathrm{NR} \\
\end{array}$ & $\begin{array}{l}0.873 \\
0.765 \\
0.858 \\
0.911 \\
\end{array}$ & $\begin{array}{l}0.958 \\
0.842 \\
0.968 \\
0.956 \\
\end{array}$ & $\begin{array}{l}18 \\
43 \\
37 \\
27 \\
\end{array}$ & $\begin{array}{l}46.3 \pm 2.6 \\
41.9 \pm 1.1 \\
38.1 \pm 0.7 \\
40.4 \pm 1.2\end{array}$ & $\begin{array}{l}42.7 \pm 1.1 \\
41.0 \pm 1.0 \\
46.9 \pm 0.5 \\
41.4 \pm 0.6\end{array}$ & $\begin{array}{c}110 \pm 40 \\
24 \pm 11 \\
70 \pm 14 \\
51 \pm 5\end{array}$ & $\begin{array}{c}34 \pm 20 \\
97 \pm 9 \\
15 \pm 9 \\
64 \pm 2\end{array}$ & $\begin{array}{l}49 \\
68 \\
31 \\
62\end{array}$ \\
\hline
\end{tabular}

- Regression by method of YORK (1969), using 10\% of each concentration value as the uncertainty (KoRoTEv, 1987a). Prior to regression, all concentration values for a given subsample were normalized by the factor needed to the bring Sc and Cr concentrations to the mean values observed for the group. This eliminates the correlation among siderophile elements due to plagioclase dilution (e.g. Drino and RnGwoOD, 1978), leaving only the correlation due to variable metal abundance.

Table 5b. Average bulk composition of metal in four melt groups of mafic melt breccias based on regressions of Fe and Co against $\mathrm{Ni}$ (all subsamples) and closure ( $\mathrm{Fe}+\mathrm{Ni}+\mathrm{Co}=100 \%$ ), with $95 \%$ confidence limits on ratios $( \pm$ ) and average metal abundance in melt.

\begin{tabular}{|c|c|c|c|c|c|c|c|c|}
\hline \multirow[b]{2}{*}{ group } & \multicolumn{3}{|c|}{ concentration in metal (\%) } & \multicolumn{2}{|c|}{$\mathrm{Fe} / \mathrm{Ni}$} & \multicolumn{2}{|c|}{$\mathrm{Ni} / \mathrm{Co}$} & \multirow{2}{*}{$\frac{\begin{array}{c}\text { metal } \\
\text { in melt }\end{array}}{(\%)}$} \\
\hline & $\mathrm{Fe}$ & $\mathrm{Ni}$ & $\mathrm{Co}$ & $(g / g)$ & $\mathbf{R}^{2}$ & $(g / g)$ & $\mathbf{R}^{2}$ & \\
\hline $\begin{array}{l}1 \mathrm{M} \\
1 \mathrm{~F} \\
\text { 2DB } \\
2 \mathrm{NR}\end{array}$ & $\begin{array}{l}94.1 \\
94.4 \\
93.6 \\
92.8 \\
\end{array}$ & $\begin{array}{l}5.5 \\
5.2 \\
6.0 \\
6.8 \\
\end{array}$ & $\begin{array}{l}0.32 \\
0.34 \\
0.36 \\
0.43 \\
\end{array}$ & $\begin{array}{l}16.9 \pm 0.6 \\
18.0 \pm 0.5 \\
15.5 \pm 0.1 \\
13.7 \pm 0.4\end{array}$ & $\begin{array}{l}0.920 \\
0.735 \\
0.981 \\
0.877 \\
\end{array}$ & $\begin{array}{l}17.3 \pm 0.2 \\
15.6 \pm 0.2 \\
16.5 \pm 0.1 \\
15.7 \pm 0.1\end{array}$ & $\begin{array}{l}0.989 \\
0.977 \\
0.990 \\
0.990\end{array}$ & $\begin{array}{l}1.89 \\
1.00 \\
1.70 \\
0.88\end{array}$ \\
\hline
\end{tabular}

- Based on average $\mathrm{Ni}$ concentrations of the melt groups and assumption that the nonmetal portion of the melt contains $50 \mu \mathrm{g} / \mathrm{g} \mathrm{Ni}$ for each group (Table 5a).

Table 5c. CI-chondrite-normalized ratios of siderophile elements in metal of four melt groups based on simple means of all subsamples for which the analytical uncertainty in the ratio ( $1-\sigma$ counting statistics) is less than $10 \%$ (Ir/Ni and $\mathrm{Au} / \mathrm{Ni}$ ) or $20 \%$ (Ir/Au) of the ratio, with $95 \%$ confidence limits $( \pm$ ) and average Ir and Au concentrations of metal.

\begin{tabular}{|c|c|c|c|c|c|c|c|c|}
\hline \multirow[b]{2}{*}{ group } & \multicolumn{2}{|c|}{ conc. in metal $(\mu \mathrm{g} / \mathrm{g})$} & \multicolumn{2}{|l|}{$\mathbf{I r} / \mathbf{N i}$} & \multicolumn{2}{|l|}{$\mathrm{Au} / \mathrm{Ni}$} & \multicolumn{2}{|l|}{ Ir/Au } \\
\hline & Ir & Au & (CI-normalized) & $\mathbf{N}$ & (CI-normalized) & $\mathbf{N}$ & (CI-normalized) & $\mathbf{N}$ \\
\hline $\begin{array}{l}1 \mathrm{MM} \\
1 \mathrm{~F} \\
2 \mathrm{DB} \\
2 \mathrm{NR}\end{array}$ & $\begin{array}{l}1.1 \\
1.4 \\
1.5 \\
1.8\end{array}$ & $\begin{array}{l}1.3 \\
1.2 \\
1.3 \\
1.6\end{array}$ & $\begin{array}{l}0.47 \pm 0.05 \\
0.62 \pm 0.07 \\
0.59 \pm 0.03 \\
0.62 \pm 0.06\end{array}$ & $\begin{array}{l}12 \\
20 \\
35 \\
19 \\
\end{array}$ & $\begin{array}{l}1.86 \pm 0.07 \\
1.84 \pm 0.27 \\
1.75 \pm 0.04 \\
1.80 \pm 0.05\end{array}$ & $\begin{array}{r}13 \\
6 \\
32 \\
18\end{array}$ & $\begin{array}{l}0.24 \pm 0.03 \\
0.35 \pm 0.03 \\
0.34 \pm 0.02 \\
0.33 \pm 0.05\end{array}$ & $\begin{array}{l}15 \\
21 \\
38 \\
25\end{array}$ \\
\hline
\end{tabular}

Values assume that nonmetal portion of rocks contain $50 \mu \mathrm{g} / \mathrm{B}$ Ni (Table $5 \mathrm{a}$ ) for each group. Cl-normalized ratios besed on $11.0 \mathrm{mg} / \mathrm{g} \mathrm{Ni}, 481$ $\mathrm{ng} / \mathrm{g} \mathrm{Ir}$, and $140 \mathrm{ng} / \mathrm{g}$ Au ("Mean C1 Chondr." values of ANDERs and GrEvEsse, 1989) with no correction for indigenous Au (GROS et al., 1976).

to $\mathrm{Sc}$ concentrations that are $10-15 \%$ greater; similarly, $\mathrm{Cr}$ concentrations are 5-10\% greater (Table 3). Like the elongated trend of group 2DB (Fig. 12), the group-2NR trend appears to result from anorthosite dilution, but with a melt component richer in $\mathrm{Sc}$ and $\mathrm{Cr}$ than that of the dimict breccias. The only other significant differences among lithophile elements between the two melt groups are that heavy REEs are relatively more abundant by a small amount in group 2NR (Fig. 9). All of these differences are consistent with a slightly greater abundance of high-Ca pyroxene in group $2 \mathrm{NR}$. Group-2NR melt breccia is the common ITE-rich melt lithology found as clasts in the feldspathic fragmental breccias that are so common at North Ray crater (STOFFLER et al., 1985) and is the principal carrier of ITEs in these breccias. The major-element composition of group $2 \mathrm{NR}$ is not as well defined as that for other compositional groups, because most samples are small and few samples have been analyzed by high-precision techniques. However, available data suggest that the $\mathrm{Al}_{2} \mathrm{O}_{3}$ concentration and $M g^{\prime}$ of group $2 \mathrm{NR}$ are indistinguishable from those of group 2DB (Table 4).

Group 2NR is more diffuse than group $2 \mathrm{DB}$, and assignment of specific samples to the group is more arbitrary (Fig. 17). Some interelement ratios are not as constant as for samples of group 2DB ( Table A 1). Like group 2DB, group 2NR is texturally diverse. Samples $63355[U]$ and $63547[L]$ are poikilitic, $63536[C], 63545[I]$, and $65785[\mathrm{~K}]$ are subophitic to intersertal, and $63585[G]$ has multiple textures (STOFFLER et al., 1985).

The mode of occurrence supports the dichotomy between groups $2 \mathrm{DB}$ and 2NR. Most of the likely group-2NR samples are from stations 11 and 13 and are associated with feldspathic fragmental breccias. Only three melt rocks from the central (62245[b]) and southern (64515[q] and 65785[K]) stations have compositions that fall in the group-2NR range (each of these samples shows some minor compositional anomalies, however; Table Al). Similarly, among small fragments of melt breccia in the regolith, only a few of those from the central and southern stations have the composition of group 2NR (Fig. 14), although group 2NR predominates among such fragments at North Ray crater (Fig. 17). Ancient regolith breccias occur at central and southern stations, but not at North Ray crater (MCKAY et al., 1986); these breccias contain clasts of group-2DB composition, but not group 2NR (Figs. 14, 15).

\section{Other Group-2 Melts}

Of the remaining twenty-seven samples assigned here to group 2, no three are sufficiently similar to each other in composition that they represent a compositional group in 


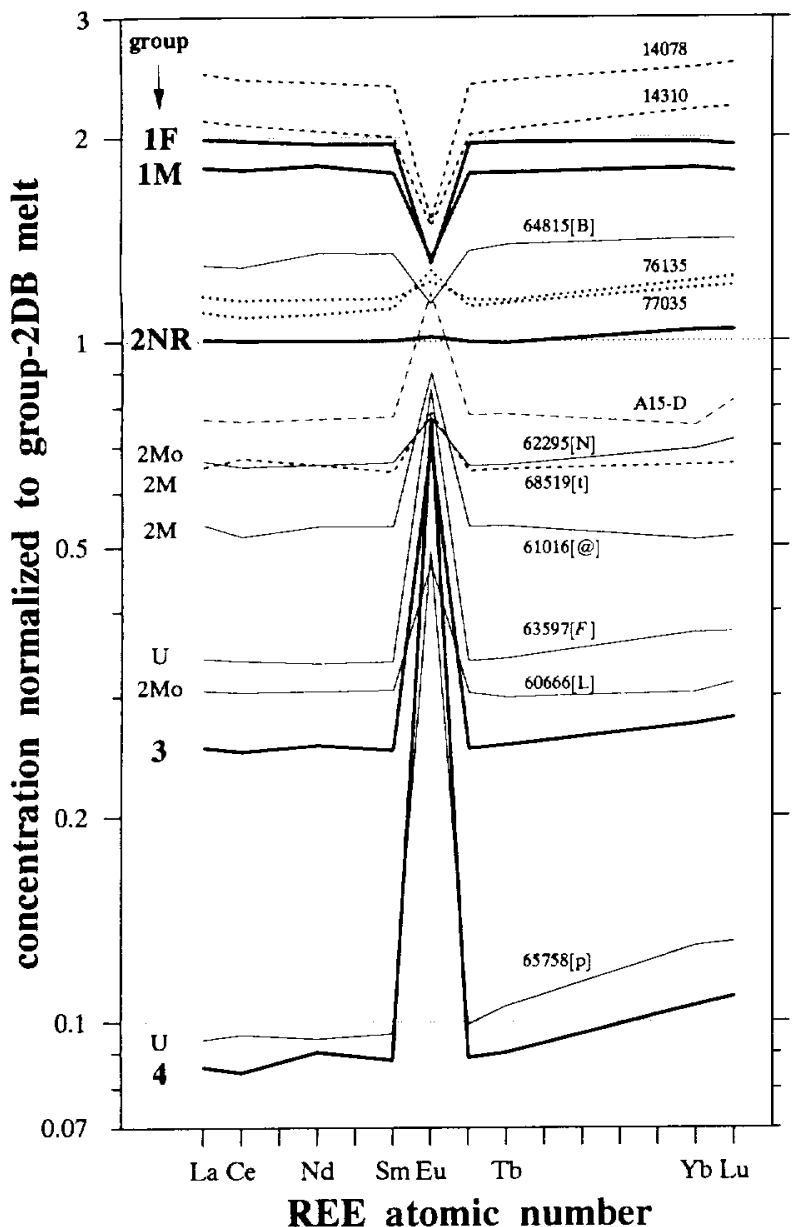

FIK. 9. Rare earth concentrations in various melt rocks normalized to mean concentrations in group-2DB (dimict breccia) melt. Even though trivalent REE concentrations are nearly twice as great in groups $1 \mathrm{~F}$ and $1 \mathrm{M}$ as group $2 \mathrm{DB}$, normalized REE concentrations do not vary with atomic number. suggesting that the target rocks of groups $1 \mathrm{M}, 1 \mathrm{~F}$, and $2 \mathrm{DB}$ as well as the ITE-rich (KREEP) component of these melt rocks are similar. This is distinctly not the case for the Apollo 14 melt rocks $(14078,14310)$, which are relatively enriched in both light and heavy REEs, and the Apollo 17 melt breccias ( 76135 , 77035 ), which are relatively enriched in heavy REEs compared to the Apollo 16 melt rocks. Also, melt breccias from Apollos 15 ("A) 5 D") and 17 are relatively enriched in Eu compared to Apollo 16 breccias of similar trivalent REE concentrations (this leads to shallower $\mathrm{Eu}$ anomalies in chondrite-normalized patterns compared to Apollo 16 samples). Sample 64815 and group-2NR melt are both relatively enriched to a small degree in heavy REEs compared to group-2DB melt. Both heavy REE enrichment and the higher $\mathrm{Sc}$ and Cr concentrations (Figs. 3,7) are consistent with a greater abundance of pyroxene. Among group- 2 samples, those plotting to the high-Sc side of the Sc-Sm trend of Fig. 18a (e.g. 62295[N]) tend to be relatively cnriched in heavy REEs while those plotting on the low-Sc side tend to be heavy-REE 'flat' $(68519[\mathrm{t}])$ or heavy-REE depleted $(61016[@])$. Groups 3 and 4 are probably uncontaminated by KREEP. "U" signifies ungrouped, anomalous samples. All data are from this work, except "A15-D" is the mean of ten subsamples of group-D melt breccia from Apollo 15 (mostly from 15445 and 15555: RYDIR and SPUDIS, 1987: LINIDSTROM et al., 1988).

the sense that groups $2 \mathrm{DB}$ and $2 \mathrm{NR}$ do. Interelement ratios such as $\mathrm{Cr} / \mathrm{Sc}, \mathrm{La} / \mathrm{Yb}$, and $\mathrm{Sm} / \mathrm{Eu}$ are constant within groups $2 \mathrm{DB}$ and $2 \mathrm{NR}$, but are more variable among other group-2 melt rocks. However, for convenience of discussion, I lump together most group-2 samples averaging more than $8 \mu \mathrm{g} / \mathrm{g}$ Sc (approximately $<26 \% \mathrm{Al}_{2} \mathrm{O}_{3}$; Fig. 1), but which are not samples of groups $2 \mathrm{DB}$ or $2 \mathrm{NR}$, as "group $2 \mathrm{M}$ " ( mafic); the remaining samples ( $<8 \mu \mathrm{g} / \mathrm{g} \mathrm{Sc}$ ) are assigned to "group $2 \mathrm{~F}$ " (feldspathic). (The exception to the $8-\mu \mathrm{g} / \mathrm{g}-\mathrm{Sc}$ division are the samples of group $2 \mathrm{Mo}$, discussed below ). This subdivision is somewhat arbitrary, but together the samples of groups 2DB, $2 \mathrm{NR}$, and $2 \mathrm{M}$ effectively constitute the "VHA basalts" (Table 2). Within groups $2 \mathrm{M}$ and $2 \mathrm{~F}$ there are some systematic compositional and textural variations among the samples that justify further subgrouping of samples; these are designated by lower case letters, e.g., groups $2 \mathrm{Mo}$ and $2 \mathrm{Fg}$ (below and Table Al).

\section{Feldspathic variants of groups $2 D B$ and $2 N R$}

Some samples of groups $2 \mathrm{M}$ and $2 \mathrm{~F}$ appear related to the samples of group 2DB in that they are compositionally

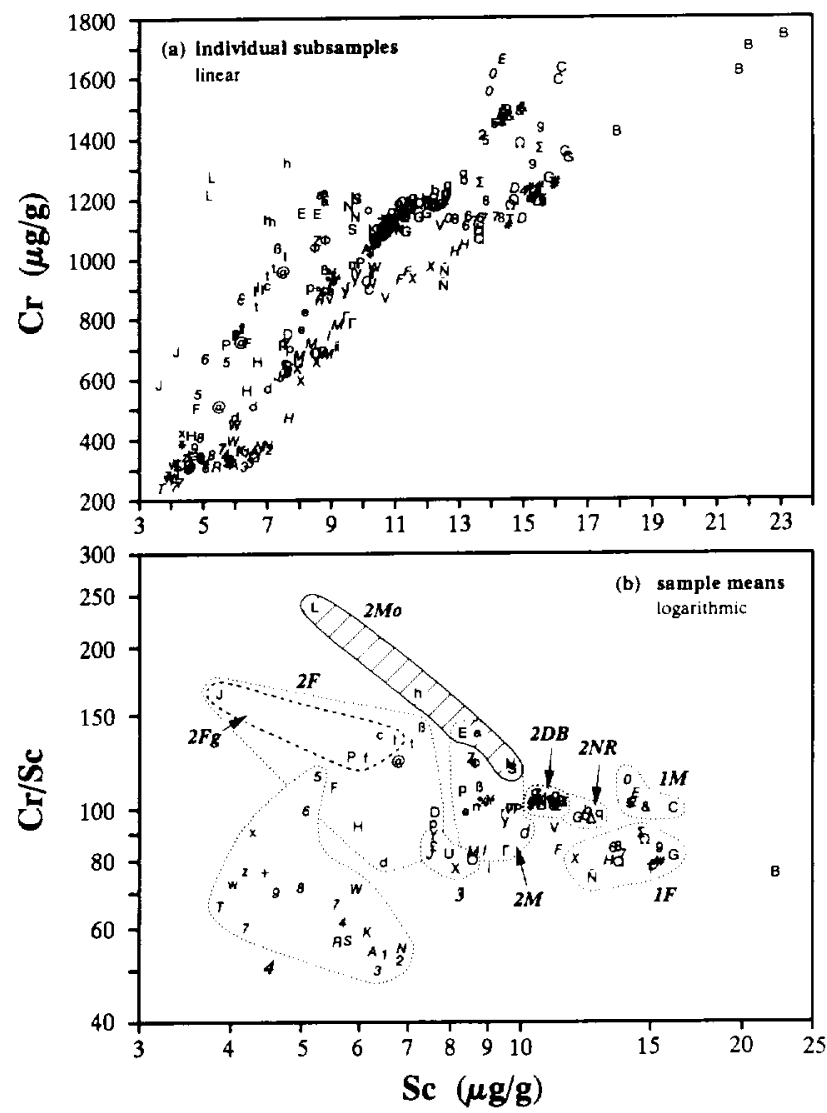

FIG 10 . (a) Concentrations of $\mathrm{Cr}$ correlate roughly with those of $\mathrm{Sc}$ in Apollo 16 melt rocks, but differences in the $\mathrm{Cr} / \mathrm{Sc}$ ratio reflect differences in mafic mineralogy. (b) The various melt groups and subgroups are indicated. Subgroup $2 \mathrm{Fg}$ includes all known glassy melt rocks analyzed here, although the field (not shown) of glassy group-A "impact melt splashes" of MORRIS et al. (1986) covers nearly the entire group- $2 \mathrm{~F}$ field. The samples of group $2 \mathrm{Mo}$, which are rich in olivine. form a distinct trend at the high- $\mathrm{Cr} / \mathrm{Sc}$ extreme of the range of the group-2 samples. Group-4 samples tend to have low $\mathrm{Cr} /$ Sc ratios: the two group-4 samples with the highest $\mathrm{Cr} / \mathrm{Sc}$ ratios (63526[5] and 63528[6]) are also unusually rich in Ni (Fig. 19) and probably contain a Cr-bearing meteoritic component. possibly as glass. 

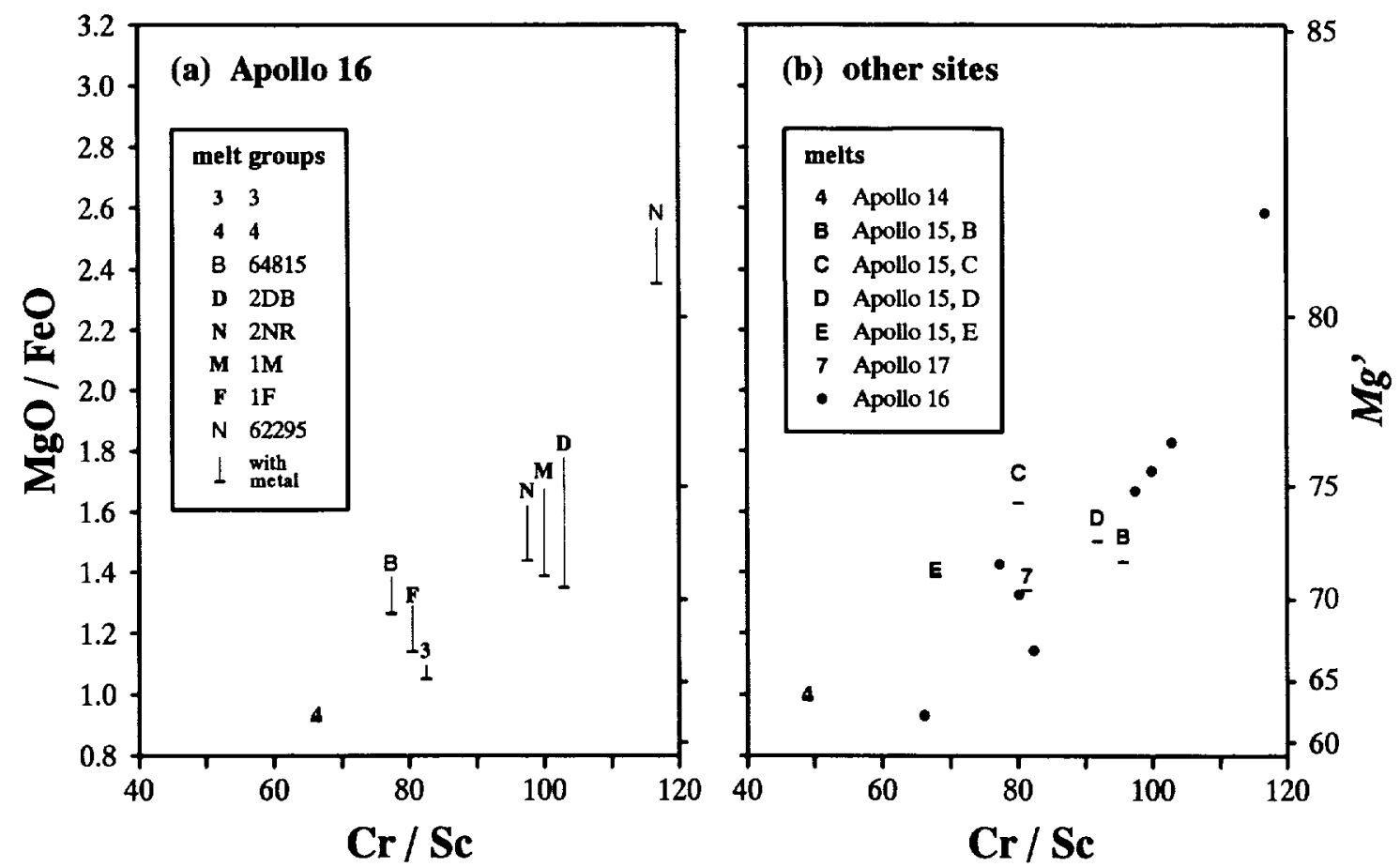

FIG. 11. Variation of $\mathrm{MgO} / \mathrm{FeO}$ with $\mathrm{Cr} / \mathrm{Sc}$. (a) Among Apollo 16 mafic melt breccias, $\mathrm{MgO} / \mathrm{FeO}$ ratios (and $\mathrm{Mg}^{\prime}$ ) tend to increase with $\mathrm{Cr} / \mathrm{Sc}$ ratios. This trend continues to sample $60666[\mathrm{~L}]$, which plots off scale $(\mathrm{Cr} / \mathrm{Sc}=238$ and $\mathrm{MgO} / \mathrm{FeO} \approx 3.5$ ). For 60666,62295 , and the other samples of group $2 \mathrm{Mo}$ (Fig. 18), the correlation is the result of a greater proportion of modal olivine and/or spinel. For mafic melt breccias of Apollo 16 (all symbols except 3 and 4), a significant fraction of the $\mathrm{Fe}$ is carried by Fe-Ni metal. The points designated by alphanumeric symbols are plotted on a metal-free basis, i.e., the ratios ( $\mathrm{MgO} / \mathrm{FeO}$ and $\left.M g^{\prime}\right)$ are based on the estimated concentration of oxidized $\mathrm{Fe}$ (Table 4). The dashes under each point show the uncorrected ratios based on total $\mathrm{Fe}$ as $\mathrm{FeO}$. The metal-free points estimate the average ratios for the mafic silicates. For example, for melt group 2DB, the average $M g^{\prime}$ of the mafic silicates estimated in this manner is 76.8 , which compares well with the range of 74-77.5 obtained on dimict-breccia melt by electron microprobe analysis with a defocused beam (JAMES et al., 1984). If all the metal is of extralunar origin, then the metal-free values also represent the ratios in the target rocks. However, if some of the metal is produced by reduction during impact, then the metal-free values overestimate $\mathrm{MgO} / \mathrm{FeO}$ and $\boldsymbol{M g}$ in the target rocks. For groups $I F$ and IM, the data represent the mean of the two samples (each) listed in Table 4. For the feldspathic melt rocks (groups 3 and 4 ). Ni concentrations are much lower ( Fig. 19) and there is no strong evidence that the $\mathrm{Ni}$ is associated with metal containing 5-7\% Ni. For consistency, however, the correction procedure has been applied to these melt rocks also. (b) To a first approximation, mafic melt breccias from other Apollo sites also follow the trend, but within the suite of Apollo 15 melt rocks, the trend is not followed (Apollo 15 group-A melt rocks are not plotted because they are highly variable in $\mathrm{MgO} / \mathrm{FeO}$ ). Sources of data: references in Table 4, plus PHILPOTTS et al. (1972), RoSE et al. (1972), WANkE et al. (1972), WiLlis et al. (1972), RYDER and SPUDIS (1987), LAUl et al. (1988). LindSTROM et al. (1988, 1990), and Korotev and KREMSER (1992).

equivalent to mixtures of group-2DB melt and typical ferroan anorthosite for all elements measured here (designated $2 \mathrm{Md}$ and $2 \mathrm{Fd}$ in Table A 1 ). These samples are almost certainly feldspathic variants of group-2DB melt; i.e., they are samples of dimict-breccia melt containing a greater proportion of anorthosite component. On any two-element variation diagram, these samples plot between the field for group 2DB and ferroan anorthosite with $\sim 4 \mu \mathrm{g} / \mathrm{g} \mathrm{Sc}$ (Fig. 12). Samples $63536[C]$ and $63545[I]$ may be similar feldspathic variants of group 2NR (Fig. 17).

\section{Glassy melts}

A number of group- 2 melt rocks have high $\mathrm{Cr} / \mathrm{Sc}$ ratios compared to groups 2DB and 2NR (Fig. 10). The high-Cr/ Sc samples fall into two categories, glassy samples with a large component of meteoritic silicates (this section) and crystalline samples with a high modal olivine abundance ( next section).

A subset of the group $2 \mathrm{~F}$ samples studied here are glassy melt breccias. These are equivalent to the Group-A IMS ("impact melt splashes") of MORRIS et al. (1986) (Figs. 4, 13) that are commonly found as coatings on dimict breccias and other Apollo 16 rocks (RYDER and NORMAN, 1980). Three samples studied here, designated as "group $2 \mathrm{Fg}$," are known to be vitreous or have a glassy matrix and all have compositions falling in the range of the Group-A IMS with $3-8 \mu \mathrm{g} / \mathrm{g} \mathrm{Sc}$ and 2-8 $\mu \mathrm{g} / \mathrm{g} \mathrm{Sm}$ (Table A 1). Samples of group $2 \mathrm{Fg}$ typically have high $\mathrm{Ni}$ concentrations and high $\mathrm{Cr} / \mathrm{Sc}$ ratios because they contain a high abundance of a component of chondritic meteorite, $7.3 \%$ (average, volatile-free CIchondrite equivalent; MORRIS et al., 1986). Addition of 


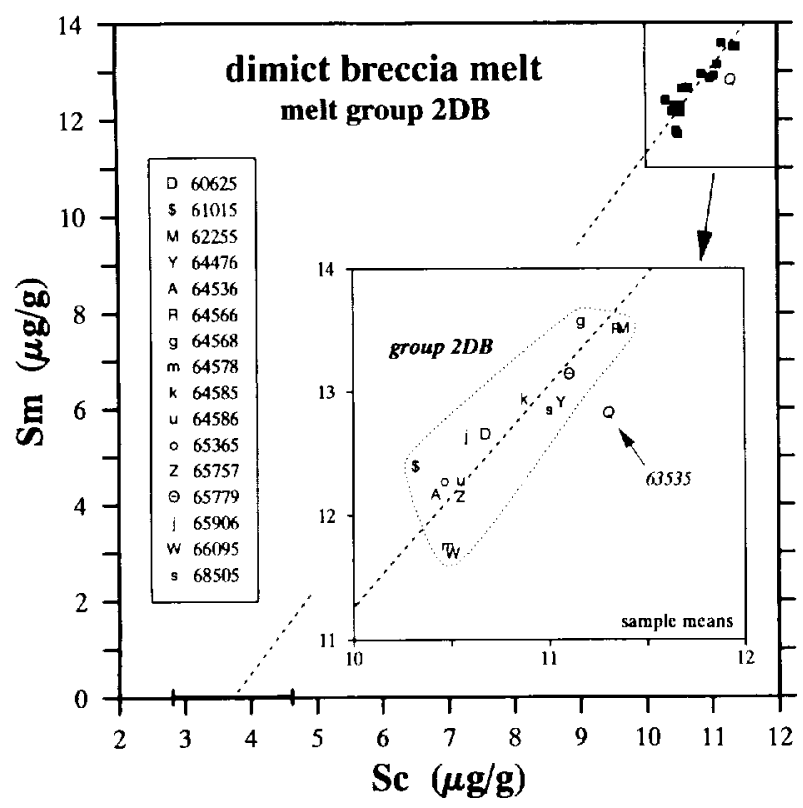

FIG. 12. Melt group 2DB is represented here by sixteen samples, although a few subsamples of some of the samples are so feldspathic that they plot outside the field defined here (Fig. 13). Seven of the samples are from station $4(64 \times x x)$ and all but three are from southern stations (Fig. 2). No dimict breccias were found at the northern stations, but sample $63535[Q]$ from station 13 near North Ray crater has a composition that plots closer to the 2DB field than to the $2 \mathrm{NR}$ field. Although the range in concentrations is small, $\mathrm{Sm}$ correlates with Sc among the samples $\left(R^{2}=0.81\right)$ suggesting that the trend is caused by 'dilution' with anorthosite. The dashed line is a best fitline to the sixteen points, which represent sample means (weighted averages of subsamples). For the fit. $2 \%$ uncertainties were assumed for Sc and Sm concentrations because $2 \%$ is essentially the intrasample RSD for these two elements. The line extrapolates to $3.7 \pm 0.9 \mu \mathrm{g} /$ g Se (95\% confidence), indicating that the anorthosite component Causing the variation contains about $32 \% \mathrm{Al}_{2} \mathrm{O}_{3}$ (Fig. 1).

chondritic material to Apollo 16 material has no effect on the $\mathrm{Sc}$ concentration, but increases the $\mathrm{Cr}$ concentration (e.g., CI chondrites: $2660 \mu \mathrm{g} / \mathrm{g} \mathrm{Cr}, 5.82 \mu \mathrm{g} / \mathrm{g} \mathrm{Sc} . \mathrm{Cr} / \mathrm{Sc}=457$; ANDERS and GREVESSE, 1989).

I have done some mass-balance calculations and agree with the conclusions of MORRIS et al. (1986) that the group-2Fg glasses (Group-A IMS) are probably mixtures of some type of anorthosite, mafic melt of group 2 (e.g., 2DB, 2M), and chondritic meteorite, and that group- 1 melt is probably not a significant component. However, the anorthosite component is probably anorthosite with a range of pyroxene plus olivine abundance, not discrete components of highly feldspathic anorthosite and anorthosite norite, as modeled by MORRIS et al. (1986). In contrast, the Group-B IMS of MORRIS et al. (1986), which includes most of the "melt bombs" found in the regolith of North Ray crater (BOR(HARIDT et al.. 1986), are compositionally consistent with being secondary melts of group-2NR crystalline melt and feldspathic fragmental breccia, both of which are common constituents of the ejecta from North Ray crater (Fig. 13b). Contrary to the conclusion of MORRIS et al. (1986), the
Group-B IMS do not correspond to soil melts when all elcments are considered; the high $\mathrm{Sc}$ concentrations derive from the group-2NR melt-rock component, not from soils. which are rich in Sc because of a minor mare component (e.g., KOROTEV, 1991).

\section{Group 2Mo: $\mathrm{High}-\mathrm{Cr}$, olivine-rich melt rocks}

A few melt breccias contain a significant amoung of high$M g^{\prime}$ olivine and, sometimes. spinel. As a consequence, they have high-Cr/Sc ratios like the glassy melts, but are dissimilar in being Ca-poor (Fig. 18b) and only moderately rich in $\mathrm{Ni}$ (300-800 $\mu \mathrm{g} / \mathrm{g}$ : Fig. 19). The six most extreme of these samples, which I assign to "group $2 \mathrm{Mo}$ " to indicate that they are mafic and olivine rich (Table A 1; Fig. 18), are all fine-grained, crystalline melt breccias (RYDER and NORMAN, 1980). On most two-element plots, samples of group $2 \mathrm{Mo}$ plot along trends that are linear and that extend from samples 62295 [N] and $64567[\mathrm{~S}$ ] to compositionally unique sample $60666[\mathrm{~L}]$. which has the lowest $\mathrm{Ca}$ (Fig. 18b) and highest MgO concentrations (20.3\%; RYDER and SEYMOUIR, 1982). and the highest Cr/Sc ratio (Fig. 10) and $\mathrm{Mg}^{\prime}(\sim 89$, metal-free) of any Apollo 16 melt rock. Sample 60615[B] might also be assigned to group $2 \mathrm{Mo}$ as one of the two splits analyzed here plots in group Mo in most figures (e.g., Fig. 18): it is also a fined-grained. olivine-bearing melt with high bulk $M g^{\prime}(83)$.

It is not clear whether the samples of group 2Mo are genetically related to each other. The linear trends they form on two-element plots suggest a relationship involving mixing or, possibly, igneous fractionation. If the samples are related and the trends are mixing trends, then the Sm-rich component appears to be a "normal' group-2 melt of anorthositic norite composition and the Sm-poor component is troctolite, not olivine (Fig. 18c). In samples $60666[\mathrm{~L}]$ and $64576[\mathrm{~h}]$, the fraction of this troctolitic component is so large as to dilute concentrations of Sm and Sc to levels typical of the most feldspathic group-2 samples (Fig. 18a).

\section{Group 3}

Group-3 melt rocks are characterized by lower $\mathrm{Sm} / \mathrm{Sc}$ ratios and lower absolute ITE concentrations than those of groups 1 and 2 (Fig. 4). Group-3 samples are also more ferroan than those of group 2 (lower $M g^{\prime}$; Table 4 ) and their $\mathrm{Al}_{2} \mathrm{O}_{3}$ concentrations (28-29\%) are greater than those of group-2 samples of similar Sc concentration (which accounts for some of the scatter of Fig. 1 ).

Six samples of this study belong to compositional group 3. Three of these, $63549[J], 68415[\mathrm{O}]$, and $68416[\mathrm{X}]$, are the three type specimens for group 3 of FloraN et al. (1976). Two others. $60635[\mathrm{U}]$ and $65055[£]$, are samples recognized as group-3 melt by MCKINLEY et al. ( 1984). REIMOLD et al. (1985), or DeUTSCH and STOFFLER (1987). The sixth. $63537[Y]$, is compositionally indistinguishable from $63549[\mathrm{~J}]$ and is previously unanalyzed. In addition. sample 67559 of WASSON et al. (1977) is a group-3 melt rock (Table 2). Two of the samples assigned to group 3 by MC KINLEY et al. ( 1984) (65349[n] and 65915[r]) I have assigned instead to group $2 \mathrm{M}$ because of their much greater ITE concentrations 

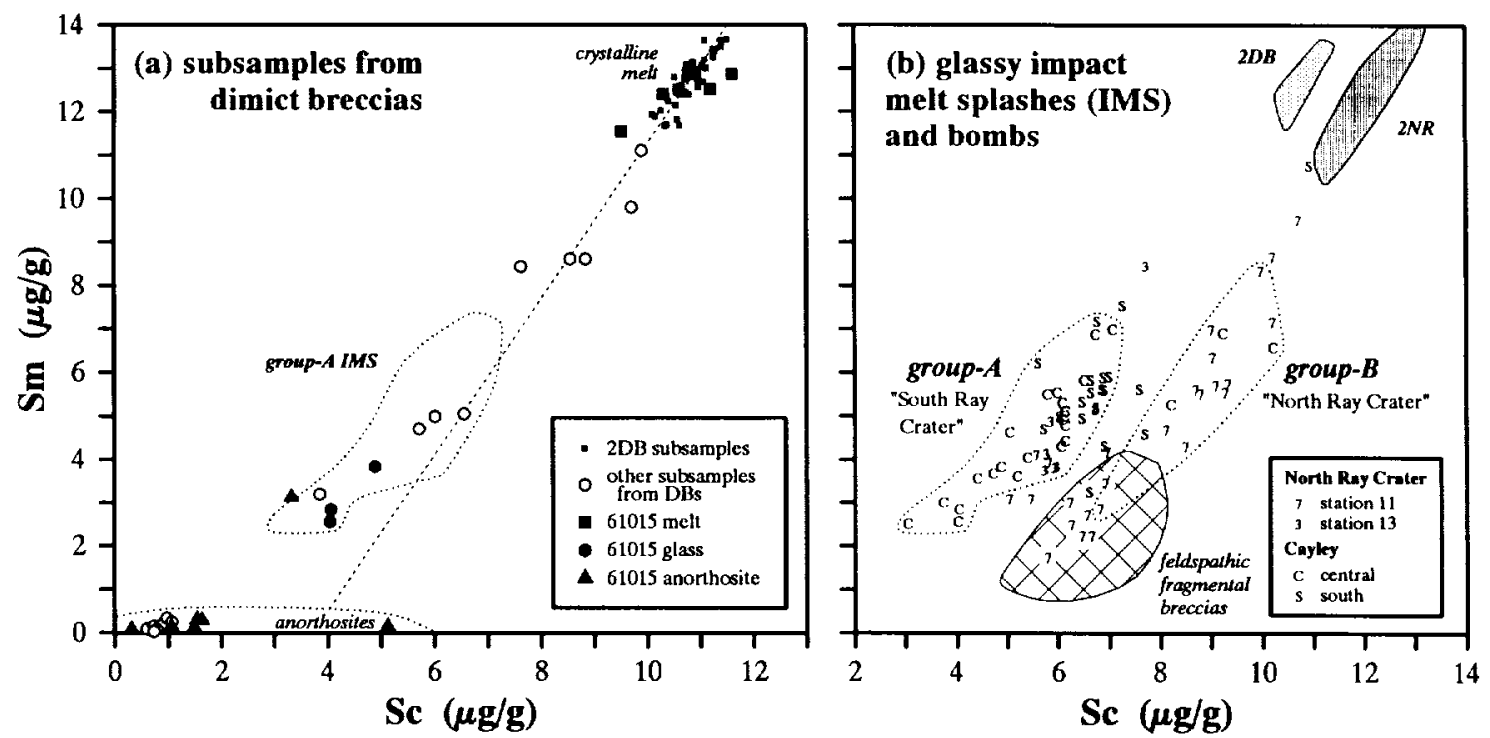

FICi. 13. (a) Subsamples from dimict breccias. Dimict-breccia lithologies uncontaminated with others are sometimes difficult to separate; thus, the composition of many subsamples plot between the mafic, crystalline melt lithology with the composition of group 2DB. and the anorthosite lithology. The dashed line is the mixing line defined by the variation in subsamples of crystalline melt only ( Fig. 12); its extrapolation into the field of anorthosites should yield the average composition of the clastic anorthosite causing the compositional variation in the crystalline melt ( $3.7 \mu \mathrm{g} / \mathrm{g} \mathrm{Sc}$ ). Most anorthosite separates from dimict breccias are more feldspathic $(<2 \mu \mathrm{g} / \mathrm{g} \mathrm{Sc})$ than the inferred clastic anorthosite component, probably because of deliberate avoidance during sampling of more mafic anorthosite in efforts to obtain separates uncontaminated with melt. Dimict breccias are often coated with glass with the composition of the GroupA IMS (impact-melt splashes) of MORRIS et al. (1986), and veins of glass may account for some of the systematic variation of Fig. 12. (b) Compositions of glassy melt splashes and bombs. The dotted lines encircle samples identified as "Group-A" and "Group-B" impact-melt splashes of MorRIS $\mathrm{ct}$ al. (1986); samples plotting outside these fields are from other studies. Most group-A glassy melts are from the central and southern stations of the Cayley plains while most group-B glasses are the "melt bombs" of BORCHARDT et al. (1986) found in the regolith of North Ray crater. Group-A glass is compositionally equivalent to an impact mixture of ferroan anorthosite and crystalline melt of groups $2 \mathrm{DB}$ (field plotted) and $2 \mathrm{M} / 2 \mathrm{Mo}$ (not plotted), while group-B glass corresponds to a mixture feldspathic fragmental breccia (a noritic anorthosite composition) and crystalline melt of group $2 \mathrm{NR}$. The group-B glasses were not formed in the North Ray crater impact, but are thought to have been formed by numerous impacts forming craters $<1.5 \mathrm{~km}$ in diameter in the vicinity of North Ray crater (BORCHARDT et al., 1986). Data for 61015 are from JAMES et al. (1984), with other dimict breccia data from this work. PALME et al. (1978), and JAMES and LINDSTROM (1991a,b). Glass data are mostly from MORRIS et al. (1986) and BORCHARDT et al. (1986), with additional data from HASKIN et al. (1973), LAUL and SCHMITT (1973), LAUL et al. (1974). WARNer et al. (1976a). JamFs et al. (1984), and LINDSTROM (1984).

and high $\mathrm{Sm} / \mathrm{Sc}$ ratios typical of group 2 (Fig. 4). The seven samples I classify as group 3 are all clast-poor, subophiticophitic-intersertal melt rocks (RYDER and NORMAN, 1980: STOFFI.FR et al., 1985). The similarity in texture of all samples of this group is important, considering the textural diversity of group-2 melt rocks and the rarity of clast-poor melt rocks among Apollo 16 samples.

Despite the high degree of compositional similarity among these samples, the two station- 8 samples $(6841 \times[O, X])$ are demonstrably different in composition from the station-13 samples $(635 \times \times[Y, J])$ and these differences do not correspond in any obvious way to variation in clast abundance. Relative REE concentrations differ between the station- 8 samples and station-13 samples (Fig. 16b), as do Ir/ Au ratios ("Group 3 and 4" section). Although the magnitudes of the differences are small, such differences are not observed, for example, in group 2DB (Fig. 16a). Average concentrations of $\mathrm{Na}, \mathrm{Ca}, \mathrm{Cr}$, and $\mathrm{Fe}$ are virtually identical in $635 \times \mathrm{x}$ and $6841 \mathrm{x}$, yet concentrations of $\mathrm{Sc}, \mathrm{Sm}$, and $\mathrm{Eu}$ are all about
$90 \%$ as great in $635 \times x$ as in $6841 \times$ (Table 3 ). There is no reasonable component that can be added to $6841 \mathrm{x}$ to generate the composition of $635 \times x$ (or conversely); the difference in Eu concentrations combined with similarity in $\mathrm{Na}$ and $\mathrm{Ca}$ concentrations is particularly difficult to rationalize by any simple mixing relationship. Nevertheless, the trends of intragroup variation are the same as those of the intrasample variation, suggesting the samples are all related. For most elements, 65055 [ $f$ ] is similar in composition to 63537 [ $Y$ ] and $63549[J]$, while $60635[\mathrm{U}]$ is intermediate. Reported differences in modal petrography do not correlate in any obvious way with the compositional differences noted here (VANIMAN and PAPIKE, 1980).

\section{Group 4}

Melt group 4 was invoked by MCKINLEY et al. (1984) to account for the numerous highly aluminous. ITE-poor melt rocks. None of the samples identified as group- 4 melt rocks 


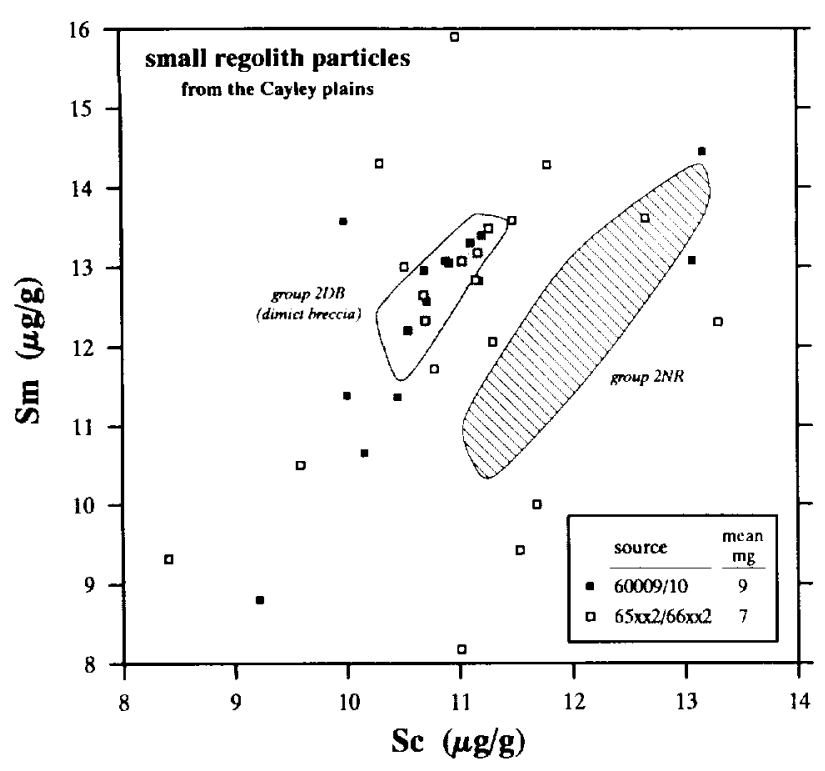

FIG. 14. Comparison of fields for groups $2 \mathrm{DB}$ and $2 \mathrm{NR}$ with small regolith particles $(1-2 \mathrm{~mm})$ from the Cayley plains. The figure shows that more of the particles have an affinity with group 2DB than with group 2NR (compare with Fig. 17). Only a few of the particles have been studied petrographically. All of those studied are melt breccias, but some of the unstudied samples may be polymict breccias containing more than one melt lithology. The " $60009 / 10 "$ particles are from a depth of $20-58 \mathrm{~cm}$ in a core from the LM area (KOROTLV,

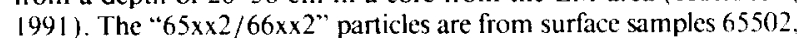
65702, and 66042 at stations 5 and 6 (HASKIN et al.. 1973 and R. L. Korotev, unpubl. data).

by MC KINLEY et al. (1984) was analyzed in this study, but their group 4 appears to correspond to the large number of samples with low $\mathrm{Sm} / \mathrm{Sc}$ ratios and $\mathrm{Sc}$ and $\mathrm{Sm}$ concentrations less than those of group 3 (Figs. 3, 4).

Group- 4 melt rocks vary considerably in composition, although this variation is not evident unless relative differences are examined, because concentrations of most lithophile elements are so low (e.g., Fig. 3). Most of the group-4 samples are from station 13 and most of these are feldspathic microporphyritic melt breccias or intergranular melt breccias (STÖFFLER et al., 1985). These two textural variants overlap entirely in composition, although the microporphyritic melts are slightly more feldspathic on average (Table 3 ). The microporphyritic and intergranular melt breccias plot along a linear trend on most plots of lithophile elements (e.g., Fig. 3 ). As with the group-2DB melt rocks, this trend extrapolates toward an anorthosite component with $-3 \mu \mathrm{g} / \mathrm{g} \mathrm{Sc}$, indicating, again, a range in abundance of some anorthosite component among the samples. The two texturally distinct station-13 samples, $63505\left[W^{\prime}\right]$ (micropoikilitic) and 63506 [ $T$ ] (subophitic-intersertal), are also compositionally distinct from each other and the other group-4 samples (Figs. 3, 10; Table A1). Only four of the seventy-three samples studied here that are not from station 13 fall in group 4 $(68526[w], 68845[x], 68846[z]$, and $(60002 c[+])$. These four samples are each at the low-Sc, low-Sm. low-Na extreme of the group- 4 samples and together tend to form a tight cluster on most two-element plots.
I leave samples $65758[\mathrm{p}]$ and 64817 [i] as "ungrouped", because on most two-element plots they are anomalous and plot outside the fields for groups 3 and 4 (Figs. 3,4). Sample $63597[F]$, the most Sc-rich sample along the low-Sm/Sc trend of Fig. 4, is also left ungrouped ("Samples not included in group 1" section).

\section{SIDEROPHILE ELEMENTS}

The previous section has focused on lithophile elements. Some inferences based on lithophile elements are supported by data for siderophile elements (SE). This section combines observations and discussion.

\section{Mafic Melt Breccias of Groups 1 and 2}

The mafic, ITE-rich melt breccias constituting groups $1 \mathrm{M}$. IF, 2DB. and 2NR (hereafter, "mafic melt breccias") have high absolute concentrations of siderophile elements, which reside in grains of $\mathrm{Fe}-\mathrm{Ni}$ metal. (Many of the generalizations made here about the 'supergroup' of mafic melt breccias also apply to sample 64815 [B] and some or all of the individual samples of groups $2 \mathrm{M}$ and $2 \mathrm{Mo}$.) Among the mafic melt breccias, concentrations of total Fe correlate better with the

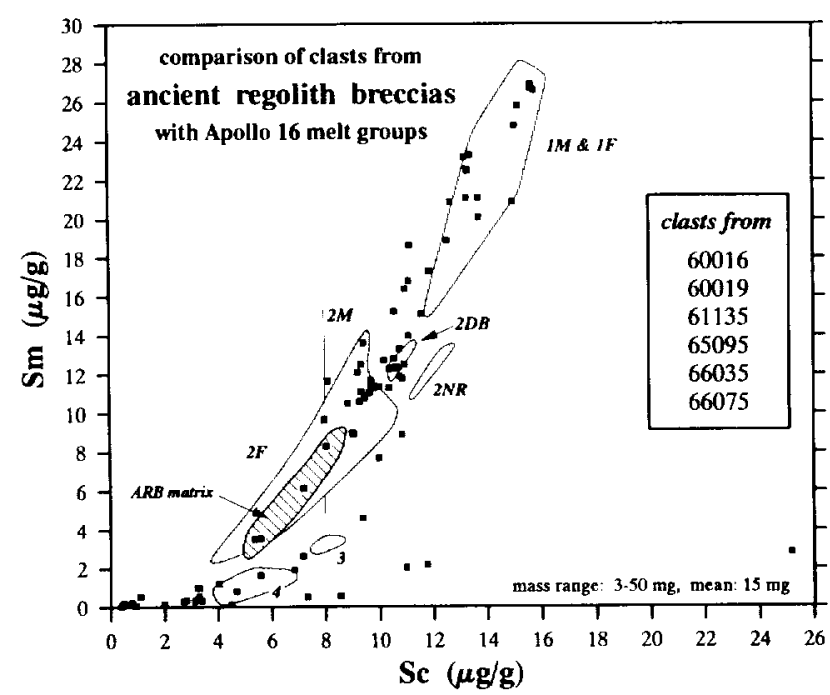

FICi. 15. Comparison of compositions of melt-breccia groups with clasts extracted from Apollo 16 ancient regolith breccias (ARBs: M( KAY et al., 1986). Not all of the clasts are melt breccias, and only a few of them have been examined petrographically. Some of the low-Sm clasts are granulitic breccias and anorthosites, although others are feldspathic melt breccias. However. all of the high-Sm clasts that have been examined petrographically are melt breccias and almost certainly the others are melt breccias or polymict breccias containing a large melt component. This suite of clasts is not necessarily representative of all clasts in the ARBs, but only of the larger ones that could be easily extracted, such as coherent melt rocks. Several of the clasts are compositionally equivalent to group-2DB melt (for all elements determined) and a number of others appear to be more feldspathic variants ( the latter may be contaminated with ARB matrix). Clasts of group-2DB composition were found in each of the breccias except 60019: most are from 60016. None of the ARB clasts have the composition of the group-2NR melt, which is the predominant melt type in feldspathic fragmental breccias from North Ray crater ( Fig. 17). Clasts with group-2F composition are rare. 

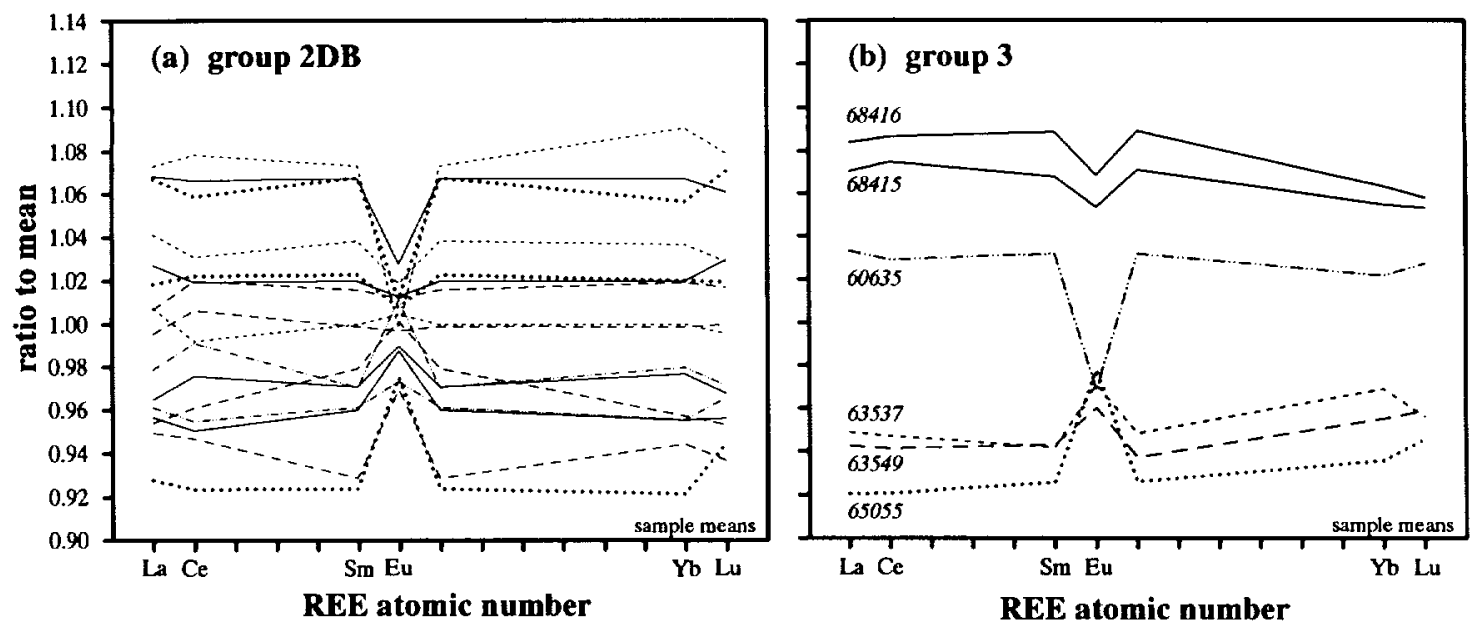

FIG. 16. Relative concentrations of REEs in samples from groups 2DB and 3 normalized to the mean concentration for each group. (a) REE 'patterns' for samples of group-2DB melt are 'flat' for trivalent REEs, when normalized to the mean, and concentrations of divalent Eu are similar for all samples (RSD = 1.7\%; Table 3). (b) For group-3, REE patterns show a systematic change in slope with increasing REE concentration, and Eu concentrations diverge (RSD $=4.8 \%$; Table 3 ). (For clarity, the patterns are based only on the elements listed along the ordinates because these are determined with a precision of $1-2 \%(1 \sigma)$; Nd and Tb are determined too imprecisely to be of value in this comparison. The 'kinks' at $\mathrm{Ce}$ and $\mathrm{Yb}$ are not significant considering the magnitude of the uncertainties $(1-2 \%)$.)

concentrations of Ni than with those of Sc (Fig. 20a). This indicates that a significant fraction of the $\mathrm{Fe}$ is contained in the metal and that heterogeneous distribution of metal grains is the major cause of the scatter in total Fe abundances within any compositional group (Fig. 20a) or among subsamples of a given sample (KOROTEV, 1987a, 1990). The heterogeneous distribution of metal grains leads to strong correlations among concentrations of $\mathrm{Fe}, \mathrm{Co}$, and $\mathrm{Ni}$ for subsamples of a given compositional group (Fig. 20b,c; Table 5b). The correlations allow the average composition of the metal in each group to be calculated by linear regression, assuming the concentrations of $\mathrm{Fe}, \mathrm{Ni}$, and $\mathrm{Co}$ in the metal sum to $100 \%$ (KOROTEV, 1987a). Concentrations of $\mathrm{Ni}$ are also highly correlated with those of Ir and Au (Table 5a). Assuming that all the Ir and Au are in the metal phase, extrapolation of regression lines to zero concentration of $\mathrm{Ir}$ and $\mathrm{Au}$ yields estimates of the $\mathrm{Ni}$ concentrations in the nonmetal phases (KOROTEV, 1987a). Although estimates based independently on Ir and $\mathrm{Au}$ do not agree well with each other in all cases, they nevertheless indicate that the average $\mathrm{Ni}$ concentrations in the silicates and oxides is low, about $30-70 \mu \mathrm{g} / \mathrm{g}$ (Table $5 \mathrm{a}$ ). This range is the same as measured in nonmagnetic separates from three Apollo 16 mafic melt breccias (26-74 $\mu \mathrm{g} / \mathrm{g}$; KOROTEV, 1990). Because there is no strong indication that concentrations of $\mathrm{Ni}$ in the nonmetal portions of the melt differ from group to group, I use $50 \mu \mathrm{g} / \mathrm{g}$ for all groups in subsequent calculations.

Once the $\mathrm{Fe} / \mathrm{Ni}$ ratio of the metal and the concentration of $\mathrm{Ni}$ in the nonmetal phases are known, the concentration of metal in any sample or group can be calculated from the total $\mathrm{Ni}$ concentration. For example, melt groups $2 \mathrm{DB}$ and $1 \mathrm{M}$ contain $1.7 \%$ and $1.9 \%$ metal ( Table $5 \mathrm{~b}$ ). Remarkably, $27 \%$ of the $\mathrm{Fe}$ in the dimict-breccia melt occurs in reduced form. The concentrations of $\mathrm{Fe}^{2+}$ carried by mafic silicates and ilmenite can also be calculated (Table 4 ) and, as expected, these correlate much better with Sc concentrations (Fig. 20d) than do concentration of total Fe (Fig. 20a). Because Fe concentrations vary greatly among subsamples of a given rock and because such a large fraction of the Fe is metallic, total $\mathrm{Fe}$ abundance cannot be used for estimating the $M g^{\prime}$ of the mafic silicates in melt breccias of groups 1 and 2 (Table 4; Fig. 11).

The average composition of the $\mathrm{Fe}-\mathrm{Ni}$ metal differs slightly in the four groups of mafic melt breccia (Table $5 b, c$ ). As argued later, regardless of the cause of these differences, the differences support the inferences made above on the basis of lithophile elements that at least four populations of mafic, ITE-rich, SE-rich melt breccia occur at Apollo 16. Previous estimates on a smaller dataset suggested that the average $\mathrm{Ni}$ / Co ratio of the metal in group- 2 melt from dimict breccias ( $17.3 \pm 0.3,95 \%$ confidence) was greater than that of group2 melt from North Ray crater (14.9 \pm 0.3 ) (KOROTEV, 1987a). Based on the data obtained here, the magnitude of the difference in the ratios is not as great, but the difference is still significant (2DB: $16.5 \pm 0.1$ and $2 \mathrm{NR}$ : $15.7 \pm 0.1$; Table $5 b$ ). The difference in $\mathrm{Ni} / \mathrm{Co}$ ratio of the metal of groups $1 \mathrm{M}$ and $1 \mathrm{~F}$ is also significant ( $1 \mathrm{M}: 17.3 \pm 0.2$ and $1 \mathrm{~F}: 15.6 \pm 0.2$ ). The metal of group 2 has higher average $\mathrm{Ni}$ concentrations ( 6.0 and $6.8 \%$ ) than the metal of group 1 ( 5.2 and $5.5 \%$ ). Metal compositions obtained by the regression technique agree reasonably with compositions obtained by direct analysis (e.g., 61015, JAMES et al., 1984; 65015, TAYLOR et al., 1976; also KOROTEV, 1990).

Although Ir/Au ratios among different samples of a given group (and even different subsamples of a given sample) are variable, $\mathrm{Ir} / \mathrm{Ni}$ and $\mathrm{Ir} / \mathrm{Au}$ ratios in group $1 \mathrm{M}$ are significantly lower, on average, than the ratios of the other three groups (Fig. 2 la,b; Table 5c). Thus, subdivision of group 1 into groups $1 \mathrm{M}$ and $1 \mathrm{~F}$ based on lithophile elements ("Subdivision of group 1" section) is supported both by differences in siderophile-element ratios and average $\mathrm{Ni}$ concentration (Fig. 


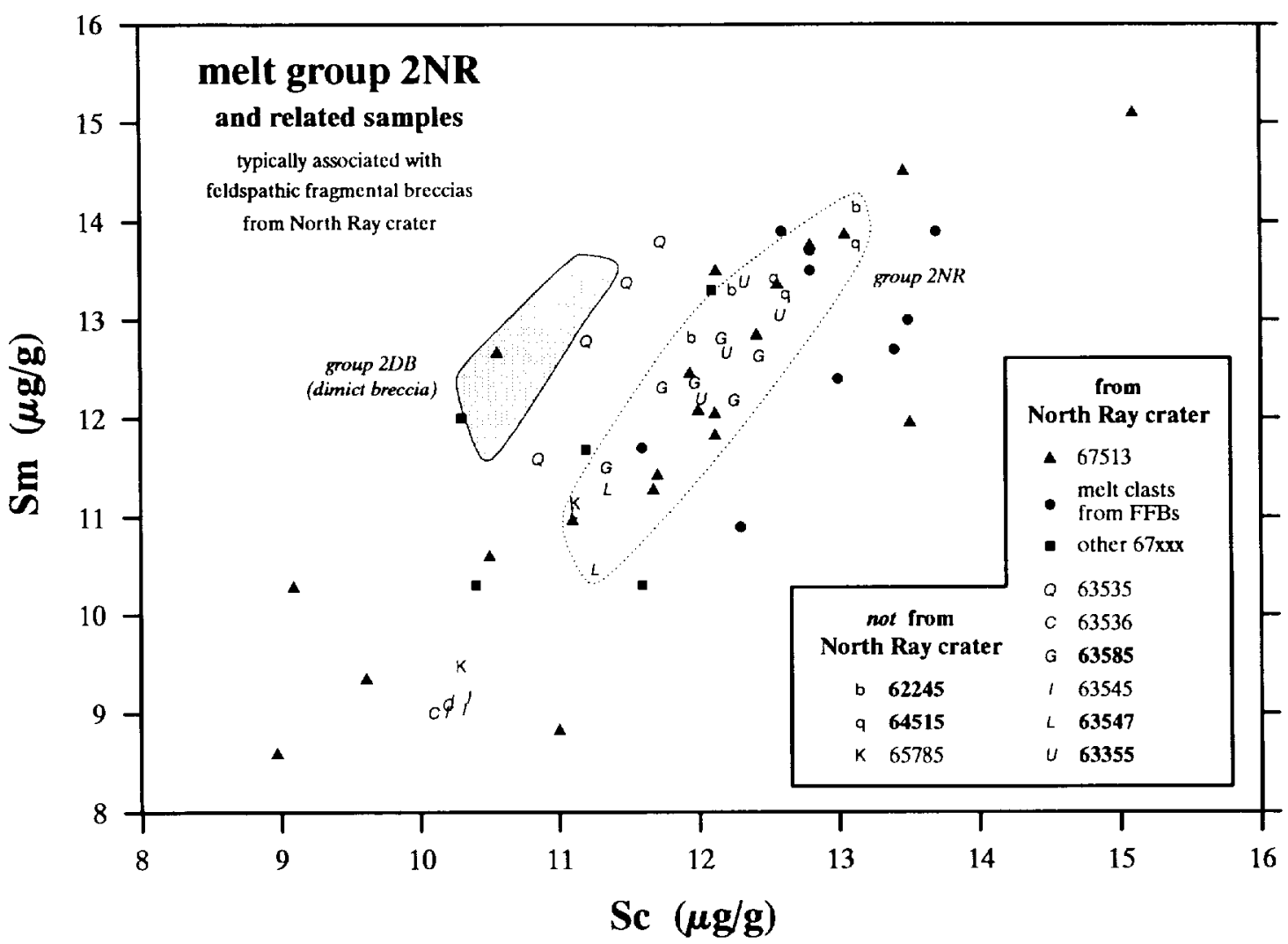

FIG. 17. Melt group-2NR is distinct from the melt lithology associated with the dimict breccias (group 2DB) in being richer in Sc and, to a lesser extent. Cr. Many samples of this melt lithology are found as small clasts in feldspathic fragmental breccias (FFBs) at North Ray crater and as small particles in North Ray crater soils, which are primarily disaggregated FFBs. The latter are represented by small $(\sim 20 \mathrm{mg})$ particles from station-11 soil 67513 . For the large melt-breccia samples (letter symbols), all subsamples are plotted. All but three of the samples that have the group$2 N R$ composition are from the North Ray crater area and only one North Ray crater sample $(63535[Q])$ is ambiguous in the sense that it plots near the field for group-2DB. To obtain the average group-2NR composition of Tables 3 and 4 , the five bold-faced samples in the legend plus the average composition of the most typical 67513 particles were used: these samples are enclosed by the dotted line. Except for $63535[Q]$, the remaining rock samples, $63536\left[C^{\prime}\right], 63545[I]$. and $65785[K]$, appear to be more feldspathic variants of the group-2NR melt, although each shows some compositional anomalies compared to the bold-faced samples (Table A1). Additional data are from LINDSTROM and SAIPAS (1981. 1983), MARVIN and LINDSTROM ( 1983), MARVIN et al. (1987). MC KINL.tY et al. (1984). WÄNKe et al. (1976), and PALME et al. (1978).

$21 \mathrm{c})$. Groups $2 \mathrm{DB}$ and $2 \mathrm{NR}$ have $\mathrm{Ir} / \mathrm{Au}$ ratios indistinguishable from group $1 \mathrm{~F}$.

Siderophile-element ratios correlate weakly with lithophileelement abundance among the six group-2Mo samples (Fig. $18 \mathrm{~d})$. If this correlation is significant and if the samples of group $2 \mathrm{Mo}$ are related in that they contain different amounts of some common olivine-bearing component (Group 2Mo section), the correlation suggests that the olivine-bearing component or assemblage of subcomponents has a high Ir/ Au ratio (more nearly chondritic) as well as moderately high absolute concentrations of siderophile elements (Fig. 19). This suggests that the olivine-bearing component of group $2 \mathrm{Mo}$ is not plutonic lunar troctolite but is of extralunar origin.

\section{Glassy Melts of Group 2}

In contrast to the crystalline mafic melt breccias, samples of glassy melt spheres and coatings on other rocks typically have chondritic Ir/Au ratios because much of the glass was produced by recent impacts of chrondrites, such as that which formed South Ray crater (MORRIS et al., 1986). Most samples of glassy melt (group $2 \mathrm{Fg}$ ) have Ir/Au ratios between these two extremes (Fig. 22) as well as high absolute concentrations of siderophile elements ( Fig. 19), because they are secondary melts of a target dominated by mafic group- 2 melt and anorthosite and they contain a substantial chondritic component ("Glassy melts" section and MORRIS et al., 1986). The scatter of Fig. 19 ( $\mathrm{Sm}$ vs. $\mathrm{Ni}$ ) represents a four-component system: mafic crystalline melt (high $\mathrm{Sm}$, low $\mathrm{Ni}$ ). Fe-Ni metal with a nonchondritic SE signature (low $\mathrm{Sm}$, high $\mathrm{Ni}$, low Ir/Au), anorthosite and perhaps mafic plutonic rocks (low to intermediate $\mathrm{Sm}$, low $\mathrm{Ni}$ ), and chondritic meteorite (low $\mathrm{Sm}$, high $\mathrm{Ni}$, high $\mathrm{Ir} / \mathrm{Au}$ ). Because the $\mathrm{Fe}-\mathrm{Ni}$ phase is physically associated with the mafic, Sm-rich melt breccias, Ni concentrations are usually greatest (Fig. 19) and Ir/ $\mathrm{Au}$ ratios are lowest (Fig. 22) in the most Sm-rich samples. However, in- 

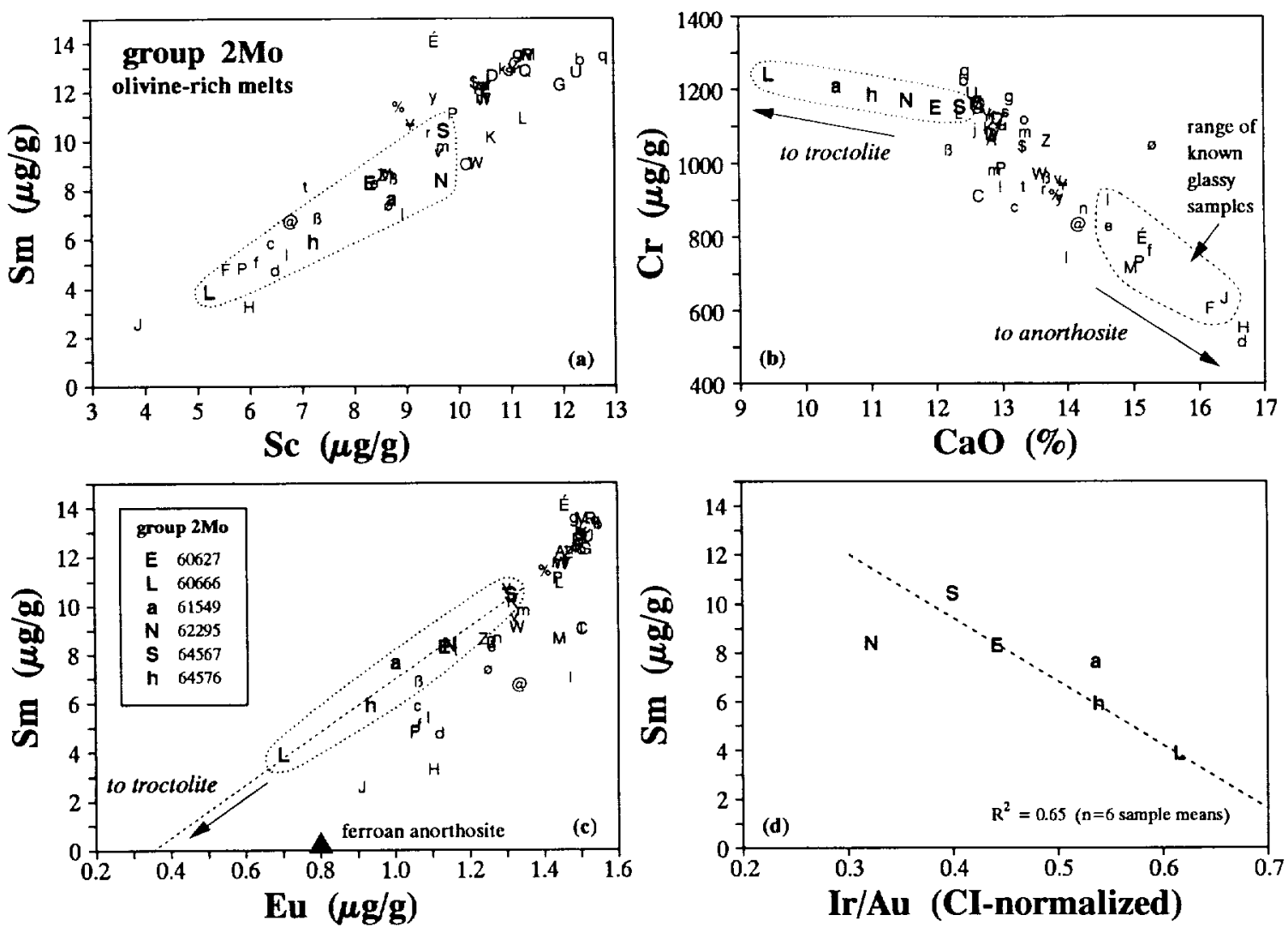

FIG. 18. (a-c) Comparison of sample means for the six samples of group 2Mo (bold faced letters in dotted fields) with those of other group-2 samples. Each of the group-2Mo samples is unusual in being rich in olivine and having a high $\mathrm{Cr} / \mathrm{Sc}$ ratio (Fig. 10). Samples of group 2Mo have concentrations of Se and Sm typical of other group-2 samples (a), but they are distinct on plots involving elements that distinguish plagioclase from olivine, like Ca (b) and Eu (c). The six samples may not be related to each other. If they are related, then the linear trends suggest 2-component mixing between a Sm- and Ca-rich component and a Sm- and Ca-poor component. The Sm-poor component is not pure olivine. Variation in normative olivine abundance would produce linear trends that extrapolate toward the origin of (c) because olivine has effectively zero concentrations of $\mathrm{Sm}$ and Eu. Instead, the trends are consistent (to a first approximation) with differences among the samples in the ratio of a mafic, Sm-rich norite (melt of group-2 composition?) and a Sm-poor troctolite component (i.e., $<1 \mu \mathrm{g} / \mathrm{g} \mathrm{Sm}$, but non-zero $\mathrm{CaO}$. Sc, and Eu concentrations). (d) Among group-2Mo samples, Ir/Au ratios are variable and tend to decrease with increasing troctolite component; there is no correlation between $\mathrm{Sm}$ and $\mathrm{Ni}$ among the samples, however $\left(R^{2}=0.05\right.$; Fig. 19).

dividual subsamples of mafic melt breccia vary widely in metal content, causing the large range in $\mathrm{Ni}$ concentration at high $\mathrm{Sm}$ concentration. The glassy melt carries the chondritic component, which also varies widely in abundance among different subsamples of glass. Samarium abundances are determined primarily by the relative abundance of mafic melt-breccia component, while SE abundances and ratios are determined by the absolute and relative abundances of the two meteoritic components.

\section{Groups 3 and 4}

Concentrations of siderophile elements are much lower in groups 3 and 4 than in groups 1 and 2 (Fig. 19; Table 3). Group 4 has the lowest concentrations of any group; concentrations of Ir and $\mathrm{Au}$ are at or below detection limits of INAA. Three group- 4 subsamples are anomalously enriched in $\mathrm{Ni}$ (Fig. 19), and these same subsamples have high $\mathrm{Cr} /$ Sc ratios (Fig. 10). This enrichment pattern suggests con- tamination with a component, possibly glass, that contains siderophile elements and $\mathrm{Cr}$ of meteoritic origin.

In group 3, the Ir/Au ratio of 68415 and $68416(0.6 \pm 0.2$, Cl-normalized; Table 6 ) is significantly greater than the ratio typical of groups 1 and $2(<0.35$; Fig. 21$)$. This observation contrasts with previous conclusions (based on much smaller datasets) that the Ir/Au ratio of 68415 is the same as that of groups 1 and 2, i.e., that group-3 melt rocks have the signature of "ancient meteorite group 1H" (HERTOGEN et al., 1977; MORGAN and JAMES, 1981). The other group-3 melt rocks have Ir/Au ratios that are even greater and are chondritic within uncertainty (Table 6).

\section{DISCUSSION}

\section{Relation to Regional Geology-Eastern and Western Trends}

A conspicuous feature of the $\mathrm{Sc}-\mathrm{Sm}$ plots is that nearly all Apollo 16 melt rocks fall on one of either of two trends of 


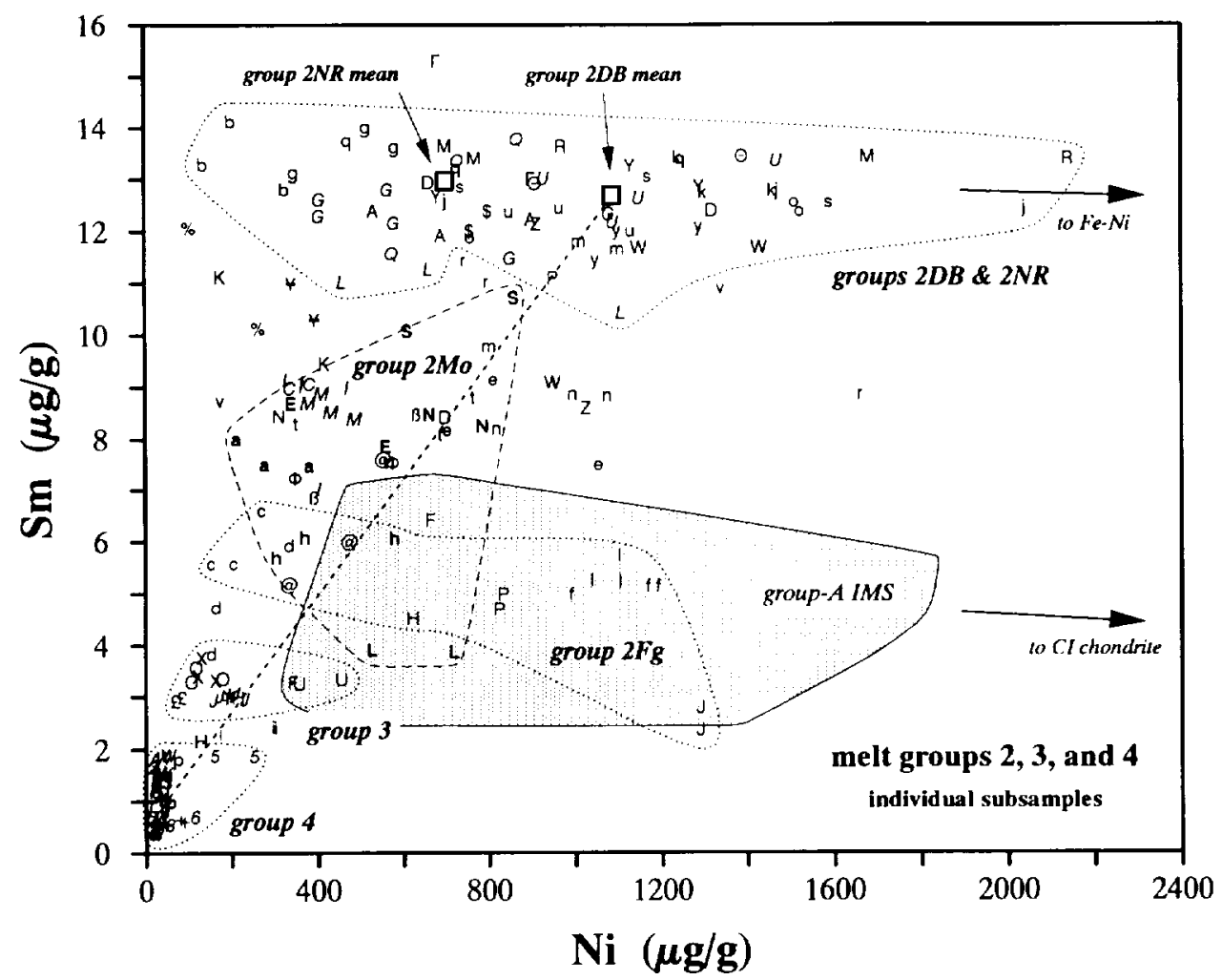

FIG. 19. Ni abundances in melt groups 2. 3. and 4. Concentrations of $\mathrm{Ni}$ (and other siderophile elements) are high and variable among subsamples of groups $2 \mathrm{DB}$ and $2 \mathrm{NR}$ (i.e., samples with $11-15 \mu \mathrm{g} / \mathrm{g} \mathrm{Sm}$ ) as a result varying abundances of Fe-Ni metal grains. Most other group-2 melt breccias (i.e., samples with $4-12 \mu \mathrm{g} / \mathrm{g} \mathrm{Sm}$ ) have lower concentrations of $\mathrm{Ni}$. Exceptions are the glassy melts typically found as coatings on rocks from the central and southern stations, represented by the field labeled "group-A IMS" ( impact-melt splashes; MORRIS et al., 1986). The few samples of this type analyzed in this work are represented by the field labeled "group $2 \mathrm{Fg}$ " (feldspathic, glassy). The glassy melts are primarily impact mixtures of mafic, crystalline rocks of group 2 and anorthosite (MORRIS et al., 1986). This mixing relationship is represented by the diagonal (dashed) mixing line between the group-2DB mean composition and anorthosite (effectively, the origin). Group-2Fg samples are rich in $\mathrm{Ni}$ (with respect to the mixing line) because they contain a significant amount of a third component, carbonaceous chondrite (e.g.. $\sim 7 \%$ for $61548[\mathrm{~J}]$ : volatilefree $\mathrm{Cl}$ equivalent). All of the group- $2 \mathrm{Fg}$ samples have higher $\mathrm{Cr} / \mathrm{Sc}$ ratios than do samples of groups $2 \mathrm{DB}$ and $2 \mathrm{NR}$ (Fig. 10b). Addition of anorthosite cannot alter the $\mathrm{Cr} / \mathrm{Sc}$ ratio, but the excess $\mathrm{Cr}$ in most of the Ni-rich, group- $2 \mathrm{Fg}$ samples can be quantitatively explained by the large chondrite component (MORRIS et al., 1986). Note that the six samples of group $2 \mathrm{Mo}$ (mafic, olivine-rich: in bold-faced letters encircled by long-dash ficld). which also have high $\mathrm{Cr} / \mathrm{Sc}$ ratios ( Fig. 10), are not as rich in $\mathrm{Ni}$ as are some of the glassy samples. but have Ni concentrations similar (on average) to group 2NR. Compared to group 2, siderophile-element concentrations are much lower in groups 3 and 4 .

increasing $\mathrm{Sm}$ concentration, with increasing Sc concentration (compare Fig. 4 with Fig. 23a). Samples constituting groups 3 and 4 , along with some ungrouped samples, lie on a trend of low $\mathrm{Sm} / \mathrm{Sc}$ slope, while samples of groups 1 and 2 lie along a trend (but not linear) of high $\mathrm{Sm} / \mathrm{Sc}$ slope. This compositional dichotomy corresponds to the distinction between the young. KREEP-bearing Western rocks and old, KREEP-free Eastern rocks of STOFFLER et al. (1985). Thus, $I$ refer to the two trends as the Western trend (groups 1 and 2 ) and the Eastern trend (groups 3 and 4). Most samples of groups 3 and 4 are ejecta from North Ray crater, while the majority of the samples of groups 1 and 2 are from the surface of the Cayley plains (Fig. 2). In addition to lower $\mathrm{Sm} / \mathrm{Sc}$ ratios, Eastern-trend rocks are characterized by lower and more varied $\mathrm{Sm} / \mathrm{Yb}$ ratios (Fig. 23b), much lower concentrations of siderophile elements (Fig. $23 \mathrm{c}$ ), and lower $\mathbf{M g}^{\prime}$ than Western-trend melt rocks (Fig. 11). The constancy of the $\mathrm{Sm} / \mathrm{Yb}$ ratio in rocks of the Western trend results from the KREEP component, which is similar, but not identical. to the KREEP components of Apollos 14 and 17 (Figs. 9. 23b). Even the most KREEP-poor Western-trend samples (high $\mathrm{CaO}$; Fig. 23b) have greater $\mathrm{Sm} / \mathrm{Yb}$ ratios than any of the Eastern-trend samples, including those with the greatest concentrations of $\mathrm{Sm}$. [Note that the east-west distinction made here is with respect to the Apollo 16 site and is different from that of WARREN and WASSON (1980), who noted a difference in magnitude of Eu anomalies in pristine rocks between western sites (Apollos 12 and 14) and eastern sites (other Apollo sites).]

The fact that trends occur at all on Sc-Sm plots. i.e., that $\mathrm{Sm}$ and $\mathrm{Sc}$ concentrations roughly correlate among different rocks, reflects that variation in abundance of a chemical or normative component of anorthosite is the principle cause of compositional variation and that for samples of either trend 

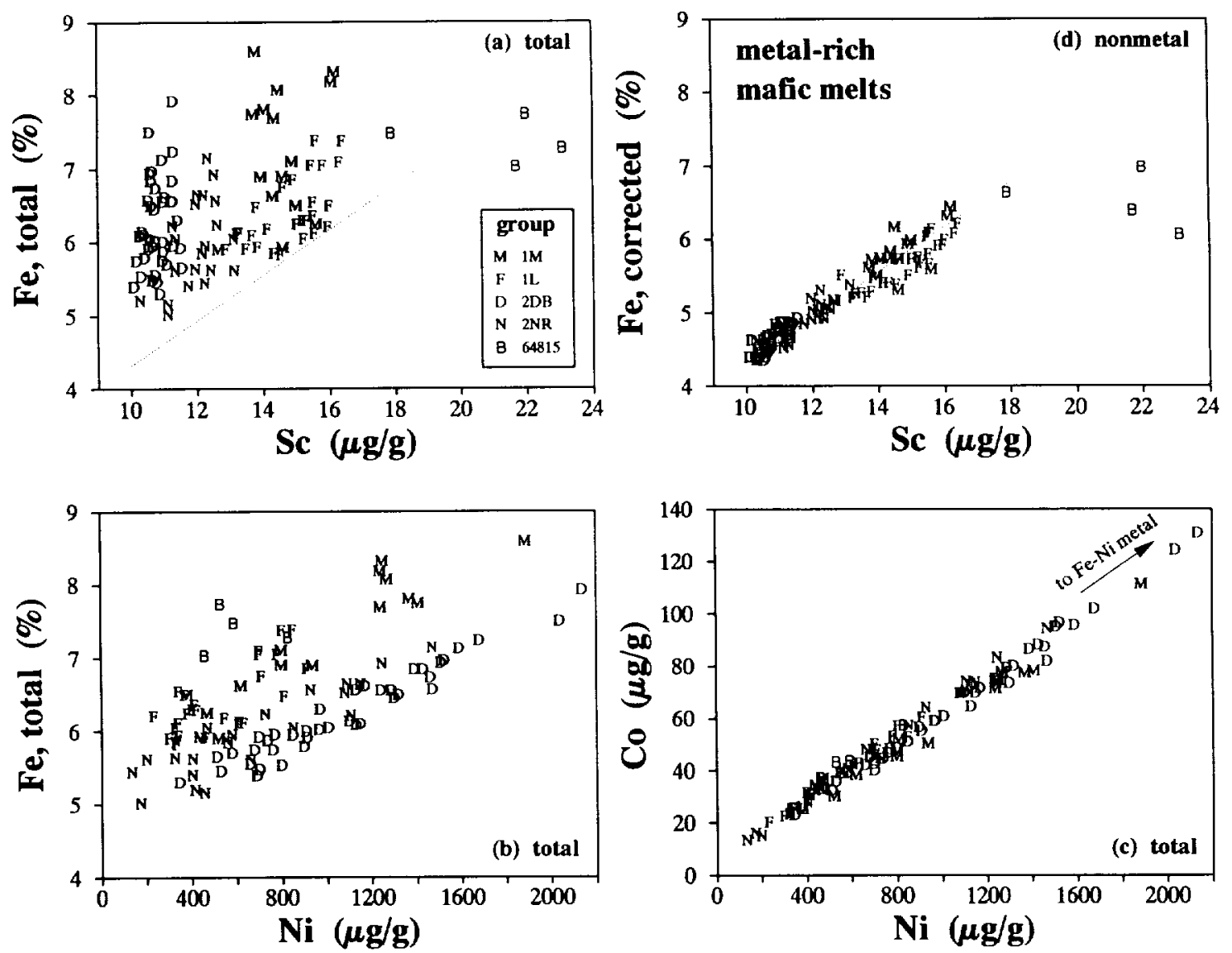

FIG. 20. (a) In group-1 and group-2 melt rocks, Sc is not well correlated with total Fe because $\mathrm{Sc}$ resides solely in the mafic silicates and oxides whereas $\mathrm{Fe}$ also resides in $\mathrm{Fe}-\mathrm{Ni}$ metal, which is highly variable in abundance among the small subsamples. (b) As a result, total $\mathrm{Fe}$ correlates better with $\mathrm{Ni}$ than with $\mathrm{Sc}$, particularly within a given melt group (e.g., 2DB). (c) A good correlation exists between $\mathrm{Ni}$ and $\mathrm{Co}$ because both of these elements are carried principally by the metal phase. The composition of the metal in each melt group can be calculated from the correlations of (b) and (c) (Table 5b). (d) Using the calculated metal compositions, observed Ni concentrations, and the assumption that $50 \mu \mathrm{g} / \mathrm{g}$ of $\mathrm{Ni}$ resides in the mafic silicates (Table 5a), "corrected" Fe concentrations can be estimated that approximate the $\mathrm{Fe}^{2+}$ carried by mafic silicates and ilmenite. "Corrected" $\mathrm{Fe}$ correlates well with $\mathrm{Sc}$. The $\mathrm{Fe}^{2+} / \mathrm{Sc}$ ratio is similar for the four melt groups; however, anomalous sample 64815 [B] is enriched in $\mathrm{Sc}$ with respect to $\mathrm{Fe}^{2+}$. The dotted line is for reference in comparing (a) and (d).

the ratio of ITE-bearing phases to mafic phases remains relatively constant (but that it is substantially different between the two trends). The compositional disparities between the two trends indicate that the rocks of the Western trend are more closely related to each other than they are to the rocks of the Eastern trend and that there is a fundamental difference in the igneous precursors of the target rocks of the two trends. Two distinct reservoirs of mafic material are implicated. The melt rocks and breccias of the Eastern trend probably derive from impacts into feldspathic, KREEP-poor material typical of the upper crust, such as that which presently in the Descartes formation east of the Apollo 16 site (METzGER et al., 1981; RYDER and SEYMOUR, 1982; MCKINLEY et al., 1984), while the Western-trend breccias share some affinity with mafic, KREEP-bearing melt breccias such as those collected at Apollos 14, 15, and 17 west and north of the Apollo 16 site.
The Significance of Fe-Ni Metal and Siderophile Elements in the Mafic Melt Breccias

The most unusual aspect of the mafic melt breccias of Apollo 16 compared to melt breccias of otherwise similar composition from other sites is their uniformly high abundances of siderophile elements (KOROTEV, 1987a). In Apollo 16 melt groups $2 \mathrm{DB}$ and $1 \mathrm{M}$, average concentrations of $\mathrm{Ir}$ and Au exceed $20 \mathrm{ng} / \mathrm{g}$ ( Table 3 ) and Ni concentrations are about five times those of mafic melt breccias from Apollo 15 and 17 (Fig. 21 ); even in group IF, with the lowest siderophile-element concentrations, the $\mathrm{Ni}$ concentration is about 2.5 times greater. Average abundances of $\mathrm{Fe}-\mathrm{Ni}$ metal in the four groups range from $0.9 \%$ to $1.9 \%$ (Table $5 \mathrm{~b}$ ). The metal is compositionally distinctive in that $\mathrm{Ir} / \mathrm{Ni}$ and $\mathrm{Ir} / \mathrm{Au}$ ratios are low compared to $\mathrm{CI}$ ratios (Table $5 \mathrm{c}$ ), and $\mathrm{Ni} / \mathrm{Co}$ ratios $(\sim 16$; Table $5 b)$ are lower than ratios in $\mathrm{CI}$ chondrites $(22)$ 

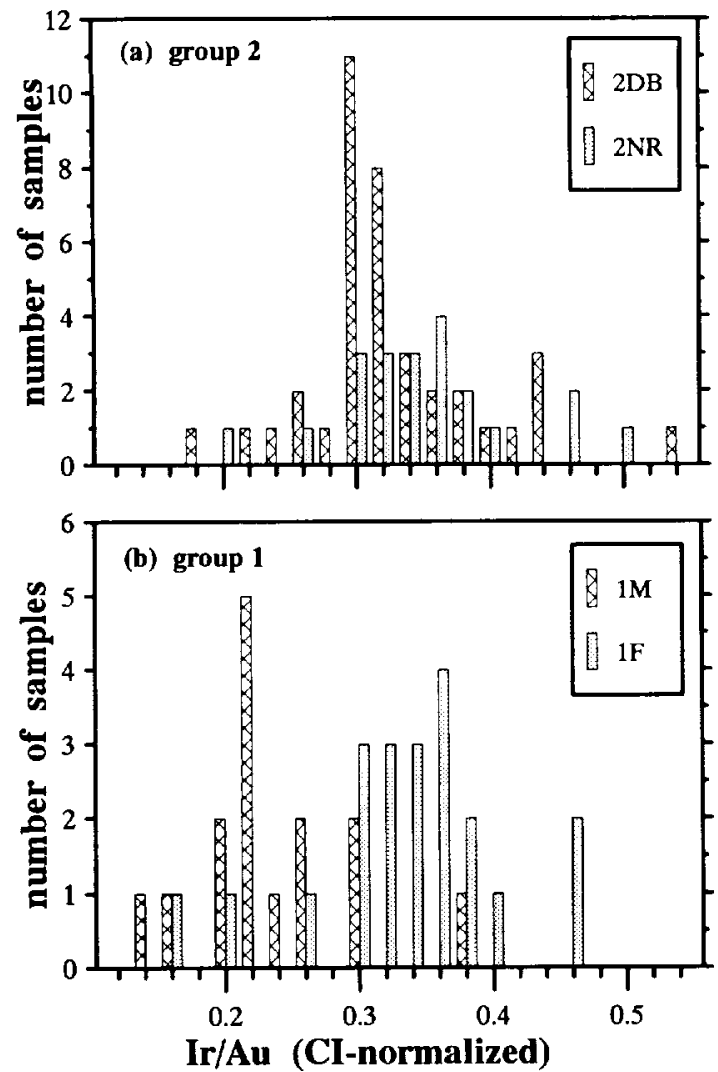

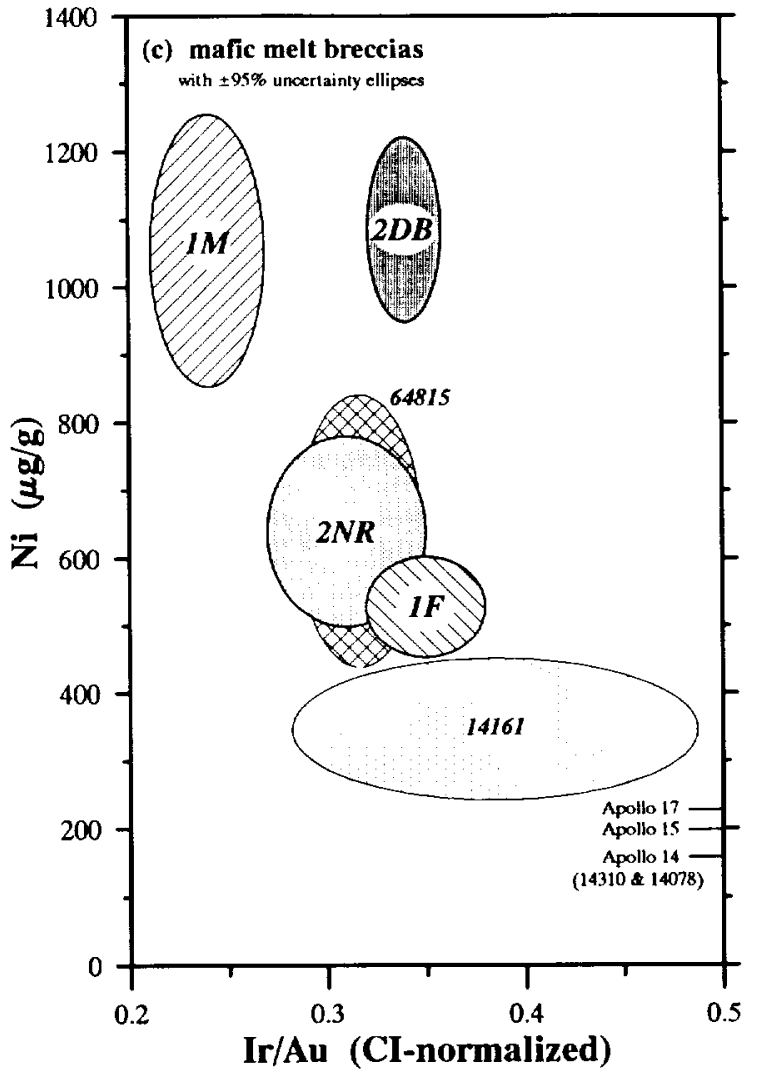

FIG. 21. (a,b) Histograms of chondrite-normalized Ir/Au ratios in individual subsamples of mafic melt breccias from A pollo 16, keyed by group. Although intragroup variation in the Ir/Au ratio is large. intrasample variation can be nearly as large. The worst-case example is group-2DB sample 65365[0]; Ir/Au ratios for the three subsamples from this rock are $0.24,0.43$, and $0.53( \pm 0.03)$, which nearly covers the range of observed values. There is no significant difference in $\mathrm{Ir} / \mathrm{Au}$ ratio between groups $2 \mathrm{DB}$ and group $2 \mathrm{NR}$. However samples from group $1 \mathrm{M}$ tend to have lower Ir/Au ratios than those of group IF or group 2. Melt group $1 \mathrm{M}$ of this work corresponds to "ancient meteorite group ILL" of HER TOGEN et al. (1977), postulated on the basis of a single rock, 60315 (a group-IM sample. Fig. 6), and three soil samples. The low Ir/Au ratio of 60315 was also noted by WäNKF et al. (1978). Melt groups IF, 2DB, and 2NR of this work correspond to "ancient meteorite group $1 \mathrm{H}^{\prime}$ of E. Anders and coworkers (HERTOGEN et al., 1977). (c) Comparison of average siderophile-element concentrations, represented by Ni, among mafic-melt-breccia groups from Apollo 16 and to mafic melt breccias from other sites, and average of Ir/Au ratios among Apollo 16 and to mafic melt groups. Group IF, which is similar to group IM in lithophile element composition (Figs. 6, 8), differs from group $1 \mathrm{M}$ in absolute $\mathrm{Ni}$ concentration as well as $\mathrm{Ir} / \mathrm{Au}$ ratio. Similarly, groups $2 \mathrm{DB}$ and $2 \mathrm{NR}$ have similar lithophile element concentrations and Ir/Au ratios. but differ by nearly a factor of two in mean $\mathrm{Ni}$ concentration. Most nearly equivalent to the Apollo 16 mafic melt breccias are the typical ITE-rich melt breccias from Apollo 14 (represented here by $\sim 20$ small particles from soil 14161: JoLLIFF et al.. 1991a). The ellipses for the Apollo 16 samples and 14161 represent the $95 \%$ confidence interval for the population mean based on many subsamples (Table $5 \mathrm{c}$ ). For $\mathrm{Ni}$, the ellipse is centered on the simple mean of all subsamples assigned to the group (thus values differ slightly from those of Table 4 , in which sample means are averaged). For Ir/Au, the ellipse is centered on the mean only of those subsamples for which the estimated analytical uncertainty in the ratio is $<20 \%$ ( $1 \sigma$; only those subsamples are plotted in the histograms as well). The horizontal lines represent average $\mathrm{Ni}$ concentrations of mafic melt rocks from other sites; no attempt is made here to represent the spread in $\mathrm{ir} / \mathrm{Au}$ ratios, although samples from other sites tend to have higher Ir/Au ratios than the 0.24-0.35, typical of the Apollo 16 samples plotted here (HERTOGEN et al., 1977). Sources of data: this work, WASSON et al. (1977), WÄNKE et al. (1976), and EBIHARA et al. (1992) for 64815; this work and unpublished data of this lab for 76135, 77035, and melt breccia particles from 76503; references of Fig. 25 for Apollo 15; this work for clast-poor melt rocks 14078 and 14310.

and ordinary chondrites (19-21; WASSON and KALLEMEYN, 1988). Although some melt breccias from Apollos 14 (14161 particles; Fig. 21$)$ and 15 (15303, 15445, 15455; HERTOGEN et al., 1977; LAUL et al., 1988) have Ir/Au ratios equivalently low, metal abundances in melt breccias from other sites are not nearly as high as those of Apollo 16 Western-trend melt breccias.

\section{Preservation of ratios}

The significance of the $\mathrm{SE}$ abundances and ratios in Apollo 16 samples has been the source of much discussion and some confusion (e.g., ANDERS, 1978: DELANO and RINGWOOD, 1978; WÄNKE et al., 1978; DRFIBUS et al.. 1981; JAMES, 1981; KOROTEV, 1987a, RINGWOOD et al., 1987; WARREN et al., 


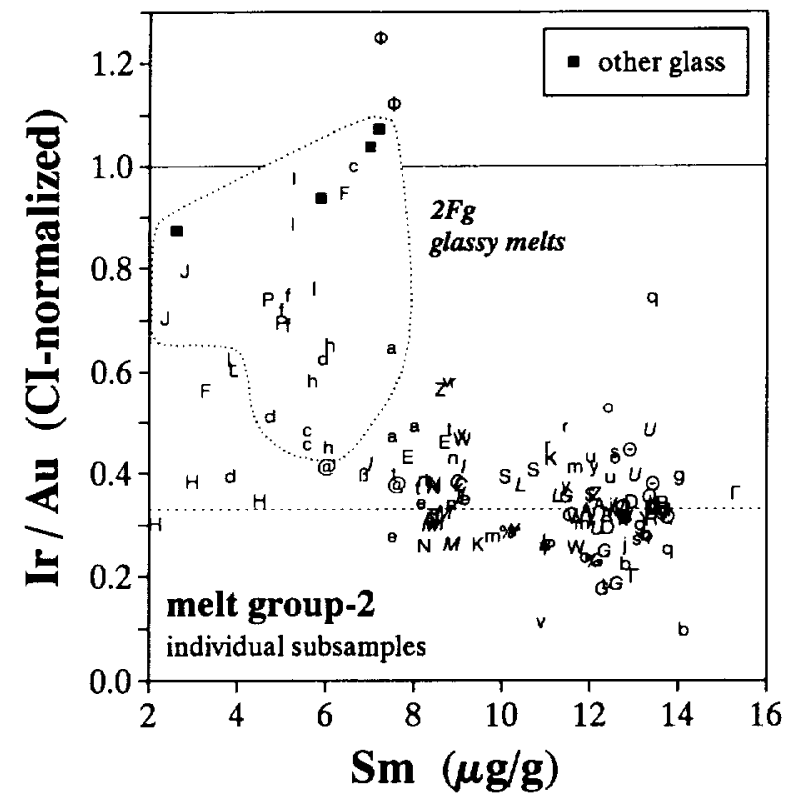

FIG. 22. Most crystalline melt breccias of group 2 have low $\mathrm{I} / \mathrm{Au}$ ratios (dashed line) characteristic of "ancient meteorite group" $1 \mathrm{H}$ of HERTOGEN et al. (1977). In contrast. Ir/Au ratios in the more recently formed glassy melts of group $2 \mathrm{Fg}$ are more nearly chondritic ( solid line). It is likely that most of the $\mathrm{Sm}$ in the glassy melts derives from a component of crystalline melt (e.g., MORRIS et al., 1986). As a consequence, some glassy melts have intermediate Ir/Au ratios because they contain siderophile elements derived subequally from both components. For reference, four samples of pure glass melt ("other glass") are plotted (glass spheres 60095 and 65016 and glass coating on 61015 and 64455; JAMES et al., 1984; MORRIS et al., 1986; and GANAPATHY et al., 1974).

1989; KOROTEV, 1990; RINGWOOD and WÄNKE, 1990; WANKE et al., 1990). A point of contention is whether SE ratios observed in a lunar melt breccia are the same as those of the impactor that formed the melt and, thus, provide a "signature" of the impactor. At one extreme are those who use siderophile-element ratios (e.g., Ir/Au) of lunar breccias to argue that some breccias were produced in different impacts than others (e.g., HERTOGEN et al., 1977; JAMES, 1986). At the other extreme are those who note that $\mathrm{Ir} / \mathrm{Au}$ and $\mathrm{Ni} / \mathrm{Co}$ ratios cannot be used for this purpose because $\mathrm{Au}$ is more volatile than Ir, leading to mobilization and redistribution of Au on the lunar surface, and that partly lithophile elements like $\mathrm{Co}$ and $\mathrm{Ni}$ can be extracted from lunar silicates, thus changing the composition of metal (DREIBUS et al., 1981; WÄNKE et al., 1978, 1990).

Unless otherwise noted in the discussion that follows, $I$ make no specific assumption that siderophile-element ratios observed in lunar melt breccias are the same as those of the impactor(s) that form the breccias or, for example, that compositional group $1 \mathrm{M}$ represents a different impact than group IF because of the difference in $\mathrm{Ir} / \mathrm{Au}$ ratio. The purpose of this paper is to demonstrate and review the observations imposed by the sample compositions, including siderophile elements, and consider the ramifications. Some process or sequence of processes has led to populations of mafic melt breccia with four different and characteristic lithophile-ele- ment compositions, and those processes have also resulted in slightly different SE compositions among the groups. The processes may have involved one impact or they may have involved four or more distinct impacts; SE ratios may or may not have been preserved. Regardless, the compositional differences among the groups provide information about those processes.

\section{Postimpact processes}

With this caveat aside, however, I reiterate arguments made previously that if the metal in the Apollo 16 mafic melt breccias is primarily extralunar, then there is little need to invoke substantial postimpact modification of the ratios of $\mathrm{Ir}$ and $\mathrm{Au}$ to $\mathrm{Ni}$ and that any attempt to do so quantitatively requires assumptions that are equally $a d$ hoc as the suggestion that the breccias were formed by the impact of one or more metalrich impactors with non-chondritic siderophile-element ratios (KOROTEv, 1987a; RingwOOD et al., 1987). I review some relevant observations here.

Arguments that the $\mathrm{Ni} / \mathrm{Co}$ ratio of the metal may have been influenced by postimpact processes are convincing (WÄNKE et al., 1990). Such processes may account, for example, for the difference in average $\mathrm{Ni} / \mathrm{Co}$ ratio (Table $5 \mathrm{~b}$ ) between the metal of groups $1 \mathrm{~F}$ and $1 \mathrm{M}$, especially when it is considered that group $1 \mathrm{M}$ has a higher $\mathrm{Mg} / \mathrm{Fe}$ ratio and higher normative olivine abundance. However, even if the $\mathrm{Ni} / \mathrm{Co}$ ratio of an impactor is not preserved, the difference in $\mathrm{Ni} / \mathrm{Co}$ ratio in the metal may reflect different conditions in two different units of melt, which may or may not have been produced in the same impact. Thus, differences in SE ratios provide additional evidence that the different groups represent different batches of melt, regardless of the cause of the differences in ratios.

Although it is easy to discount Ir/Au ratios as irrelevant because of some poorly understood postimpact process, the ratios are difficult to rationalize quantitatively (ANDERS, 1978). The low Ir/Au ratio (with respect to Cl chondrites) may be regarded as a combined effect of low $\mathrm{Ir} / \mathrm{Ni}$ and high $\mathrm{Au} / \mathrm{Ni}$ ratios (Table $5 \mathrm{c}$ ). For example, the average CI-normalized $\mathrm{Au} / \mathrm{Ni}$ ratios of the metal range from 1.75 to 1.86 in the four mafic melt groups (Table $5 \mathrm{c}$ ). This compares with a range of 0.7 ( $\mathrm{EH}$ ) to $1.2(\mathrm{CV})$ for the mean of various chondrite groups (WASSON and KALLEMEYN, 1988). Thus, even if the meteorite or meteorites forming these melt breccias were chondritic, Au has been only moderately fractionated from $\mathrm{Ni}$. If the impactors were some type of chondrite and some fractionation has occurred, then the high $\mathrm{Au} / \mathrm{Ni}$ ratios of the metal indicate that the metal has acquired Au from lunar sources preferentially to $\mathrm{Ni}$. Concentrations of $\mathrm{Au}$ and $\mathrm{Ni}$ in subsamples of mafic melt breccias are highly correlated ( Table 5a); within analytical uncertainty the $\mathrm{Au} / \mathrm{Ni}$ ratio of all subsamples is nearly constant, regardless of group. Thus, if Au concentrations in the metal of Apollo 16 mafic melt breccias are substantially different from that of metal in the impactor or impactors that formed the melts because of preferential assimilation of $\mathrm{Au}$ from the Moon, then some process has acted to buffer the $\mathrm{Au} / \mathrm{Ni}$ ratio of the metal independent of the intergroup differences in lithophile element compo- 
Table 6. Some siderophile elements abundances and ratios in group-3 melt rocks. The differences in $\mathrm{Ir} / \mathrm{Au}$ and $\mathrm{Ir} / \mathrm{Ni}$ ratios between the $68415 / 68416$ and $63537 / 63549$ means are significant at the $99 \%$ confidence level

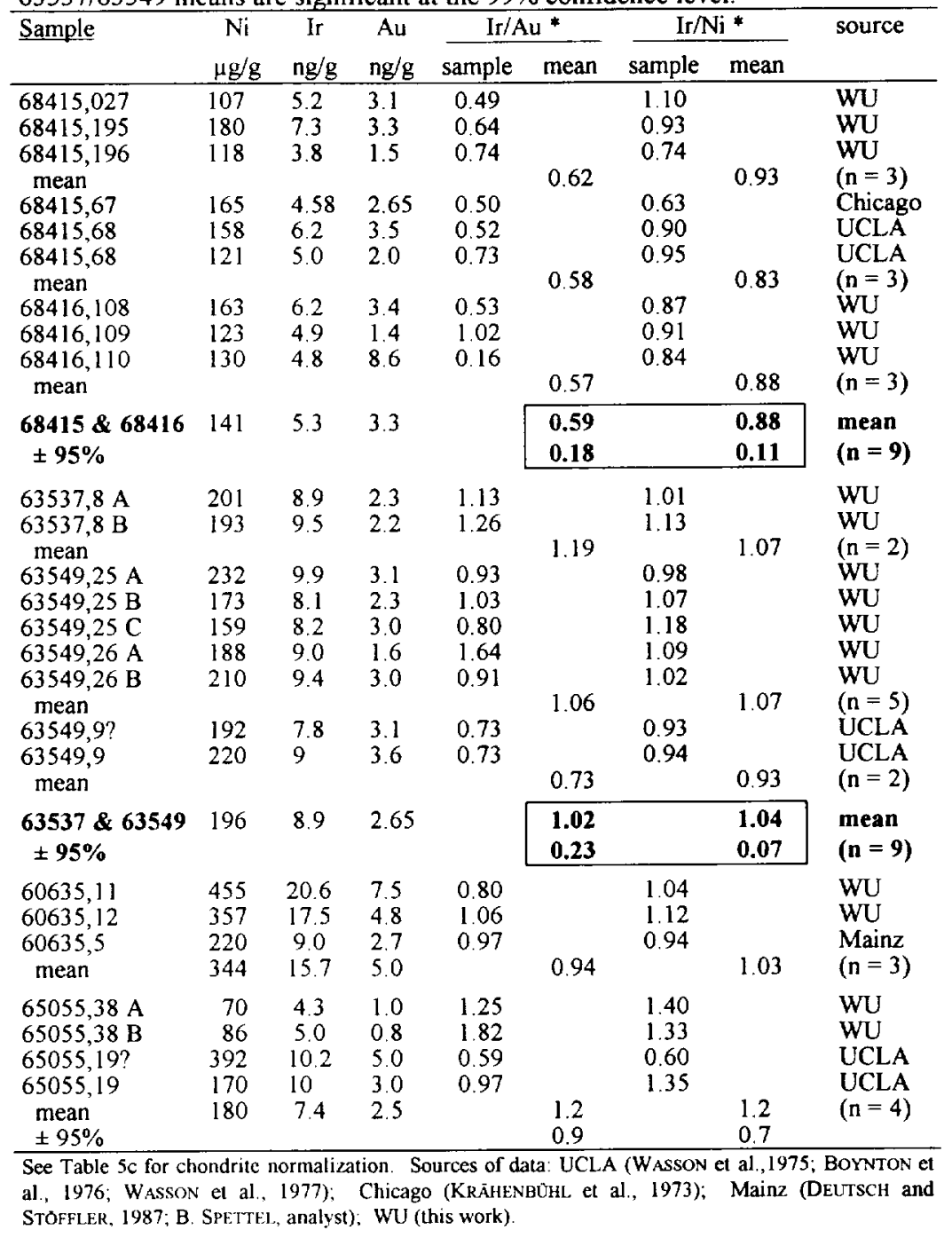

sition. This observation is difficult to reconcile with any opensystem volatilization process. A closed-system extraction process is also unlikely. If at time of impact the melt contained $1 \%$ metal having $6 \pm 1 \% \mathrm{Ni}$ (Table $5 \mathrm{~b}$ ) and a $\mathrm{Cl}$ ratio of $\mathrm{Au}$ to $\mathrm{Ni}$ (i.e., $0.76 \mu \mathrm{g} / \mathrm{g} \mathrm{Au}$ ) and if the metal equilibrated with Au-bearing molten lunar silicates ( 100 times greater mass) to raise the $\mathrm{Au}$ concentration of the metal to the observed value (mean: $1.35 \mu \mathrm{g} / \mathrm{g}$; Table $5 \mathrm{c}$ ), then the lunar silicates must have contained about $6 \mathrm{ng} / \mathrm{g}$ Au. Although the extraction process would have been efficient because the metal is finely disseminated in the melt, a level as high as $6 \mathrm{ng} / \mathrm{g}$ of indigenous $\mathrm{Au}$ in the ancient lunar crust is difficult to reconcile with models of lunar crust formation. Even if the excess Au derives from previous impacts of extralunar material, a mechanism is still required for fractionation of $\mathrm{Au}$ from $\mathrm{Ni}$ in a way to yield a nearly constant ratio in the metal of the mafic melt breccias despite the differences in lithophile-element composition.
Similarly, Ir mass balance is difficult to explain by post impact processes. If it is assumed that all the Ir is extralunar and derives from an extralunar source with a chondritic Ir/ $\mathrm{Ni}$ ratio, then the only way the metal can presently have Ir/ $\mathrm{Ni}$ ratios approximately half the $\mathrm{Cl}$ ratio (Table $5 \mathrm{c}$ ) is through dilution by assimilation of a large amount of lunar Ni. However, the amount of lunar $\mathrm{Ni}$ assimilated by the metal cannot be large because, at $\sim 6 \%$, the $\mathrm{Ni}$ concentration of the metal is at the low end of the range observed for Fe-Ni metal in meteorites (KOROTEV, 1987a).

In summary, although it may be true that differences in Ir/Au or $\mathrm{Ni} / \mathrm{Co}$ ratios among the different compositional groups are not strong arguments that the different groups represent different impact melting events, the differences are real and reflect some process or processes. Thus, that $\mathrm{Au}$ is volatile and $C_{0}$ is partly lithophile are not reasons to exclude $\mathrm{Ir} / \mathrm{Au}$ and $\mathrm{Ni} / \mathrm{Co}$ ratios from consideration in this discussion; these ratios still require quantitative explanation. If the 

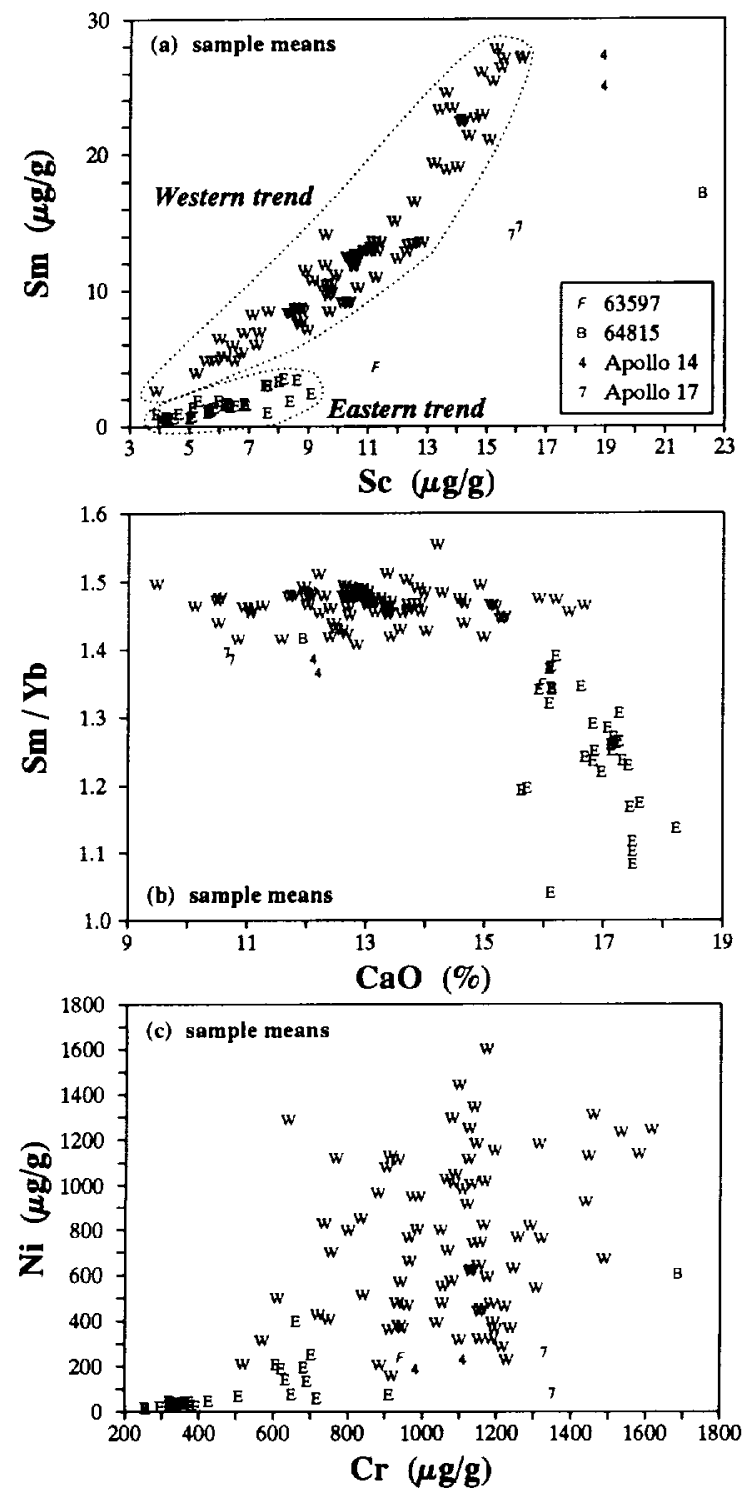

Fig. 23. (a) Nearly all Apollo 16 melt rocks fall on one of two trends of increasing Sm concentration with increasing Sc concentration. Western-trend samples (melt groups 1 and 2) extend to more mafic compositions than Eastern-trend melt rocks (groups 3 and 4) and have high concentrations of incompatible trace elements (i.e., large KREEP component). For Western-trend melt rocks, $\mathrm{Sm} / \mathrm{Sc}$ ratios exceed 0.54 ( $>0.66$ if heterogeneous sample $61156[\mathrm{H}]$ is excluded; Fig. 3) while for Eastern-trend melt rocks, $\mathrm{Sm} / \mathrm{Sc}$ ratios are less than 0.45 . (b,c) Western-trend melt rocks are also characterized by high $\mathrm{Sm} / \mathrm{Yb}$ ratios characteristic of KREEP, high concentrations of siderophile elements such as $\mathrm{Ni}$, and high $\mathrm{Mg} / \mathrm{Fe}$ ratios (Fig. 11). Sample means are plotted with heterogeneous samples 61569 [V] and $61156[\mathrm{H}]$ excluded.

composition of Fe-Ni metal in Apollo 16 mafic melt breccias has been strongly influenced by postimpact processes, then the metal compositions provide important constraints on the course of those processes, and the data and observations presented here should be useful to modeling efforts by advocates of such processes. However, the high metal abundances in the Apollo 16 breccias compared to those of terrestrial and other lunar melt breccias is reason alone to suspect that they were not formed by impacts of any kind of chondrite. The CI-normalized $\mathrm{Au} / \mathrm{Ni}$ ratio of $\sim 1.8$ in the metal (Table $5 \mathrm{c}$ ) is within the range of some nonchondritic meteorite groups, e.g., the mean ratio for group-IA irons is 1.8 (KRACHER et al., 1980; MALviN et al., 1984). Consequently, the high Au/ $\mathrm{Ni}$ (and $\mathrm{Au} / \mathrm{Ir}$ ) ratio of the metal is not so unusual as to require some postimpact redistribution of $\mathrm{Au}$

\section{Sonrce of the metal}

Any explanation for the mafic melt breccias of Apollo 16 must account for their unusually high metal abundances compared to melt breccias from other sites. If the metal was formed primarily by reduction on impact, why are noritic melt breccias from other Apollo sites not also rich in metal? On the other hand, if the metal was acquired primarily from the impactor(s), why did such a large fraction of the extralunar material remain in the melt at Apollo 16? (The $\mathrm{Ni}$ concentrations of melt rocks of groups 1 and 2 correspond to the equivalent of $5-10 \% \mathrm{CI}$ material, or $4-7 \%$ on a volatilefree basis.) Something special happened in the formation of the Apollo 16 melt breccias.

A simple explanation is that the metal derives from the impact of one or more metal-rich meteoroids (KOROTEV, 1987a ). It may be a general property of impacts by iron meteorites, as opposed to chondrites, that a larger fraction of the projectile remains in the melt (e.g., MITTLEFEHLDT et al., 1992). However, the high SE abundances of the mafic melt breccias may indicate that the impact (s) occurred with velocity (or incidence angle) sufficiently low to prevent significant vaporization of the projectile( $s$ ). In his revival of the cataclysm hypothesis to explain the large number of lunar impacts at 3.8-3.9 Ga, RYDER (1990) speculates that a possible cause of the cataclysm is the collision of bodies in geocentric orbit. Debris from such a collision would impact the Moon and Earth at velocities lower than those of objects presently approaching from the asteroid belt and, thus, leave a larger proportion of extralunar material in the melt phase than is typically seen in modern impacts. If the metal comes from the core of a planetesimal and if the Ir / Au ratio of the metal in the melt breccias is largely unchanged from that of the impactor (or impactors), then the low Ir/Au ratios imply that only a fragment (or a few related fragments) of a fractionated core were involved and that other pieces of the planetesimal (s) may have impacted elsewhere on the Moon or Earth (JOLLIFF et al., 1991b). Regardless of the specific nature of the impactor ( $\mathrm{s}$ ), the Apollo 16 melt breccias were formed early in solar system history under conditions that do not presently exist. Thus, there is no reason to expect that metal from such impacts should exactly match that of any known classes of meteorites (ANDERS et al., 1973; KOROTEV, 1987a).

\section{Compositional Homogeneity of Impact Melt}

Studies of terrestrial impact-melt breccias have led to the widely held view that ". . . melt rocks tend to be homogenized, and that the resulting glasses or crystalline rocks, depending upon cooling rate, represent remarkably homoge- 
nized mixtures of the target lithologies" (HORZ et al.. 1991) or that the "melt body chemically is extremely homogeneous" (REIMOLD, 1982). This outlook, in turn, has led to the notion that if two lunar melt rocks are similar in composition, then they are probably fragments of a single melt sheet, but if they differ significantly, then they must have formed during different impacts. The degree of homogenization that has occurred during impact into terrestrial targets consisting of different rocks types is indeed remarkable. However, terms like "remarkably" and "extremely" suggest a degree of homogenization somewhat greater than actually observed and this has led to subjective placement of the line between 'similar' and 'different' in divers studies. Often, most samples of melt breccia from a terrestrial melt body are similar in composition, but some are not. For some elements, different samples vary by a factor of two in concentration. Even concentration ratios are not always constant (e.g., Sm/Sc; Fig. 24). Reasons for these differences have not been well described, but incomplete mixing (FLORAN et al.. 1978), terrestrial alteration processes (REIMOLD, 1982), and clast incorporation along the margin of a flowing melt (KOROTEV et al., 1993) have been suggested. Also, no terrestrial impact structure compares in size with the lunar basins, and it is the largest craters that are most likely to lead to melt rocks of different composition ("Hypothesis 2" section). Thus, the lesson from terrestrial impact melts is that compositional similarity of different samples is consistent with formation in a single melting event, but dissimilarity is not necessarily a strong argument against it.

Only compositional data combined with unambiguous geochronologic data can be used to confirm whether two different rocks or two compositionally distinct groups of rocks do or do not derive from two different impacts - in some cases. For example, all four samples of Apollo 16 group-3

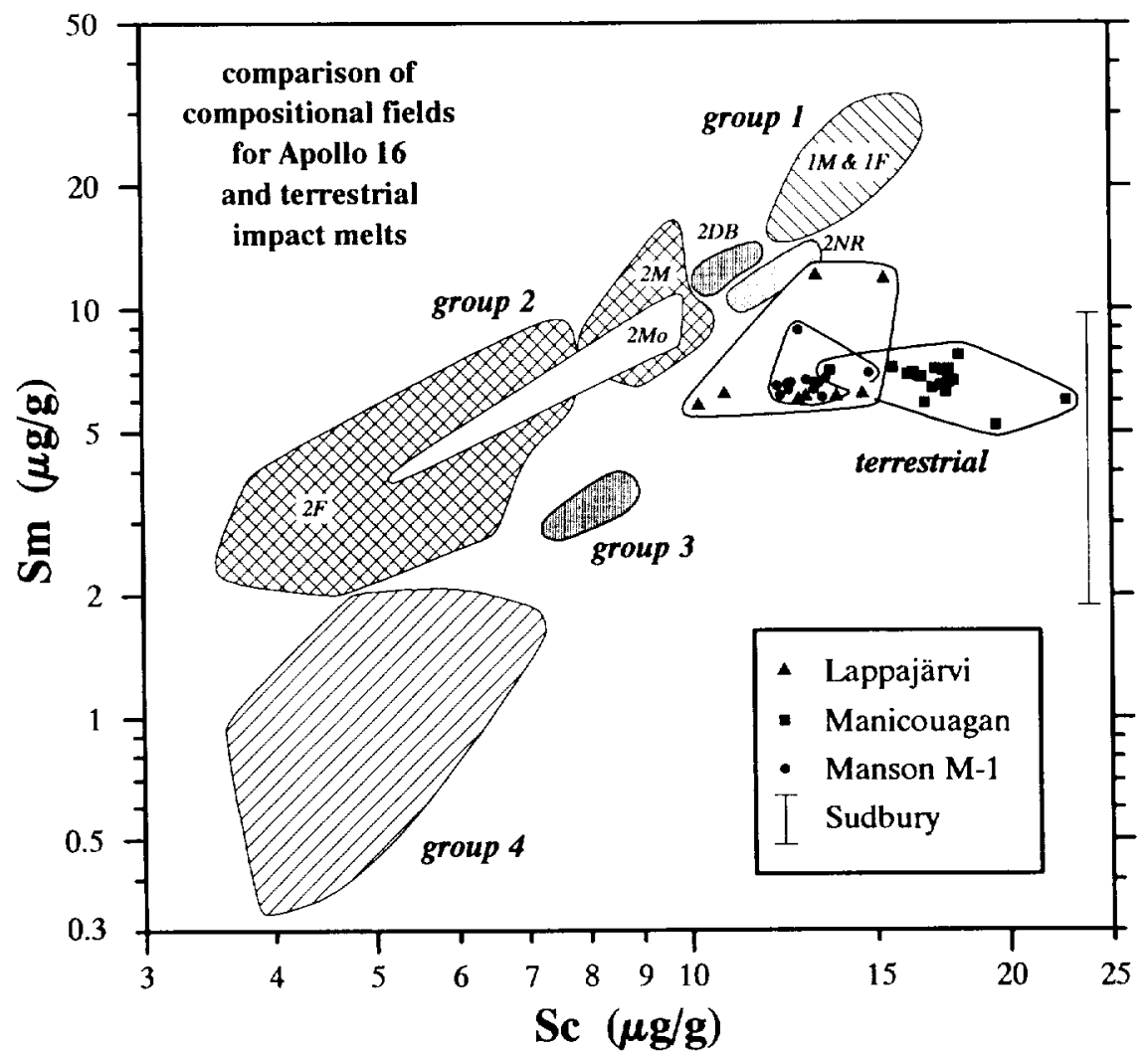

Fig. 24. Comparison of the compositional variation and range for Apollo 16 melt groups (from Fig. 3) with that of melt breccia samples from Lappajärvi crater, Finland ( $17 \mathrm{~km}$ diameter; REIMOLD, 1982), the Manicouagan impact structure, Quebec ( $100 \mathrm{~km}$ diameter; Floran et al., 1978) and the M-1 core into the Manson impact structure. Iowa ( $35 \mathrm{~km}$ diameter; Koronev et al., 1993) (crater diameters from GrIEve, 1991). For the Sudbury Igneous Complex, Ontario $(200 \mathrm{~km}$ diameter). Sc data are not available and only the range of Sm concentrations is shown (KUO and CROCKETT, 1979). Note the logarithmic scales, which emphasize relative differences, in contrast to similar plots in other works in which linear scales were used (RYDER, 1981; REIMOLD and NIEBER-REIMOLD, 1984; MCKINI.FY et al. . 1984). One highly anomalous Lappajärvi sample $(62 \mu \mathrm{g} / \mathrm{g} \mathrm{Sm})$ is not plotted. Note that in this work and all other studies of lunar samples, the field for any particular lunar melt group on a two-element plot is defined by points corresponding to subsamples each representing, at most, a few hundred milligrams of material. Although it is not entirely clear from the descriptions of sample preparation, it appears that each Manicouagan point represents tens to hundreds of grams of powdered material and each Lappajärvi point represents several kilograms of material (FLORAN et al., 1978; REIMOLD, 1982). The Manson points, however. represent samples equivalent in size to the Apollo 16 samples analyzed here (KOROTEV et al.. 1993). 
melt rocks for which there are geochronologic data have essentially identical $\mathrm{Rb}-\mathrm{Sr}$ isochron ages of about $3.75 \mathrm{Ga}$ (DEUTSCH and STOFFLER, 1987), which is significantly younger than the 3.8-3.9 Ga typically obtained for melt breccias of groups 1 and 2 (e.g., JAMES, 1981; MC KINLEY et al., 1984; REIMOLD et al., 1985; MARVIN et al., 1987). Thus we can say with some confidence that if the group-3 melt rocks are all the product of one impact event, then that impact was a different impact from the impact or impacts that produced the melt rocks of groups 1 and 2. However, we do not know whether the compositional differences discussed above between group-3 samples $635 \mathrm{xx}$ and $6841 \mathrm{x}$ result from (1) heterogeneity of both lithophile and siderophile element concentrations within melt produced in a single impact or (2) two nearly simultaneous impacts into similar, but not identical, target areas. Given that melt rocks with the texture and composition of the group- 3 melt rocks can be formed in craters as small as $5-7 \mathrm{~km}$ in diameter (DEUTSCH and STOFFLER, 1987) and that the composition of the group-3 melt rocks is similar to the average composition of the lunar highlands surface, either scenario is reasonable. Similarly, the samples of group 4 and ungrouped samples of the Eastern trend probably represent several small impacts into feldspathic upper crust, but compositional and petrographic data alone cannot assure that this is the case.

\section{The Enigma of the Mafic Melt Breccias}

The case of the mafic melt breccias of groups 1 and 2 is similarly ambiguous, but more consequential because these are the samples that are most likely to be the products of basin forming impacts, if basin melts occur at Apollo 16. Compositions are consistent with four different impacts, yet geochronologic data are equivocal. No previous work has established an age difference between groups 1 and 2 (e.g., JAMES, 1981; MCKINLEY et al., 1984; REIMOLD et al., 1985; MARviN et al., 1987). Although a thorough review of the geochronologic data is beyond the scope of this paper, I contend that no data argue that one group is significantly different in age from any other, when intragroup variation in ages is taken into account.

Thus, this discussion will focus only on those constraints actually imposed by the compositional data. Various scenarios will be entertained. The problem for any scenario involves reconciling the data for lithophile and siderophile elements. As noted above, regardless of whether the SE signatures derive unmodified from the projectile(s) or result from some postimpact interaction of lunar and meteoritic material, the observations remain valid: the different melt groups identified by lithophile element composition each have different absolute and relative concentrations of siderophile elements and together the Apollo 16 mafic melt breccias have some $\mathrm{SE}$ characteristics that set them apart from melt breccias from other sites, most notably, high metal abundances.

\section{Hypothesis 1: Two or more hasin impacts}

First, I consider the possibility that the Apollo 16 mafic melt breccias are basin melts. The main argument for this hypothesis is their similarity in major-element composition, particularly for group 1, to melt breccias from other sites that were almost certainly produced during basin formation. There is also the probabilistic argument that any given sample of melt is more likely to have been produced in a large crater because the ratio of melt volume to crater volume increases with crater size (e.g., GRIEVE and CINTALA, 1992). SPUDIS (1984), for example, suggested that the group 1 rocks derive from Imbrium and the group-2 rocks are products of the Nectaris impact. HERTOGEN et al. (1977) suggested that the SE signature of samples of groups $1 F, 2 D B$, and $2 \mathrm{NR}$ of this work ("ancient meteorite group $1 \mathrm{H}$ ") may be that of the Nectaris impact.

The hypothesis most easily discounted is that the mafic melt breccias derive from two or more basin impacts. This conclusion is based largely on the similarity of lithophileelement ratios among Apollo 16 melt breccias and their dissimilarity as a 'supergroup' to mafic melt breccias at other sites (Fig. 25). For example, relative concentrations of trivalent REEs are nearly identical for the four Apollo 16 groups but different from those of melt breccias from Apollos 14 and 17 (Fig. 9). Concentrations of Eu are greater in melt breccias of Apollos 15 and 17 than those of Apollo 16 with similar Sm concentrations (Fig. 9). This is significant because the magnitude of the "Eu anomaly" is taken as an indicator of regional provenance (WARREN and WASSON, 1980). Also, compared to mafic melt rocks ("LKFM") of other sites, Sc concentrations are low (Fig. 25), Al concentrations are high, and $M g^{\prime}$ is high (Fig. 11). These various differences indicate that if more than one impact formed the Apollo 16 mafic melt breccias, the impacts all occurred in a region dominated by a particular suite of primitive rock types and that the different compositional groups do not represent basins separated by distances such as that which separates Imbrium and Nectaris. It also seems unlikely that groups $1 \mathrm{M}$ and $2 \mathrm{DB}$, for example, can each represent different basins when they both have unusually high concentrations of siderophile elements compared to mafic melt breccias from Apollos 14, 15 , and 17 (Fig. $21 \mathrm{c}$ ), and $\mathrm{Ir} / \mathrm{Au}$ ratios that are distinctively low. If the Apollo 16 mafic melt breccias are basin melts, then they were all formed in one basin. For purposes of subsequent discussion, 1 initially assume that basin is Nectaris, as the Nectaris impact has had the greatest effect on the site (STOFFLER et al., 1985; SPUDIS et al., 1989).

\section{Hypothesis 2: One basin impact}

The consideration that the mafic melt breccias of Apollo 16 were formed in one impact event requires abandoning the notion that all impact melt produced in a given impact has the same composition ("Compositional Homogeneity

$\therefore$ section). If they were formed in one impact, the different melt groups must each represent different melt regimes, and the apparent groupings discussed here must simply represent inadequate sampling of heterogeneous melt (P. $\mathbf{H}$. Warren, pers. commun.). Two processes that might lead to such heterogeneity are igneous fractionation and assimilation of clastic material of different compositions by different units of melt. If such processes have occurred, the Apollo 16 samples indicate that they can lead to large compositional differences. However, as discussed in the following paragraphs, 


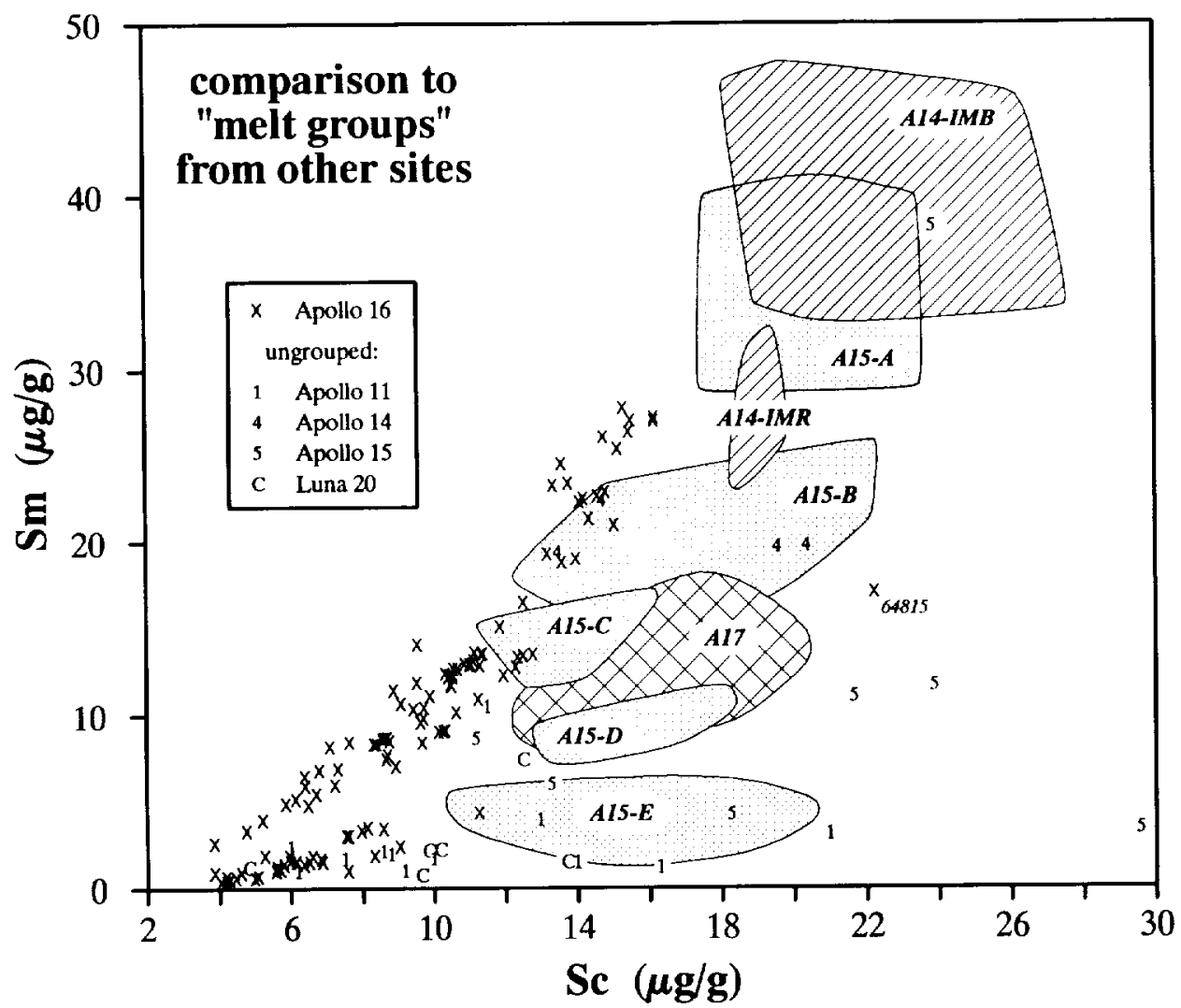

FIG. 25. Comparison of Apollo 16 melt rocks (sample means) with mclt rock groups from other sites. Some anomalous, ungrouped samples from Apollos 14 and 15 are shown as numerals ( 4 and 5 ) as are highlands melt-breccia fragments from Apollo 11 ( 1 : LAUL et al., 1983). Some very small melt-breccia fragments from Luna 20 are also plotted individually (C: SWINDLE et al., 1991). For Apollo 14, the two fields are for clast-free impact-melt rocks (IMR), based on samples 14078 and 14310 (this work and JOLLIFF, unpublished data), and clast-laden impact-melt breccias (IMB. 2-4 mm particles from 14161; Jol LIFF et al.. 1991a). Five compositions of melt rocks are recognized from Apollo 15 (although group ( may be just the feldspathic extreme of group B), and different samples from each group are highly variable in composition (RYDER and SPUDIS, 1987); additional Apollo 15 data from RYDER et al. (1988). LALI et al. (1988). and LINDSTROM et al. (1988). Apollo 17 data are from BL.ANCHARI) et al. (1975. 1976). JAMES et al. (1975, 1978). PALME et al. (1978), and Rockow et al. (1994).

either process requires some special and improbable conditions if it is to account quantitatively for the Apollo 16 samples.

GRIEVE et al. (1991) have suggested that the Sudbury igneous complex, one of the largest terrestrial impact structures ( $200 \mathrm{~km}$ diameter), is a differentiated melt sheet, and thus it is reasonable that differentiation may have occurred in melt pooled in a basin the size of Nectaris $(860 \mathrm{~km}$ : SPUDIS et al.. 1989). However, there are numerous reasons why igneous differentiation is unlikely to be the cause of the compositional differences observed here. First, if it is assumed that bulk composition of the breccias (Table 4 ) represents a liquid composition, then none of the four groups of mafic melt breccia can be related to any of the others by any simple igneous-fractionation process. For example, olivine is the liquidus phase for the group $1 \mathrm{M}$ composition and plagioclase the liquidus phase for group $1 \mathrm{~F}$ and all group-2 compositions (e.g. Simonds et al., 1973). The igneous-fractionation hypothesis also does not account for the intragroup trends ("Anorthosite mixing . . ." and "Group 2DB" sections).
Plagioclase or olivine separation should yield trends that extrapolate to the origin of a Sc-Sm plot; instead, the trends extrapolate to the composition of anorthosites with a substantial mafic, Sc-bearing component (e.g., Figs. 8. 12). Textural observations are also difficult to reconcile with an igneous-fractionation model. For example, the dimict breccias are thought to have formed at the bottom of a large impact crater by injection of melt into fragmented anorthositic bedrock (STOFFI.ER et al., 1979: JAMES et al., 1984). If this model is correct, then it is likely that portions of this same melt ponded elsewhere in the crater and the ponded melt is the source of the poikilitic-textured group-2DB samples and some other group-2DB samples that do not contain the anorthosite lithology typical of dimict breccias. But how do the ITE-rich, poikilitic, group- 1 melt rocks relate to such a scenario? And how can rocks from the bottom of the Nectaris basin be so abundant at the Apollo 16 site? It also seems unlikely that metal would be so finely disseminated and in such high concentrations in a melt that underwent extensive igneous fractionation. Finally, if the four groups represent different layers 
in the stratified melt sheet of a basin, some large subsequent impact is required to have delivered such a large volume of melt (below) to the Apollo 16 site.

O. B. James (pers. commun.) makes the cogent observation that even if the initial melt was homogeneous at the time of formation, as it flowed radially outward along the crater bottom, it would assimilate and dissolve clastic material - "this process must lead to heterogeneity, because different radii in the target will be lithologically different; the larger the crater, the greater the degree of lateral heterogeneity that is likely in the target." Thus, melt breccia ejected from the crater in one direction will be different in composition than that ejected in another. Evidence that such a process actually occurs has been obtained from the Mistastin Lake crater (Labrador) in which breccia samples taken from different radial locations around the crater have different clast distributions (MCCORMick et al., 1989).

A process such as this can explain some of the observations. For example, the differences in composition and geographic occurrence between groups $2 \mathrm{DB}$ and $2 \mathrm{NR}$ could be related to jets of ejecta (superheated impact melt and fragmented clastic material ) that left a crater along different trajectories. The anorthosite-dilution trend observed in group IF and the apparent trend of varying troctolite component in group $2 \mathrm{Mo}$ are both consistent with the jetting hypothesis, as clast incorporation need not be uniform along a jet.

However, the jetting hypothesis requires some special conditions if Nectaris (or some other basin) is the source of the melt. First, it requires that a large fraction of the material at the Apollo 16 site is Nectaris impact melt (with entrained clasts), even though the site is about 1.4 crater radii from the center of Nectaris. This constraint is imposed by the regolith composition. Impact-melt breccias of groups 1 and 2 are the major carriers of ITEs in the Apollo 16 regolith; no other KREEP-like lithologies occur at the site. As noted in the Introduction, about $35 \%$ of the regolith must consist of ITE-rich, mafic melt breccia in order to account for the high concentrations of ITEs and elements associated with mafic minerals in the soil. Mass balance considerations for siderophile elements lead to a similar conclusion. The upper 0.6 $\mathrm{m}$ of soil at station $10(\mathrm{LM})$ contains $0.72 \pm 0.02 \% \mathrm{Fe}-\mathrm{Ni}$ metal containing an average of $6.6 \% \mathrm{Ni}$ (KOROTEV and MORRIS, 1993). Some of this metal has accumulated over time from micrometeorite impacts but most is "ancient" metal derived from the component of mafic melt breccia. Assuming the soils contain $0.5 \%$ Fe-Ni metal from the mafic melt breccias (KOROTEV, 1987b) and that the melt-breccia component contains $1.5 \%$ metal (average of groups $1 \mathrm{M}, 1 \mathrm{~F}$, and $2 \mathrm{DB}$; Table $5 \mathrm{~b}$ ), the soils must contain $33 \%$ mafic melt breccia. [The calculations of SPUDIS (1984) based on soil petrography concluding that the volume of melt at Apollo 16 is much lower than this ignores that much of the mafic melt component is petrographically disguised in agglutinates, which compose $30-60 \%$ of typical, mature soils. This consideration raises his estimates of fraction of pure melt by a factor of 1.7-1.8.] Second, except for group 2NR, the mafic melt breccias of Apollo 16 are components of the Cayley plains. If the melt rocks are not of local origin, then they were most likely transported to the site from the northwest toward Imbrium, which requires that large volumes of Nec- taris melt were initially emplaced even further from the basin before redistribution by Imbrium. Third, the dimict breccias and their occurrence at the Apollo 16 site are not explained by the hypothesis of melt jetting from a basin. Fourth, even if there are mechanisms (oblique impact?) for delivering such high volumes of melt breccia from Nectaris to the Apollo 16 site, there is no evidence that Nectaris ejected such ITE-rich materials. Highland impact-melt breccias in the regolith of Mare Tranquillitatis north of Nectaris are not rich in ITEs (Fig. 25). Nectaris ejecta sampled from orbit are not rich in Th, as are ejecta from Imbrium; Th concentrations decrease in the direction of Nectaris from Apollo 16 (METZGER et al., 1981). Finally, if compositional differences among Apollo 16 mafic melt breccias are caused by different jets of melt from the Nectaris basin, somehow the site must have received material from at least four different jets.

Some of the above arguments for why the mafic melt breccias are unlikely to derive from Nectaris apply also to Imbrium. From the compositional perspective, however, Imbrium is a more likely source than Nectaris because of the high ITE concentrations around the Imbrium basin. Weighing against this possibility is the dissimilarity of the compositions of the Apollo 16 melt breccias to those from Apollos 14 and 15 (Fig. 25).

In summary, if the mafic melt breccias of Apollo 16 are products of basin formation, compositional data argue strongly that they were all formed in one basin, not two or more. If the breccias are basin melts, then there exist mechanisms for (1) producing, in a single impact, regimes of melt breccia that have significantly different major- and trace-element compositions and that are not easily relatable to each other by the processes of mixing or igneous fractionation, and (2) delivering large volumes of four compositionally distinct units of melt breccia to the Apollo 16 site.

\section{Hypothesis 3: One local impact}

Siderophile elements provide the main arguments that the Apollo 16 mafic melt breccias are related by a single impact: (1) they are all unusually rich in metal, (2) the metal compositions in the different melt groups are all similar (but not identical), and (3) siderophile-element ratios in the Apollo 16 samples are generally dissimilar to those of mafic melt breccias from other sites (HERTOGEN et al., 1977; JAMES, 1986). If the Apollo 16 breccias were all produced in one impact and some mechanism like jetting is the cause of the differences in lithophile-element compositions, then the source of the breccias is most likely a crater close to the Apollo 16 site. A scenario that circumvents the problem of moving large volumes of melt laterally is the impact of a large, preImbrian, metal-rich object close enough to the Apollo 16 site that the site lies in or very near the crater, e.g., crater Unamed A of HEAD (1974). Each of the melt groups then represents a different jet of melt ejected from the crater or different lobes pooled in the crater; the dimict breccias derive from the fractured floor. Reworking of these melt units by secondaries of Imbrium mixes them and redeposits previously ejected melt in the crater cavity. The slight differences in siderophile-element compositions of the metal in the four 
groups ( Table 5) can be ascribed to postimpact reequilibration involving different batches of melt. In this regard, it should be noted that despite the differences between groups $1 \mathrm{M}$ and $\mathrm{IF}$ discussed here (e.g., Ir/Au), relative concentrations of other siderophile, chalcophile, and volatile elements suggest that samples 603 I5 (IM) and 65015 (1F) are more closely related to each other than they are to any other groups of melt breccia (O. B. James, pers. commun., based on data of KRÄHENBÜHL et al., 1973 and GANAPATHY et al., 1974).

As with the basin hypothesis, the local-crater hypothesis still requires that the process that leads to compositional heterogeneity, whether jetting or some other process, is efficient enough to lead to the observed variation in ITE concentrations and $M g^{\prime}$ observed among the mafic melt breccias. However, from the quantitative mixing perspective, it is still not clear how the different compositional groups relate to each other. For example, the jet or pool yielding group $1 \mathrm{M}$ must have assimilated normative components of olivine, alkali feldspar, ilmenite, and chromite in excess of that assimilated by group $1 \mathrm{~F}$ ( subdivision of group 1 section ). In contrast to group $2 \mathrm{Mo}$, which appears to contain a nonuniformly distributed troctolite component (Group 2Mo section), the carrier of the excess $\mathrm{Cr}$ (olivine, chromite) must have been assimilated uniformly by the group-1M melt, because the range of the $\mathrm{Cr} / \mathrm{Sc}$ ratios in group- $1 \mathrm{M}$ samples (104 \pm 5 , mean \pm standard deviation, $n=6)$ is small compared to the difference in the ratio between groups $1 \mathrm{M}$ and $1 \mathrm{~F}(1 \mathrm{~F}: \mathrm{Cr}$ ) Sc $=81 \pm 4, n=15$; see Fig. 7a). At the same time, group IF appears to contain highly variable abundances of a clastic noritic-anorthosite component ("Anorthosite mixing . . ." section). Observations such as these must be explained by any specific model which intends to account for these breccias as products of a single impact.

\section{Hypothesis 4: Several local impacts}

Finally, I consider the possibility that the Apollo 16 mafic melt breccias are products of several impacts. If lithophile element concentrations only are considered, it is easily argued that groups $1 \mathrm{M}, 1 \mathrm{~F}, 2 \mathrm{DB}$, and $2 \mathrm{NR}$ differ in composition because they were each produced by a different impact. The sizes of the fields for the lunar groups on two-element plots are similar to those for terrestrial impact melts. Also, Apollo 16 melt groups tend to form elongated trends on two-element plots that appear to be caused by variation in the ratio of anorthositic clasts to melt matrix. Linear trends are also seen in different samples of melt from terrestrial craters (Fig. 24), although the causes have not been established.

As noted above, the similarity in lithophile-element ratios among the groups indicates that the several impacts all occurred in the same region, presumably local to the Apollo 16 site. Because the mafic melt breccias are more mafic than the surface regolith ( Fig. 1), the craters must have been large (RYDER and WOOD, 1977), probably on the order of the several craters of $50-150-\mathrm{km}$ diameter that occur in the vicinity of the site (HEAD, 1974). A major point in the argument of SPUDIS (1984) that the melts of groups 1 and 2 are not of local origin is that the upper crust in the Apollo 16 vicinity is too feldspathic to yield melts this mafic. The argument can be reversed, however, to conclude that if the melts are of local origin, the upper crust cannot be feldspathic to a depth that is large, compared to the depth sampled by an impact forming a crater with a diameter of $50-150 \mathrm{~km}$. That the four impacts all happened about the same time, $\sim 3.9 \mathrm{Ga}$ ago, is not a serious argument against multiple impacts, because this is a common age for many lunar rocks.

More difficult to explain in terms of multiple impacts is the similarity in siderophile elements. Like the lithophile elements, siderophile-element data suggest that the Apollo 16 mafic melt breccias are somehow more closely related to each other than they are to melt breccias from other sites. How can melts produced in four different impacts each have high, but differing, abundances of Fe-Ni metal with similar, but not identical, compositions and SE ratios? The various observations on siderophile and lithophile elements in mafic melt breccias from Apollo 16 are consistent with a model in which the Central Highlands were impacted by several metalbearing fragments from the core of a disaggregated planetesimal (KOROTEV, 1987a). This hypothesis is ad hoc, requires the coincidence that related bodies impacted the same region of the Moon at about the same time (WARREN et al., 1989), and is not easily testable, but purely from the reference frame of the lunar samples, it explains the data in a simple way.

Another possibility is that the metal derives primarily from a single, large, early impact and that subsequent smaller impacts in the Apollo 16 region produced secondary melts of differing lithophile-element compositions by mixing the primary, metal-bearing melt (probably mafic) with other lunar material (probably more feldspathic). If the primary melt was rich in Ir- and Au-bearing metal (for whatever reason), then subsequent impacts may have altered the original SE signature only slightly (e.g., MORGAN and JAMES, 1981). Some impacts clearly have occurred in previously formed craters. For example, it is likely that any melt produced in the formation of crater Unamed B of HEAD ( 1974 ) includes a component of the melt from Unamed $A$, and that the melt from Unamed D contains a component of melt from both Unamed $A$ and $B$.

If the bulk of the metal and the SE signature derived from a single impact (perhaps modified by postimpact processes), then the mafic melt breccias should each contain a volumetrically significant component of the early, primary melt; perhaps one of the four groups even represents the primary melt. Such a model is testable, because it should be possible to account for the composition of the secondary melts as mixtures involving lunar crustal material and a melt component. For example, it is evident from the geometry of Figs. 4 and 24 that, to a first approximation, addition of feldspathic material of the upper crust to melt with the composition of groups $1 \mathrm{M}$ or $1 \mathrm{~F}$ can account for the composition of any group-2 melt. In detail, however, no such simple mixture of any of the mafic-melt-breccia compositions with typical lunar material accounts for the composition of any of the other melt breccias. The task, in essence, is to account simultaneously for the concentrations of $\mathrm{Al}, \mathrm{Fe}, \mathrm{Mg}$, ITEs, and SEs. No such model I have attempted succeeds in quantitatively accounting for these key elements and element groups without invocation of some unusual composition for the lunar-crustal component. For example, group-2DB melt can be modeled reasonably well as an approximately 50:50 mixture of group- 
$1 \mathrm{M}$ melt and ITE-poor noritic anorthosite. However, because $\mathrm{Mg} / \mathrm{Fe}$ and $\mathrm{Cr} / \mathrm{Sc}$ ratios and $\mathrm{SE}$ concentrations are virtually identical for groups $2 \mathrm{DB}$ and $1 \mathrm{M}$, the noritic anorthosite component must have high $\mathrm{Mg}^{\prime}(\sim 75)$ and a high $\mathrm{Cr} / \mathrm{Sc}$ ratio ( $\sim 103 ; \mathrm{Fig} .7 \mathrm{a})$ compared to estimates of average crust composition (KOROTEV et al., 1980; TAYLOR, 1982), and the model underestimates $\mathrm{SE}$ concentrations by a factor of two. Even more difficult is relating groups $1 \mathrm{M}$ and $1 \mathrm{~F}$ by any mixing process ("Subdivision of group 1 " section).

In summary, lithophile element data are consistent with, but do not demand, that the mafic melt breccias of Apollo 16 were involved in four impact events (or possibly more, when the other samples of groups $2 \mathrm{M}$ and $2 \mathrm{Mo}$ are considered) in the vicinity of the Apollo 16 site. Siderophile-element data suggest that if four or more impacts were involved, then the different melt breccias are all related by some process that somehow yielded (1) unusually high metal abundances in all the breccias and (2) metal compositions that are similar, but not identical, among melts produced by the four impacts. That process may have been the impact of several related meteoroids or the impact of a single meteoroid with reworking of the impact melt produced in that event by subsequent impacts. However, none of these hypotheses accounts for the compositions of the four groups of melt breccia in a quantitative way without invoking some $a d$ hoc and improbable assumptions about the nature of the impactors and impact events or composition of possible components of the melts.

\section{CONCLUSIONS}

Four compositionally distinct types of mafic impact-melt breccia each represented by at least six samples occur at the Apollo 16 site, two of group 2 ("VHA") composition and two of group 1 ("LKFM") composition. Of the two types of group-2 melt breccia, the one associated with the feldspathic fragmental breccias of North Ray crater (group 2NR) is slightly richer in $\mathrm{Sc}, \mathrm{Cr}$, and heavy REEs than the one associated with the dimict breccias of the Cayley plains (group 2DB). Of the two types of group- 1 melt breccia, one (group $(\mathrm{M})$ is more mafic and richer in components of normative olivine and alkali feldspar than the other (group IF).

Within each group, systematic compositional variation exists among samples. For any given group, the major trend of variation (when all elements are considered) is not in the direction of one of the other groups. Instead, intragroup variation results from differences in the abundance of a component of anorthosite. These differences, in turn, probably reflect differences in clast abundance (both discrete clasts and clasts assimilated by superheated melt). The composition of the inferred clastic anorthosite component of group IF (and probably group $1 \mathrm{M}$ ) is consistent with typical noritic anorthosite material of the upper crust while the anorthosite component( $\mathrm{s}$ ) of the group-2 melts is more feldspathic.

There is no simple explanation for the origin of the four melt groups that accounts for the compositions. Concentrations of both trace lithophile and siderophile elements suggest that all four groups are more related to each other than they are to mafic melt breccias collected at other sites. If they are related by a single impact, then some process has acted to produce units of melt breccia with different compositions, each with a distinct trend of variation in abundance of anorthositic clasts. That process may have been igneous fractionation in a large melt pool, radial jetting of melt from the crater or basin with assimilation of different clastic materials by different jets, or reimpact of a large melt sheet by subsequent impacts. However, none of these processes can quantitatively explain the observed compositional differences without invocation of some ad hoc assumptions or special circumstances. The igneous fractionation hypothesis is the least satisfactory. Alternatively, the breccias may have been produced in several different impacts. In this case, the breccias are related in that the impacts all occurred in the same geochemically distinct region, the Central Highlands, and either (1) the region of the impacts retained the siderophile-element signature of a previous impact or (2) the four impacts were by related planetary fragments with similar siderophile-element signatures. It is unlikely that any of these melt breccias were produced in the impacts that formed the Nectaris or Imbrium basins, in which case Nectaris and Imbrium melts are both rare at Apollo 16.

The samples of compositional group 3 (noritic anorthosite) are often regarded as the products of a single impact, because of their similar compositions and textures. Unlike groups 1 and 2, their composition is that of typical, feldspathic, KREEP-poor, upper crust and they may have been formed in a smaller impact than those of groups 1 and 2. However, differences in ratios of several elements occur among the samples that exceed those observed in groups 1 and 2 . In particular, both lithophile- and siderophile-element ratios differ between samples 68415 and 68416 from station 8 and samples 63537 and 63549 from station 13. This either speaks to the range of compositional variation expected within a single lunar impact, or indicates that more than one impact produced the group-3 melts.

Note added in proof: RYDER et al. (1988) report on two 2-4 mm samples of poikilitic melt breccia from the Apennine Front at Apollo 15. regolith samples 15243,40 and 15243,41 (probably fragments of a single larger rock), that are identical in texture and composition, including the unusual siderophile-element signature, to Apollo 16 group IM. Because of the unique composition of group IM, the 15243 samples are almost certainly from the same unit of impact melt as the group-1M samples. This is the least ambiguous case of which I am aware of a compositional match between samples of a melt breccia occurring at different Apollo sites. As samples of group $1 \mathrm{M}$ are more common at Apollo 16 than at Apollo 15, their occurrence at $A$ pollo 15 does not strengthen any argument that group $1 \mathrm{M}$ is "the Imbrium melt"; however, it does suggest that the group-1 M crater is large and perhaps in the direction of Apollo 15 from Apollo 16.

Acknowledgments-This work was supported by the National Aeronautics and Space Administration through grants NAG 9-56 and NAGW-3343 to L. A. Haskin. Analytical costs were supported in part by the Department of Energy through Reactor Sharing grant DE-FG07-80ER 10725 to the University of Missouri Research Reactor. This work has benefited greatly by the careful reviews and suggestions of G. Dreibus, O. B. James, H. Palme, G. Ryder, D. Stöfller, and P. H. Warren on an earlier, somewhat longer version of the manuscript; the author greatly appreciates the thoughtful, although divergent advice.

Editorial handling: H. Palme 


\section{REFERENCES}

ANDERS E. ( 1978 ) Procrustean science: Indigenous siderophiles in the lunar highlands, according to Delano and Ringwood. Proc: 9th Lunar Sci. Conf. 161-184.

ANDERS E. and GREveSSE N. (1989) Abundances of the elements: Meteoritic and solar. Geochim. Cosmochim. Acla 53, 197-214.

anders E., Ganapathy R., Krähenbúhl U, and Morgan J. ( 1973 ) Meteoritic material on the Moon. The Moon 8, 3-24.

ARvidson R. A., Crozaz G., Drozd R. Y., Hohenberg C. M., and MORGAN C. Y. (1975) Cosmic Ray exposure ages of features and events at the Apollo landing sites. The Moon 13, 259-276.

Blanchard D. P., Haskin L. A., Jacobs J. W., Brannon J. C., and KOROTEV R. L. ( 1975 ) Major and trace element chemistry of boulder 1 at station 2, Apollo 17. The Moon 14, 359-371.

Bi.anchaRd D. P., JaCOBS J. W., BRANNON J. C., and HaSkIN L. A. (1976) Major and trace element compositions of matrix and aphanitic clasts from consortium breccia 73215. Proc. 7th Lunar Sci. Conf., 2179-2187.

BORCHARDT R. et al. (1986) Composition, structure, and age of the Apollo 16 subregolith basement as deduced from the chemistry of post-Imbrium melt bombs. Proc. 17th Lunar Planet. Sci Conf., E43-54.

Boynton W. V. BaEdecker P. A., ChOU C.-L., Robinson K. L., and WASSON J. T. (1975) Mixing and transport of lunar surface materials: Evidence obtained by the determination of lithophile, siderophile, and volatile elements. Proc. 6th Lunar Sci. Conf., 22412259.

BOYNTON W. V., ChOU C.-L., ROBINSON K. L., WaRREN P. H., and WASSON J. T. (1976) Lithophiles, siderophiles, and volatiles in Apollo 16 soils and rocks. Proc. 7th Lunar Sci. Conf., 727-742.

Brunfeit A. O., Heier K. S., Nil.ssen B., Sundvol.t. B., and STEINNES E. (1973) Geochemistry of Apollo 15 and 16 materials. Proc: 4th Lunar Sci. Conf., 1209-1218

BVSP (Basaltic Volcanism Study Project) (1981) Lunar Highlands Basalts. In Basaltic Volcanism on the Terrestrial Planets, Chap. 1.2.10. pp. 268-281. Pergamon.

Christian R. P., Berman S., Dwornik E. J., Rose H. J.. Jr., and SCHNEPPE M. M. (1976) Composition of some Apollo 14, 15, and 16 lunar breccias and two Apollo 15 fines. Lunar Sci. VII, $138-$ 140 (abstr.).

DFIANO J. W. and RINGWOOD A. E. (1978) Siderophile elements in the lunar highlands: Nature of the indigenous component and implications for the origin of the moon. Pros. 9th Lumar $S_{i}$. Confl. $111-159$.

Delano J. W., Bence a. E., Papike J. J., and Cambron K. L. (1973) Petrology of the $2-4 \mathrm{~mm}$ soil fraction from the Descartes region of the moon and stratigraphic implications. Proc: 4 th Lumar Sci. Conf., 537-551.

DEUTSCH A. and STOFFLER D. (1987) Rb-Sr-analyses of Apollo 16 melt rocks and a new age estimate for the Imbrium basin: Lunar basin chronology and the early heavy bombardment of the moon. Goohim. Cosmochim. Acta 51, 1951-1964.

Dreibus G., Palme H., Rammensee W., Spettel. B., and Wänke H. ( 1981 ) On mobilization and redistribution of $A u$ and other siderophiles in lunar highlands materials. Lumar Planet. Sci. XII, 240-242 (abstr.).

Dincan A. R., ERlank A. J., WILlis J. P., and Ahrens L. H (1973) Composition and interrelationships of some Apollo 16 samples. Proc. 4th Lunar Sci. Conf., 1097-1113.

Ebihara M., Wolf R., WarRen P. H., and ANDERS E. (1992) Trace elements in 59 mostly highland Moon rocks. Proc, Lumar Planet. Sci. 22, 417-426

FIORAN R. J. et al. (1976) A comparison between the geochemistry and petrology of A pollo 16-terrestrial impact melt analogs. Lunur Planel. Sici. VIl, 263-265 (abstr.).

FLORAN R. J. et al. (1978) Manicouagan impact, Quebec, 1, stratigraphy, petrology, and chemistry. J. (jeophys. Re's. 83, $2737-2759$.

Fruchter J. S., Kridelbaugh S. J., Robyn M. A., and Golls G. G. (1974) Breccia 66055 and related clastic materials from the Descartes region, Apollo 16. Proc'. 5th Lunar Sci. Conf., 10351046

Ganapathy R., Morgan J. W., Higuchi H., Anders E., and AN
DERSON A. T. (1974) Meteoritic and volatile elements in Apollo 16 rocks and in separated phases. Proc. 5 th Lumar Sil. Conf., 1659 1683.

GARRISON J. R. and TAYLOR L. A. ( 1980 ) Genesis of highland basalt breccias: A view from 66095. In Proc. Conf. Lunar Ilighlands Crust (ed. J. J. PAPIKE and R. B. MERRILl), pp. 395-417. Pergamon.

GRILVE R. A. F. (1991) Terrestrial impact: The record in the rocks. Meteroritics 26, 175-194.

GRIEVE R. A. F. and CINTALA M. J. (1992) An analysis of differential impact melt-crater scaling and implications for the terrestrial impact record. Meteoritics $27,526-538$.

Grieve R. A. F., STOFfL.F D., and DFutsch A. (1991) The Sudbury structure: Controversial or misunderstood. J. Geophys. Res. 96. 22,753-22,764

Gros J.. Takahashi H., Hertogen J.. Morgan J. W., and Anders E. ( 1976) Composition of the projectiles that bombarded the lunar highlands. Proc. 7th Lunar Sci. Conf., 2403-2425.

Haskin L. A., Helmke P. A., Bl.anchard D. P., Jacobs J. W. and TILANDER K. ( 1973 ) Major and trace element abundances in samples from the lunar highlands. Proc: $41 /$ Lumar Sci. CoH/. $1275-1296$

Haskin L. A., Lindstrom M. M., Salpas P. A.. and Lindstrom D. J. ( 1981 ) On compositional variations among lunar anorthosites. Proc. I2th Lunar Planet. Sci. Conf., 41-66.

HEAD J. W. (1974) Stratigraphy of the Descartes region (Apollo 16)-Implications for the origin of the samples. The Moon 11 , $77-99$.

Her togen J., Janssens M.-J., Tak ahashi H., Paime H., and ANDERS E. (1977) Lunar basins and craters: Evidence for systematic compositional changes of the bombarding population. Proc: $8 \mathrm{th}$ lunar Si. Comf.. 17-45.

HORZ F., Grieve: R., Heiken G.. SPIDIS P., and Binder A. (1991) Lunar surface processes. In Lunar Sourcchook (ed. G. HEIKEN et al.). Chap. 4, pp. 6l-120. Cambridge Univ. Press.

HubBard N. J., RhODES J. M., and GASt P. W. (1973a) Chemistry of Very High $\mathrm{Al}_{2} \mathrm{O}_{3}$ lunar basalts. Scicnce' 181, 339-342.

HURBARD N. J. et al. ( 1973b) Lunar rock types: The role of plagioclase in non-mare and highland rock types. Proc. $41 \mathrm{~h} \mathrm{Lumar}$ Sci. Conf. $1297-1312$.

Hubrard N. J., Rhodes J. M., Weismann H., Shih C.-Y., and BANSAL B. M. (1974) The chemical definition and interpretation of rock types returned from the non-mare regions of the moon. Proc. 5th Lunar Sit. (onf., 1227-1246.

IRVING A. J. (1975) Chemical. mineralogical and textural systematics of non-mare melt rocks: Implications for lunar impact and volcanic processes. Proc. 6ih Lumar Sci. C'onf.. 36.3-394.

JAMES O. B. (1981) Petrologic and age relations of the Apollo 16 rocks: Implications for subsurface geology and the age of the Nectaris basin. Proc. 12th Lunar Planct. Sir. Conf.. $209-233$.

JAMES O. B. ( 1986 ) A new look at RNAA data for lunar fragmentIaden impact melts. Lunar Planet. Sci. XVII, 392-393 (abstr.).

JAMES O. B. and LINDSTROM M. M. ( $199 \mathrm{la}$ ) Apollo 16 dimict breccias: I. Sample 64425. Lunar Planet. Sci. XXII, 635-636 (abstr.).

JAMES O. B. and LINDSTROM M. M. (199/b) Apollo 16 dimict breccias: Il Sample 65035. Lunar Pland Sci XXII, 637-638 (abstr.)

JAMES O. B. et al. (1975) Consortium studies of matrix of light gray breccia 73215. Proc. 6ih Lunar Sci. Cont. 547-577.

James O. B., Hedenquist J. W. Blanchard D. P.. BUIdahN J. R., and COMPSTON W. (1978) Consortium breccia 73255: Petrology, major- and trace-element chemistry, and $\mathrm{Rb}-\mathrm{Sr}$ systematics of aphanitic lithologies. Proc. 9th Lunar Sci. Con/. 789-819.

JAMES O. B., FloHR M. K., and LINDSTROM M. M. (1984) Petrology and geochemistry of lunar dimict breccia 61015. Proc. 15th Lunar Planet. Sci. Conf. C63-C86.

JOI. .IFF B. L. ( 1991 ) Compositional variations of particles from North Rav crater soils 67513 and implications for the composition of the lunar highlands. Lunar Planet. Sci. XXII, 653-654 (abstr.).

JOLLIFF B. L. (1992) Mafic, ferroan lithologies from North Ray crater. Apollo 16: Implications for crustal abundance. Lunar Planet. Sci. XXIII, 623-624 (abstr.).

JOll.HF B. L., KOROTFV R. L., and HASKIN L. A. (199/a) Geochemisiry of 2-4-mm particles from Apollo 14 soil $(14161)$ and 
implications regarding igneous components and soil-forming processes. Proc: Lunar Planet. Sci. 21, 193-219.

JOLLIFF B. L., KoROTEV R. L., and HASKIN L. A. (1991b) A ferroan region of the lunar highlands as recorded in meteorites MAC88104 and MAC88105. Geochim. Cosmochim. Acta 55, 3051-3071.

Kempa M. J., Papike J. J., and White C. (1980) The Apollo 16 regolith: A petrographically-constrained chemical mixing model. Proc. 1/th Lunar Planet. Sci. Conf:. 1341-1355.

KOROTEV R. L. (1981) Compositional trends in Apollo 16 soils. Proc. 12th Lunar Planet. Sci. Conf., 577-605.

KOROTEV R. L. (1987a) The meteoritic component of Apollo 16 noritic impact melt breccias. Proc. I7th Lunar Planet. Sci. Conf.. E491-E512

KOROTEV R. L. (1987b) The nature of the meteoritic components of Apollo 16 soil, as inferred from correlations of iron, cobalt. iridium, and gold with nickel. Proc. 17th Lunar Planet. Sci. Conf., E447-E461.

KOROTEV R. L. ( 1990 ) Cobalt and nickel concentrations in the "komatiite component" of Apollo 16 polymict samples. Earth Planet. Sci. Lett. 96, 481-489.

KOROTEV R. L. (1991) Geochemical stratigraphy of two regolith cores from the Central Highlands of the Moon. Proc. Lunar Planet. Sci. 21, 229-289.

KoroteV R. L. and KREMSER D. T. (1992) Compositional variations in Apollo 17 soils and their relationship to the geology of the Taurus-Littrow site. Proc. Lunar Planet. Sci. 22, 275-301.

KOROTEV R. L. and MORRIS R. V. (1993) Composition and maturity of Apollo 16 regolith core $60013 / 14$. Geochim. Cosmochim. Acta 57, 4813-4826.

Korotev R. L., HASKIN L. A., and LindSTROM M. M. (1980) A synthesis of lunar highlands compositional data. Proc: 1lih Lunar Planet. Sci. Conf., 395-429.

Korotev R. L., JOLLIFF B. L., Rockow K. M., HASKIN L. A., and Crossey L. J. ( 1993) A preliminary geochemical study of crystalline melt from the Manson impact structure. Metcoritics 28, 383-384 (abstr.).

Kracher A., WILl.IS J., and WASSON J. T. (1980) Chemical classification of iron meteorites-IX. A new group (IIF), revision of $\mathrm{IAB}$ and IIICD, and data on 57 additional irons. Geochim. Cosmochim. Acta 44, 773-787.

Krähenbohl U., Ganapathy R., Morgan J. W., and anders E. (1973) Volatile elements in the Apollo 16 samples: Implications for highland volcanism and accretion history of the moon. Proc. 4th Lunar Sci. Conf. 1325-1348.

Kuo H. Y. and CRocketT J. H. (1979) Rare earth elements in the Sudbury Nickel Irruptive: Comparison with layered gabbros and implications for nickel irruptive petrogenesis. Econ. Geol. 74, 590605.

LAUL J. C. and SCHMITT R. A. (1973) Chemical composition of Apollo 15, 16, and 17 samples. Proc. 4th Lumar Sci. Conf., 13491367.

LAUL J. C., HILL D. W., and SCHMITT R. A. ( 1974 ) Chemical studies of Apollo 16 and 17 samples. Proc. 5th Lunar Sci. Conf. 10471066.

Laul J. C., Papike J. J., Simon S. B., and Shearer C. K. (1983) Chemistry of the Apollo 11 highland component. Proc. 14ih Lunar Planet. Sci. Conf., B513-B524.

Laul J. C.. Simon S. B., and Papike J. J. (1988) Chemistry and petrology of the Apennine Front, Apollo 15, Part II: Impact melt rocks. Proc. 18th Lunar Planet. Sci. Conf., 203-217.

LiNDSTROM M. M. (1984) Alkali gabbronorite, ultra-KREEPy melt rocks and the diverse suite of clasts in North Ray crater feldspathic fragmental breccia 67975. Proc. I4th Lunar Planet. Sci. Conf., C50-C62.

Lindstrom M. M. and Salpas P. A. (1981) Geochemical studies of rocks from North Ray Crater, Apollo 16. Proc: 12th Lunar Planet. Sci. Cont. 305-322.

LiNDSTROM M. M. and SALPAS P. A. (1983) Geochemical studies of feldspathic fragmental breccias and the nature of North Ray Crater ejecta. Proc. I3th Lunar Planct. Sci. Conf., A671-A683.
Lindstrom M. M., Marvin U. B., Vetter S. K., and Shervais J. W. (1988) Appenine Front revisited: Diversity of Apollo 15 highland rock types. Proc. 18th Lunar Planet. Sci. Conf., 169-185.

Lindstrom M. M., Marvin U. B., Holmberg B. B., and MittleFEHLDT D. W. (1990) Apollo 15 KREEP-poor impact melts. Proc: 20th Lunar Planet. Sci. Conf.. 77-90.

LSPET (Lunar Sample Preliminary Examination Team) (1973) The Apollo 16 lunar samples: Petrographic and chemical description. Science 182, 23-34.

MaLvin D. J., WANG D., and Wasson J. T. (1984) Chemical classification of iron meteorites-X. Multielement studies of 43 irons, resolution of group IIIE from IIIAB, and evaluation of $\mathrm{Cu}$ as a taxonomic parameter. Geochim. Cosmochim. Acta 48, 785-804.

MARVIN U. B. and LINDSTROM M. M. (1983) Rock 67015: A feldspathic fragmental breccia with KREEP-rich melt clasts. Proc. 13th Lunar Planet. Sci. Conf. A659-A670.

Marvin U. B., Lindstrom M. M.. Bernatowicz T. J., Podosek F. A., and SUGIURA N. (1987) The composition and history of breccia 67015 from North Ray crater. Proc. 17th Lunar Planet. Sci. Conf. E47I-490.

McCormick K. A., Taylor J. G., Keil K., SPudis P. D., Grieve R. A. F., and RYDER G. (1989) Sources of clasts in terrestrial impact melts: Clues to the origin of LKFM. Proc. 19th Lunar Planet. Sci. Conf., 691-696.

MCKAY D. S., BOGARD D. D., MORRIS R. V., KOROTEV R. L., JOHNSON P., and WENTWORTH S. J. (1986) Apollo 16 regolith breccias: Characterization and evidence for early formation in the mega-regolith. Proc. 16th Lunar Planet. Sci. Conf.. D277-D303.

MCKINLEY J. P., TAYLOR G. J., KEIL K., MA M.-S., and SCHMITT R. A. (1984) Apollo 16: Impact melt sheets, contrasting nature of the Cayley Plains and Descartes Mountains, and geologic history. Proc. 14th Lunar Planet. Sci. Conf., B513-B524.

Metzger A. E., Etchegaray-Ramirez M. I., and Haines E. L. (1981) Thorium concentrations in the lunar surface: V. Deconvolution of the central highlands region. Proc. 12th Lunar Planet. Sci. Conf., 751-766.

Mittlefehldt D. W., SeE T. H., and HORZ F. ( 1992 ) Dissemination and fractionation of projectile materials in the impact melt rocks from Wabar Crater, Saudi Arabia. Meteroritic's 27, 361-370.

MORRIS R. V.. SEE T. H., and HÖR F. (1986) Composition of the Cayley Formation at Apollo 16 as inferred from impact melt splashes. Proc. 17th Lunar Planet. Sci. Conf., E21-E42.

MORGAN J. W. and JAMES O. B. ( 1981 ) Apollo 16 breccias and melt rocks: Correlations between siderophile-element patterns, lithology, and location. In Workshop on Apollo 16 (O. B. JAMES and F. HÖRz, eds.): LPI Tech. Rpt. 8I-0I.pp. 82-86. Lunar and Planetary Inst.

MORRISON G. H. NADK ARNI R. A. JAWORSKI J., BOTTO R. I., and ROTH J. R. (1973) Elemental abundances of Apollo 16 samples. Proc: 4h Lunar Sci. Conf., 1399-1405.

Murali A. V., Ma M.-S., Laul J. C., and Schmitt R. A. (1977) Chemical composition of breccias, feldspathic basalt and anorthosites from Apollo 15 (15308, 15359, 15382, and 15362), Apollo 16 (60618 and 65785), Apollo 17 (72435, 72536, 72559, 72735 . $72738,78526$ and 78527$)$ and Luna 20 (22012 and 22013). Lunar and Planctary Science VIII, 700-702 (abstr.)

Nakamura N., Masuda A., TanaKa T., and Kurasawa H. (1973) Chemical compositions and rare-earth features of four Apollo 16 samples. Proc. 4th Lunar Sci. Conf.. 1407-1414.

NANeY M. T. PAPIKE J. J., and VANIMAN D. T. (1977) Lunar highlands melt rocks. In Lunar Planet. Sci. VIII, 717-719 (abstr.)

NAVA D. F. (1974) Chemical compositions of some soils and rock types from the Apollo 15, 16, and 17 lunar sites. Proc. 5th Lunar Sci. Conf.. 1087-1096.

NORMAN M. D. and NAGLE J. S. (1981) Apollo 16 "black and white" rocks: South Ray ejecta?. In Workshop on Apollo 16 (ed. O. B. JAMES and F. HORZ ); LPI Tech. Rpt. 8I-0I. pp. 98-100. Lunar and Planetary Inst.

PALME H. (1978) New data on lunar samples and achondrites and a comparison of the least fractionated samples from the earth, the moon, and the eucrite parent body. Proc: 9th Lunar Planet. Sci. cont. 25-57. 
PHILPOTts J. A. et al. (1972) Apollo 14: Some geochemical aspects. Proc. 3rd Lunar Sci. Conf. 1293-1305.

REIMOLD W. U. ( 1982) The Lappajärvi meteorite crater, Finland: petrography, Rb-Sr, major and trace element geochemistry if the impact melt and basement rocks. Geochim. Cosmochim. Acta 46, 1203-1225.

REIMOLD W. U. and NiEBER-REIMOLD J. ( 1984 ) The mineralogical, chemical, and chronological characteristics of crystalline Apollo 16 impact melt rocks. Fortschr. Miner. 62, 269-301.

RE:IMOLD W. U. et al. (1985) Isotope analysis of crystalline melt rocks from Apollo 16 stations 11 and 13, North Ray crater. Proc. 15th Lunar Planet. Sci. Conf., C431-448.

RINGWOOD A. E. and WÄKE H. (1990) Cobalt and nickel concentrations in the "komatiite" component of Apollo 16 polymict samples-reply to R. L. Korotev. Earth Planet. Sci. Lett. 96, 490-498.

RiNGWOOd A. E., SEIFERT S., and WäNKF. H. (1987) A komatiite component in Apollo 16 highlands breccias: implications for the nickel-cobalt systematics and bulk composition of the Moon. Earth Planet. Sci. Lett. 81, 105-117.

Rockow K. M., Korotev R. L., Jol.l.JFF B. L., and HaSKIN L. A (1994) Compositional differences between impact-melt breccias of the North and South Massifs at Apollo 17. Lunar Planet. Sci XXV, 1151-1152 (abstr.).

ROSE H. J., Jr. et al. (1972) Compositional data for twenty-one Fra Mauro lunar materials. Proc. 3rd Lunar Sci. Conf. 1215-1229.

ROSE H. J., Jr. et al. ( 1973) Compositional data for twenty-two Apollo 16 samples. Proc. 4th Lunar Sci. Conf., 1149-1158.

RYDER G. (1981) Distribution of rocks at the Apollo 16 site. In Workshop on Apollo 16 (ed. O. B. JAMES and F. HORZ); LPI Tech. Rpt. 81-01, pp. 112-119. Lunar and Planetary Institute.

RYDER G. ( 1990 ) Lunar samples, lunar accretion and the early bombardment of the Moon. EOS 71, 313-323.

RYDER G. and NORMAN M. D. (1980) Catalog of Apollo lo Rocks: JSC 16904. NASA Johnson Space Center.

RYDER G. and SFYMOUR R. (1982) Chemistry of Apollo 16 impact melt rocks: Numerous melt sheets. lunar cratering history, and the Cayley-Descartes distinction. Lumar Planet. Sci. XIII, 673674 (abstr.).

RYDER G. and SpUDis P. (1987) Chemical composition and origin of Apollo 15 impact melt rocks. Proc. 17th Lunar Planet. Sci Conf. E432-E446.

RYDER G. and WOOD J. A. (1977) Serenitatis and Imbrium impact melt rocks: Implications for large-scale layering in the lunar crust. Proc. 8th Lunar Sci. Conf., 655-668.

RYDER G., LiNDSTROM M., and Wil.uIs K. (1988) The reliability of macroscopic identification of lunar coarse fines particles and the petrogenesis of $2.4 \mathrm{~mm}$ particles in Apennine Front sample 15423. Prec. 18th Lunar Planet. Sci. Conf. 219-232.

Simonds C. H. (1975) Thermal regimes in impact melt rocks and the petrology of the Apollo 17 Station 6 boulder. Proc. 6th Lunar Sici Cont., 641-672.

Simonids C. H., Warner J. L., and Phinney W. C. (1973) Petrology of A pollo 16 poikilitic rocks. Proc. 4th Lunar Sci. (onf., 613-632.

SPUDIS P. D. (1984) Apollo 16 site geology and impact melts. Implications for the geologic history of the lunar highlands. Proc: I5th Lunar Planet. Sci. Conf. C95-C 107.

SPudis P. D. HawkE B. R., and LuCEY P. G. (1989) Geology and deposits of the lunar Nectaris basin. Proc. 19th Lunar Planet. Sci. Conf. 51-59.

STOFFLER D., KNOLL H.-D., and MAFRZ U. (1979) Terrestrial and lunar impact breccias and the classification of lunar highland rocks. Proc. 10th Lunar Sci. Conf., 639-675.

Stöffier D., KnOll H.-D., Marvin U. B., Simonds C. H., and WARREN P. H. (1980) Recommended classification and nomenclature of lunar highlands rocks-a committee report. In Proc. Conf. Lunar Highlands (rust (ed. J. J. PAPIKF and R. B. MERRII.L). pp. $51-70$. Pergamon.
STOFFLER D. et al. ( 1985) Composition and evolution of the lunar crust in the Descartes Highlands, Apollo 16. Proc. 15th Lunar Planet. Sci. Conf., C449-C505.

SWINDle T. D., Spudis P. D., Taylor G. J., Korotev R. L. NichOlS R. H. and OLINGER C. T. (1991) Searching for Crisium basin ejecta: Chemistry and ages of Luna 20 impact melts. Proc: Lunar Planet. Sci. 21, 167-181.

TAYLOR L. A., MAO H. K., and Bel.l. P. M. (1973) "Rust" in the Apollo 16 rocks. Proc. 4th Lunar Sci. Conf., 829-839.

TAYIOR L. A. Misra K. C., and Walker B. M. (1976) Subsolidus reequilibration, grain growth, and compositional changes of native FeNi metal in lunar rocks. Proc. 7th Lunar Sci. Conf.. 837-856.

Tayior S. R. (1975) Lunar Science: A Post-Apollo View: Pergamon.

TAYLOR S. R. (1982) Planctary Science. A Lunar Perspective. Lunar and Planetary Inst.

VANIMAN D. T. and PAPIKE J. J. (1980) Lunar highland melt rocks: Chemistry, petrology and silicate mineralogy. In Proc. Conf. Lunar Highlands Crust (ed. J. J. PAPIKE and R. B. MERRILL), 271-337. Pergamon.

WÄNKE H. et al. ( 1972) Multielement analyses of lunar samples and some implications of the results. Proc. 3rd Lunar Sci. Conf., 125 I1268

WÄNKE H. et al. (1973) Multielement analyses of Apollo 15. 16 and 17 samples and the bulk composition of the Moon. Proc. $4 \mathrm{th}$ l.umar Sci. Conf., 1461-1481.

WÄNKF H. et al. (1974) Chemistry of Apollo 16 and 17 samples: Bulk composition, late stage accumulation and early differentiation of the moon. Proc. 5th Lunar Sci. Conf.. 1307-1355.

WÄNKE H. et al. ( 1976) Chemistry of lunar highlands rocks: A refined evaluation of the composition of the primary matter. Proc. 7 th Lunar Sci. Conf., 3479-3499.

Wanke H., Dreibus G., and Palme H. (1978) Primary matter in the lunar highlands: The case of the siderophile elements. Proc. 9th Limar Sci. Confl. 83-110.

WÄNE H. DREIBUS G., and PALME H. (1990) Lunar siderophiles. L.unar Planet. Sci. XXI, 1289-1290 (abstr.).

Warner R. D., Dowty E., Prinz M., Conrad G. H., Nehru C. E. and KEIL K. (1976a) Catalog of Apollo 16 Rake Samples from the LM Area and Station 5; Spec. Publ. No. 13. Univ. Inst. Meteoritics.

WARNER R. D. et al. (1976b) Consortium investigation of breccia 67435. Proc. 7th Lunar Sci. Conf.. 2379-2402.

WARREN P. H. and WASSON P. H. (1978) Compositional-petrographic investigation of pristine nonmare rocks. Proc. 9th Lunar Sci. Comf., 185-217.

WARREN P. H. and WASSON P. H. (1980) Further foraging for pristine nonmare rocks: Correlations between geochemistry and longitude. Proc. 11th Lunar Planet. Sci. Conf. 431-470.

WARREN P. H.. Jerde E. A., and Kallemeyn G. W. ( 1989 ) Lunar meteorites: siderophile element contents, and implications for the composition and origin of the Moon. Earth Planet. Sci. Lett. 91, 245-260.

WASSON J. T. and KaLLEMEYN G. W. ( 1988 ) Composition of chondrites. Phil. Trans. R. Soc. London A 325, 534-544.

WASSON J. T., CHOU C.-L., ROBINSON K. L., and BAEDECKER P. A. (1975) Siderophiles and volatiles in Apollo-16 rocks and soils. Geochim. Cosmochim. Acta 39, 1475-1485.

WASSON J. T. WARREN P. H., KaLLFMEYN G. W., MCEWING C. E. MITTLEFEHLDT D. W. and BOYNTON W. V. (1977) SCCR V. a major component of highlands rocks. Proc. 8th Lunar Sci. Conf., $2237-2252$.

Wil. IIS J. P.. ERlank A. J., Gurnf.y J. J., Theil R. H., and Ahrens L. H. (1972) Major, minor, and trace element data for some Apollo 11. 12, 14, and 15 samples. Proc. 3rd Lunar Sci. Conf., 12691273.

YORK D. (1969) Least squares fitting of a straight line with correlated errors. Earth Planet. Sci. Lett. 5, 320-324. 
Table A1. Summary of assignment to compositional groups, with description of nonuniformities, some petrographic features, and unusual compositional features. Group designations in capital letters (e.g., 1M, 2DB) represent compositionally distinct groups consisting of three or more samples; lower-case letters (e.g., v, o) represent subgroups based on petrography, collection station, and other compositional features.

\begin{tabular}{|c|c|c|c|c|}
\hline & Sample & group & petrographic features & compositional features \\
\hline$\&$ & 60315 & $\mathrm{IM}$ & & \\
\hline C & 60526 & $\mathrm{IM}$ & & \\
\hline$E$ & 63527 & $1 \mathrm{M}$ & & \\
\hline 0 & 63558 & $1 \mathrm{M}$ & 1 of 3 ssplts alkali rich & \\
\hline 5 & 64816 & $1 \mathrm{M}$ & & \\
\hline 2 & 69945 & $\mathrm{IM}$ & & \\
\hline$T$ & 60525 & $1 \mathrm{~F}$ & & \\
\hline Q & 60636 & IFv & 1 of 3 ssplts alkali rich & \\
\hline 9 & 61247 & $1 \mathrm{~F}$ & & \\
\hline $\mathbf{G}$ & 62235 & $1 \mathrm{~F}$ & & \\
\hline$D$ & 63556 & $\overline{\mathrm{IF}}$ & & \\
\hline$x$ & 63596 & IFv & v ves & lo ITEs for group l \\
\hline $\mathrm{H}$ & 63598 & $1 \mathrm{Fv}$ & 1 of 4 ssplts alkali rich, fldspthe & \\
\hline 4 & 64575 & $\mathrm{lF}$ & & \\
\hline$\#$ & 65015 & $1 \mathrm{~F}$ & & \\
\hline$\Omega$ & 65357 & $1 \mathrm{~F}$ & & \\
\hline 6 & 65358 & $\mathrm{IF}$ & & \\
\hline$\Sigma$ & 65777 & $1 \mathrm{~F}$ & & highest $\mathrm{Cr} / \mathrm{Sc}$ among group $1 \mathrm{~F}(\sim$ like $1 \mathrm{M}$ ) \\
\hline 7 & 65778 & IF & & \\
\hline 8 & 65905 & IF & & \\
\hline $\mathbf{N}$ & 68525 & IFv & ves & hi $\mathrm{Na} / \mathrm{Sm}$, hi Zn, حhi Ca; lo ITEs, lo $\mathrm{Cr} / \mathrm{Sc}$ \\
\hline$F$ & 63597 & U (IF?) & v ves, poikilitic & hi Sc, but lo $\mathrm{Sm} / \mathrm{Sc}$, lo $\mathrm{Na}$, lo $\mathrm{Sm} / \mathrm{Yb}$ \\
\hline $\bar{B}$ & 64815 & $\mathrm{U}(\mathrm{IF}$ ?) & 1 ssplt of 4 less mafic & highest Sc, hi HREE, lo $\mathrm{Zn}$, lo $\mathrm{Sm} / \mathrm{Yb}$ \\
\hline $\bar{V}$ & 61569 & $\mathrm{U}$ & all 3 ssplts different & 1 ssplt DB-like, but lo Eu \& Na; 1 ssplt vhi Cs \& Rb \\
\hline $\bar{D}$ & 60625 & $2 \mathrm{DP} 3 / 2 \mathrm{Fd}$ & 2 ssplt DB, other 1 glassy or fldspthe & \\
\hline$\$$ & 61015 & $2 \mathrm{DB}$ & & \\
\hline$M$ & 62255 & $2 \mathrm{DB}$ & & \\
\hline $\mathrm{Y}$ & 64476 & $2 \mathrm{DB}$ & & \\
\hline A & 64536 & $2 \mathrm{DB}$ & & \\
\hline $\mathrm{R}$ & 64566 & $2 \mathrm{DB}$ & & hi $\mathrm{Zn}, 1$ of 2 ssplts \\
\hline$g$ & 64568 & $2 \mathrm{DB}$ & & \\
\hline $\mathrm{m}$ & 64578 & $2 \mathrm{DDB}$ & 1 of 3 ssplts more fldspthe & \\
\hline k & 64585 & $2 \mathrm{DB}$ & & \\
\hline$\underline{u}$ & 64586 & $2 \mathrm{DB}$ & & \\
\hline 0 & 65365 & $2 \mathrm{DB}$ & & hi $\mathrm{Cr} / \mathrm{Sc}, \mathrm{l}$ of $3 \mathrm{ssplts}$ \\
\hline $\mathrm{Z}$ & 65757 & $2 \mathrm{DB} / 2 \mathrm{Fd}$ & 1 ssplt DB, other l glassy or fldspthe & \\
\hline$\Theta$ & 65779 & $2 \mathrm{DB}$ & nusty & \\
\hline 1 & 65906 & $2 \mathrm{DB}$ & rusty & $\mathrm{hi} \mathrm{Zn}$ \\
\hline$w$ & 66095 & $2 \mathrm{DB}$ & 1 of 3 ssplts lo ITEs & \\
\hline s & 68505 & $2 \mathrm{DB}$ & rusty & \\
\hline $\bar{Q}$ & 63535 & $2 \mathrm{NR}(2 \mathrm{DB} ?)$ & ves & most DB like of 63xxx \\
\hline b & 62245 & $2 \mathrm{NR}$ & & lo siderophile elements \\
\hline $\bar{U}$ & 63355 & $2 \mathrm{NR}$ & & \\
\hline$L$ & 63547 & $2 \mathrm{NR}$ & & \\
\hline$G$ & 63585 & 2NR & & \\
\hline $\bar{q}$ & 64515 & 2NR & ves & $\sim 10 \mathrm{Cs} / \mathrm{Sm}$, most $\mathrm{Sc} \& \mathrm{Sm}$ rich $2 \mathrm{NR}$ \\
\hline$\Delta$ & $67513 \mathrm{c}$ & $2 \mathrm{NR}$ & mean of twelve 2-4-mm particles & \\
\hline $\mathrm{K}$ & 65785 & $2 \mathrm{NR}(2 \mathrm{M} \times ?)$ & 1 ssplt of $2 \sim$ more fldspthe & $\sim \mathrm{hi} \mathrm{Cs} / \mathrm{Sm}$ \\
\hline C & 63536 & $2 \mathrm{M}(2 \mathrm{NR} ?)$ & fldspthe 2NR? & $\mathrm{hi} \mathrm{Eu} / \mathrm{Sm}$ \\
\hline 1 & 63545 & $2 \mathrm{M}(2 \mathrm{NR} ?)$ & fldspthe $2 \mathrm{NR} ? ; 1$ ssplt of 5 more fldspthe & $\mathrm{hi} \mathrm{Eu/Sm}$ \\
\hline$\%$ & 60018 & $2 \mathrm{M} / 2 \mathrm{~F}$ & \begin{tabular}{|ll} 
heterogeneous melt-anorth mix shocked & six \\
\end{tabular} & $\mathrm{hi} \mathrm{Cs} / \mathrm{Sm}$ \\
\hline$¥$ & 60335 & $2 \mathrm{M}$ & ( & hi Na, hi Cs/Sm \\
\hline $\bar{B}$ & 60615 & $2 \mathrm{M}(2 \mathrm{Mo} ?$ & 1 sspll of 2 unusual (olivine bearing?) & hi $\mathrm{Mg}^{\prime}$; unusual ssplt: hi $\mathrm{Cr} / \mathrm{Sc}$, lo Sc, lo $\mathrm{Ca}$, lo Na \\
\hline$y$ & 60616 & $2 \mathrm{M}$ & & $\sim$ hi $\mathrm{Sm} / \mathrm{Sc}, \sim \mathrm{lo}_{\mathrm{C}} / \mathrm{Sc}$ \\
\hline$\Phi$ & 61547 & $2 \mathrm{M}$ & glassy portion analyzed? & $\mathrm{hi} \mathrm{Cr} / \mathrm{Sc}$, hi IJ/Au \\
\hline$\Gamma$ & 61568 & $2 \mathrm{M}(1 ?)$ & anom group 1 ? dilithologic: basaltic \& poikilitic & $\mathrm{hi} \mathrm{Sm} / \mathrm{Sc}$ hi Cs $/ \mathrm{Sm}$ \\
\hline$M$ & 63587 & $2 \mathrm{M}$ & ves & hi Na, hi Eu/Sm, hi Cs $/ \mathrm{Sm}, \sim$ o $\mathrm{Cr} / \mathrm{Sc}$ \\
\hline$r$ & 65915 & $2 \mathrm{M}$ & ves & hi $\mathrm{Sm} / \mathrm{Yb}$, lo $\mathrm{Cs} / \mathrm{Sm}$ \\
\hline $\mathrm{E}$ & 60627 & $2 \mathrm{Mo}$ & no petrography, but probably olivine rich & $\mathrm{hi} \mathrm{Cr} / \mathrm{Sc} ;$ lo $\mathrm{Ca}$ \\
\hline $\mathrm{L}$ & 60666 & $2 \mathrm{Mo}$ & olivine/glass matrix, $M g^{\prime}>90$ & whi $\mathrm{CI}_{\mathrm{I}} / \mathrm{Sc}$, ,hi Ni, hi $\mathrm{Sm} / \mathrm{Yb}$, lo $\mathrm{Na}$, lo $\mathrm{Ca}$, lo $\mathrm{Eu} / \mathrm{Sm}$ \\
\hline $\mathbf{a}$ & 61549 & $2 \mathrm{Mo}$ & olivine rich & $\mathrm{hi} \mathrm{Cr}_{\mathrm{I}} / \mathrm{Sc}$; lo $\mathrm{Ca}$, lo $\mathrm{Na}$, lo Eu/Sm, lo $\mathrm{Cs} / \mathrm{Sm}$ \\
\hline $\mathbf{N}$ & 62295 & $2 \mathrm{Mo}$ & olivine \& spinel rich & hi $\mathrm{Cr} / \mathrm{Sc}, \mathrm{hi} \mathrm{Zn}, \mathrm{hi}, \mathrm{Cs} ; \mathrm{lo} \mathrm{Ca}$ \\
\hline $\mathbf{S}$ & 64567 & $2 \mathrm{Mo}$ & olivine oikocrysts & - hi Cr/Sc, lo Ca \\
\hline h & 64576 & $2 \mathrm{Mo}$ & olivine/glass matrix, $M g^{\prime}>90$ & vhi $\mathrm{Cr} / \mathrm{Sc} ;$ lo $\mathrm{Ca}$, lo $\mathrm{Na}$, lo Eu/Sm \\
\hline
\end{tabular}


